\title{
Intercomparison of shortwave radiative transfer schemes in global aerosol modeling: results from the AeroCom Radiative Transfer Experiment
}

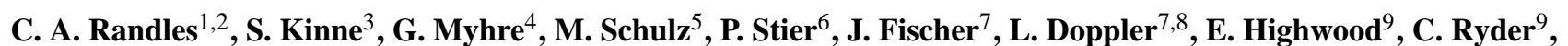
B. Harris ${ }^{9}$, J. Huttunen ${ }^{10}$, Y. Ma ${ }^{11}$, R. T. Pinker ${ }^{11}$, B. Mayer $^{12}$, D. Neubauer ${ }^{13,14}$, R. Hitzenberger ${ }^{13,14}$, L. Oreopoulos ${ }^{15}$, D. Lee ${ }^{15,16}$, G. Pitari ${ }^{17}$, G. Di Genova ${ }^{17,18}$, J. Quaas ${ }^{19}$, F. G. Rose $^{20,21}$, S. Kato ${ }^{21}$, S. T. Rumbold ${ }^{22}$,

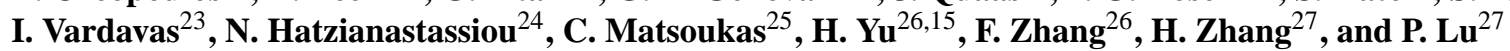

${ }^{1}$ GESTAR/Morgan State University, Baltimore, Maryland, USA

${ }^{2}$ NASA Goddard Space Flight Center (GSFC) Atmospheric Chemistry and Dynamics Lab, Greenbelt, MD, USA

${ }^{3}$ Max Plank Institute for Meteorology, Hamburg, Germany

${ }^{4}$ Center for International Climate and Environmental Research-Oslo (CICERO), Oslo, Norway

${ }^{5}$ Meteorologisk Institutt, Oslo, Norway

${ }^{6}$ Department of Physics, University of Oxford, Oxford, UK

${ }^{7}$ Institut für Weltraumwissenschaften, Freie Universität, Berlin, Germany

${ }^{8}$ LATMOS-IPSL, Paris, France

${ }^{9}$ Department of Meteorology, University of Reading, Reading, UK

${ }^{10}$ Finnish Meteorological Institute, Kuopio, Finland

${ }^{11}$ University of Maryland, Department of Atmospheric and Oceanic Science, Maryland, USA

${ }^{12}$ Ludwig-Maximilians-Universitaet, Munich, Germany

${ }^{13}$ Research Platform: ExoLife, University of Vienna, Vienna, Austria

${ }^{14}$ Faculty of Physics, University of Vienna, Vienna, Austria

${ }^{15}$ NASA GSFC Climate and Radiation Laboratory, Greenbelt, Maryland, USA

${ }^{16}$ Seoul National University, Seoul, Republic of Korea

${ }^{17}$ Department of Physical and Chemical Sciences, University of L'Aquila, L'Aquila, Italy

${ }^{18}$ Space Academy Foundation, Fucino Space Center, Ortucchio, Italy

${ }^{19}$ Institut für Meteorologie, Universität Leipzig, Leipzig, Germany

${ }^{20}$ SSAI, Hampton, VA, USA

${ }^{21}$ NASA Langley Research Center (LaRC), Hampton, Virginia, USA

${ }^{22}$ UK Met Office (UKMO) Hadley Center, Exeter, UK

${ }^{23}$ Department of Physics, University of Crete, Crete, Greece

${ }^{24}$ Laboratory of Meteorology, Department of Physics, University of Ioannina, Ioannina, Greece

${ }^{25}$ Department of Environment, University of the Aegean, Aegean, Greece

${ }^{26}$ Earth System Science Interdisciplinary Center (ESSIC), University of Maryland, College Park, Maryland, USA

${ }^{27}$ Laboratory for Climate Studies, CMA, National Climate Center, Beijing, China

Correspondence to: C. A. Randles (cynthia.a.randles@ nasa.gov)

Received: 31 July 2012 - Published in Atmos. Chem. Phys. Discuss.: 19 December 2012

Revised: 15 February 2013 - Accepted: 22 February 2013 - Published: 1 March 2013 
Abstract. In this study we examine the performance of 31 global model radiative transfer schemes in cloudfree conditions with prescribed gaseous absorbers and no aerosols (Rayleigh atmosphere), with prescribed scatteringonly aerosols, and with more absorbing aerosols. Results are compared to benchmark results from high-resolution, multiangular line-by-line radiation models. For purely scattering aerosols, model bias relative to the line-by-line models in the top-of-the atmosphere aerosol radiative forcing ranges from roughly -10 to $20 \%$, with over- and underestimates of radiative cooling at lower and higher solar zenith angle, respectively. Inter-model diversity (relative standard deviation) increases from $\sim 10$ to $15 \%$ as solar zenith angle decreases. Inter-model diversity in atmospheric and surface forcing decreases with increased aerosol absorption, indicating that the treatment of multiple-scattering is more variable than aerosol absorption in the models considered. Aerosol radiative forcing results from multi-stream models are generally in better agreement with the line-by-line results than the simpler two-stream schemes. Considering radiative fluxes, model performance is generally the same or slightly better than results from previous radiation scheme intercomparisons. However, the inter-model diversity in aerosol radiative forcing remains large, primarily as a result of the treatment of multiple-scattering. Results indicate that global models that estimate aerosol radiative forcing with two-stream radiation schemes may be subject to persistent biases introduced by these schemes, particularly for regional aerosol forcing.

\section{Introduction}

In order to understand climate and climate change, it is essential to have an accurate understanding of the Earth's radiation budget and how this budget has changed over time. Atmospheric aerosols have a direct effect on the radiation budget through scattering and absorption of primarily solar radiation, and this radiative forcing can be quantified as the net difference in flux at a given level with and without aerosol. Mainly scattering aerosols such as sulphate generally have a negative or cooling radiative effect at the top of the atmosphere (TOA). More absorbing aerosols such as black carbon can have a radiative cooling or warming effect on the climate system depending on the brightness of the surface or clouds beneath them (Chýlek and Coakley, 1974). Aerosols may also have indirect and semi-direct effects on climate, which are due to microphysical and thermodynamic interactions with clouds, respectively, that impact cloud radiative forcing.

There has been considerable progress in the global modeling of aerosols (e.g. Textor et al., 2006; Koch et al., 2009); however, the uncertainty in estimates of direct aerosol radiative forcing, often measured by the diversity in global model estimates, remains high (Forster et al., 2007; Myhre et al., 2013). In cloud-free conditions, quantification of the direct aerosol radiative effect in atmospheric models depends on knowledge of aerosol optical properties (aerosol optical depth, single scattering albedo, asymmetry parameter, and their wavelength dependence) and wavelength dependent surface albedo. While uncertainties in estimates of aerosol radiative forcing are primarily due to uncertainties in the knowledge of these properties and how they are parameterized (e.g. Boucher et al., 1998), the treatment of radiative transfer in global models, including the accuracy of the method, its spectral resolution, and the treatment of molecular and multiple-scattering, also contribute to the multimodel diversity in estimates of direct aerosol radiative forcing (e.g. Halthore et al., 2005; Oreopoulos et al., 2012).

The aerosol model intercomparison initiative (AeroCom) was created in 2002 with the goal of providing a platform for detailed evaluations of aerosol simulations in global models (http://aerocom.met.no/), focusing in particular on the diversity in global estimates of anthropogenic aerosol direct radiative forcing. AeroCom Phase I explored the inter-model diversity in aerosol processes and properties that contribute to differences in the aerosol optical properties used to quantify radiative forcing (Textor et al., 2006, 2007). Despite the diversity in aerosol properties simulated by the AeroCom models, there was surprisingly good agreement in global, annual total aerosol optical depth. However, this agreement did not extend to the sub-component level as there were large differences in the compositional mixture of the aerosol dry mass and water uptake, both of which influence aerosol absorption and radiative forcing (Kinne et al., 2006). After harmonizing emissions, the global, annual mean pre-industrial to presentday direct aerosol radiative forcing (RF) was $-0.22 \mathrm{~W} \mathrm{~m}^{-2}$ with a range of -0.41 to $+0.04 \mathrm{~W} \mathrm{~m}^{-2}$ and standard deviation (SD) of $\pm 0.16 \mathrm{~W} \mathrm{~m}^{-2}$ (or $\pm 73 \%$ of the mean; Schulz et al., 2006). Considerable diversity in aerosol residence times, mass extinction coefficients, forcing per unit optical depth (forcing efficiency) and the ratio of all-sky to clear-sky forcing contributed to the diversity in RF with harmonized emissions (Schulz et al., 2006).

Prior to AeroCom Phase I, the large inter-model diversity in aerosol models was not recognized by the community at large; however, reasons for this diversity required more investigation. As a result of this and the increasing complexity of aerosol models and their coupling to transport and climate models, investigators have proposed numerous experiments for AeroCom Phase II (Schulz et al., 2009). Three additional Phase II experiments have been proposed to investigate the model diversity in aerosol radiative forcing. Myhre et al. (2013) examines the pre-industrial to present-day anthropogenic aerosol direct radiative forcing in 16 global aerosol models of various complexity. The remaining two studies aim to understand inter-model diversity by removing host model uncertainties that arise during the simulation of aerosol distributions and aerosol optical properties. In the AeroCom Prescribed Experiment (Stier et el., 2012), 
aerosol optical properties (aerosol optical depth, Ångström exponent, single scattering albedo, and asymmetry parameter) are prescribed to examine the inter-model diversity in non-aerosol related host-model process and assumptions that impact RF calculations (e.g. surface albedo and clouds). As a subset and simplification of the Prescribed Experiment, the offline AeroCom Radiative Transfer Experiment presented here examines the diversity in aerosol radiative forcing due to differences in global model radiation schemes.

There have been numerous intercomparisons of shortwave radiation codes in the past. Fouquart et al. (1991) examined 26 radiation schemes ranging from high to low spectral resolution and found substantial discrepancies in computed fluxes for even the simplest prescription of only pure water vapor absorption. When including highly scattering aerosols and a fixed surface albedo, the relative standard deviation for the eleven models considered ranged from 23 to $114 \%$ as the solar zenith angle (SZA) decreased from $75^{\circ}$ to $30^{\circ}$ (Fouquart et al., 1991; Boucher et al., 1998). Boucher et al. (1998) found that the relatively high $(8 \%)$ standard deviation in zenith angle-average broadband forcing due to prescribed non-absorbing sulfate aerosols was due to differences in the treatment of Mie scattering, multiple scattering, phase functions, and spectral and angular model resolution. Even higher diversity was found for radiative forcing calculated at specific solar zenith angles (i.e. $7.8^{\circ}, 71.6^{\circ}$, and $83.4^{\circ}$ ). A more recent and extensive study by Halthore et al. (2005) found substantial differences in TOA RF with prescribed aerosol optical properties and surface albedo that was higher at lower solar zenith angles $\left(30^{\circ}\right.$ vs. $\left.75^{\circ}\right)$ and decreased with increased aerosol optical depth.

In this study we adapt the protocol from Halthore et al. (2005), which itself was inspired by Fouquart et al. (1991). We first focus on inter-model differences in Rayleigh scattering in cloud- and aerosol-free conditions with prescribed standard atmospheres (i.e. prescribed ozone and water vapor distributions) and surface albedo. We also consider two simple cases with prescribed aerosol optical properties, including both scattering-only and absorbing aerosols separately, to examine inter-model differences in clear-sky (cloud-free) aerosol radiative forcing. Only solar wavelengths are examined in this study because AeroCom is primarily interested in anthropogenic aerosol radiative forcing rather than longwave aerosol effects that are strongly influenced by natural (e.g. dust) aerosol. We examine the clear-sky fluxes and aerosol radiative forcing as a function of solar zenith angle (SZA). Where possible and appropriate, we make comparisons to earlier intercomparison studies. It should be noted that the conditions specified in this study are not meant to reflect actual atmospheric conditions, which may vary considerably from those considered here. For climate studies, it is not the error in calculating radiative fluxes under a given set of conditions, but the systematic error that occurs over large time and spatial scales, that is of primary importance (Arking, 2005). However, it is important to understand how forcing varies with SZA because zenith-angle averaged forcing assumes the uniform geographic distribution of aerosol optical properties, surface albedo, and clouds - conditions never achieved in the actual climate system (Boucher et al., 1998).

\section{Protocol}

Table 1 provides a brief description of the participating models, including their spectral resolution and multiplescattering and gaseous transmission schemes. More detailed descriptions and references are given in Appendix A and Appendix Table A1. The data used in this study are made publicly available via the AeroCom server (http://aerocom.met. no/). We have submissions from 31 radiation schemes. Two high-spectral resolution line-by-line (LBL) models (Models $\# 1$ and 2), where transmittance is treated explicitly, serve as benchmarks for comparison. Models \#1-3, 5-9, and 30-31 use multi-stream (i.e. $>2$-stream) approximations to the solution of the radiative transfer equation while the remaining models use the two-stream approximation. Multiplescattering schemes include the discrete-ordinate method (DISORT; Stamnes et al., 1988, Models \#1-7), variations of the Eddington approximation (e.g. Joseph et al., 1976, Models \#8-29), and the matrix-operator method (MOM; Plass et al., 1973, Models \#30-31). For the lower spectral resolution band-models, gaseous transmittance is generally achieved using either the correlated- $k$ method ( $c k-\mathrm{D}$; e.g. Lacis and Oinas, 1991; Fu and Liou, 1992; Kato et al., 1999) or the exponential sum fit transmission scheme (ESFT; e.g. Wiscombe and Evans, 1977; Sun and Rikus, 1999). A number of these schemes are currently in use in global climate models, some are used for offline calculation of aerosol radiative forcing, and still others are used, for example, to perform detailed calculations of photolysis rates in coupled climate-chemistry models (see Appendix A).

Table 2 gives an overview of the experiment protocol and the cases considered. Fluxes were reported at two nominal wavelength bands: broadband $(0.2-4.0 \mu \mathrm{m})$ and UV-visible (UV-VIS; $0.2-0.7 \mu \mathrm{m}$ ). However, due to the difficulty in configuring some models to these exact bands, we accepted variations in these wavelength ranges. To facilitate intercomparison, we normalized all flux components by the modelspecific downwards irradiance at the top-of-the-atmosphere (TOA) in the appropriate band (broadband or UV-VIS) and then scaled these normalized fluxes by the inter-model median TOA downwards irradiance (such that all flux quantities examined are in $\mathrm{W} \mathrm{m}^{-2}$; see Fig. 2). We requested the following flux fields: total (direct + diffuse) down at the surface broadband, diffuse flux down at the surface broadband, total diffuse up at TOA broadband, and total down at surface UV-visible. These flux $(F)$ quantities allow us to calculate TOA aerosol radiative forcing (RF) and absorptance $(A)$ in the broadband. Absorptance is calculated as in 
Table 1. Models, investigators, and description ${ }^{\mathrm{a}}$

\begin{tabular}{|c|c|c|c|}
\hline Model & Name & Investigator(s) & Description $^{\mathrm{b}, \mathrm{c}}$ \\
\hline 1 & GENLN2-DISORT & Myhre & 16-streams DISORT, LBL (HITRAN2008) $0.02 \mathrm{~cm}^{-2}$ resolution, $0.2-5.0 \mu \mathrm{m}$, AFGL \\
\hline 2 & RFM DISORT (RFMD) & Highwood, Ryder, Harris & 4-streams DISORT (HITRAN 2004), LBL $1 \mathrm{~cm}^{-1}$ resolution, $0.2-10 \mu \mathrm{m}$, AGFL \\
\hline 3 & Oslo-DISORT & Myhre & 8-stream DISORT, ESFT (HITRAN92 + GENLN2 for $\left.\mathrm{H}_{2} \mathrm{O}\right), 4(2 / 1), 0.3-4.0 \mu \mathrm{m}$, AFGL \\
\hline 4 & Oslo-2Stream & Myhre & 2-stream DISORT, ESFT (HITRAN92 + GENLN2 for $\left.\mathrm{H}_{2} \mathrm{O}\right), 4(2 / 1), 0.3-4.0 \mu \mathrm{m}$, AFGL \\
\hline 5 & UNIVIE-Streamer & Neubauer, Hitzenberger & 8-stream DISORT, ESFT (LOWTRAN7 + LBLRTM), 24 (10/14), 0.2-5.0 $\mu \mathrm{m}$, AFGL \\
\hline 6 & FMI-libRadtran & Huttunen & 8 -stream DISORT2 $\delta$-M scaling on, $c k$-D (HITRAN92), $32(16 / 16), 0.24-4.61 \mu \mathrm{m}$, AFGL \\
\hline 7 & LMU-libRadtran & Mayer & 6-stream DISORT2, $c k$-D (HITRAN92), 32 (16/16), 0.2401-4.6057 $\mu \mathrm{m}$, AFGL \\
\hline 8 & GSFC-FL & $\mathrm{Yu}$ & 4-stream $\delta$-Ed, $c k$-D (HITRAN82), 15 (10/5), 0.2-4.0 $\mu \mathrm{m}$, AFGL \\
\hline 9 & CAR-FLG & F. Zhang & 4-stream $\delta$-Ed, $c k$-D (1982AGFL + HITRAN2k), $6(1 / 5), 0.2-4.0 \mu \mathrm{m}, \mathrm{AFGL}$ \\
\hline 10 & LaRC-FL & Rose, Kato & 2-stream $\delta$-Ed, $c k$-D (HITRAN2k), $18(10 / 8), 0.17-4.0 \mu \mathrm{m}, 32$-layers \\
\hline 11 & CAR-RRTMG & F. Zhang & 2-stream $\delta$-Ed, $c k$-D (LBLRTM), 14 (5/9), 0.2-12.196 $\mu \mathrm{m}, \mathrm{AFGL}$ \\
\hline 12 & RRTMG-SW & Oreopoulos, Lee & 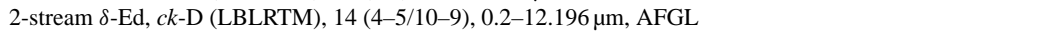 \\
\hline 13 & LMU-2stream & Mayer & 2-stream $\delta$-Ed, $c k$-D (HITRAN92), 32 (16/16), 0.2401-4.6057 $\mu \mathrm{m}$, AFGL \\
\hline 14 & MPI-2stream & Kinne & 2-stream $\delta$-Ed, $c k$-D (LOWTRAN5+Vigroux), 8 (4/4), $\mu \mathrm{m}, 20$-layers \\
\hline 15 & CAR-GSFC & F. Zhang & 2 -stream $\delta$-Ed+adding (CS), $k$-distribution (HITRAN96), 11 (8/3), 0.175-10 $\mu \mathrm{m}$, AFGL \\
\hline 16 & BCC-RAD & H. Zhang, P. Lu & 2-stream $\delta$-Ed (ES96), $c k$-D (HITRAN2k), 9 (7/2), 0.2-3.73 $\mu \mathrm{m}$, AFGL \\
\hline 17 & CAR-CCCMA & F. Zhang & $\delta$-Ed+adding, $c k$-D (HITRAN96), 4 (9-sub/3), 0.2-4.0 $\mu \mathrm{m}$, AFGL \\
\hline 18 & ECHAM5.5 & Quaas, Kinne, Stier & 2-stream $\delta$-Ed, Padé approx., $6(3 / 3), 0.185-4.0 \mu \mathrm{m}$, AFGL \\
\hline 19 & UMD-SRB & Ma, Pinker & $\begin{array}{l}\text { 2-stream } \delta \text {-Ed, } k \text {-distribution for } \mathrm{H}_{2} \mathrm{O} \text { and Lacis and Hansen (1974) for } \mathrm{O}_{3} \text { (HITRAN-96), } 7 \text { (4/3), } \\
0.2-4.0 \mu \mathrm{m}, 31 \text {-layers (Clear-Sky) otherwise variable }\end{array}$ \\
\hline 20 & ES96-6 & Highwood, Ryder, Harris & 2-stream PIFM, $c k$-D ( $\mathrm{H}_{2} \mathrm{O}:$ HITRAN 2003, $\mathrm{O}_{3}$ :HITRAN92), $6(2 / 3), 0.2-10 \mu \mathrm{m}$, AFGL \\
\hline 21 & ES96-220 & Highwood, Ryder, Harris & 2-stream PIFM, $c k$-D ( $\mathrm{H}_{2} \mathrm{O}$ : HITRAN 2003, $\mathrm{O}_{3}$ :HITRAN92), 220 (118/102), 0.2-10 $\mu \mathrm{m}$, AFGL \\
\hline 22 & ES96-6-D & Highwood, Ryder, Harris & 2-stream PIFM $+\delta$-scaling, $c k$-D ( $\mathrm{H}_{2} \mathrm{O}:$ HITRAN 2003, $\mathrm{O}_{3}$ :HITRAN92), $6(2 / 3), 0.2-10 \mu \mathrm{m}, \mathrm{AFGL}$ \\
\hline 23 & ES96-220-D & Highwood, Ryder, Harris & 2-stream PIFM $+\delta$-scaling, $c k$-D $\left(\mathrm{H}_{2} \mathrm{O}:\right.$ HITRAN 2003, $\mathrm{O}_{3}$ :HITRAN92) $220(118 / 102), 0.2-10 \mu \mathrm{m}, \mathrm{AFGL}$ \\
\hline 24 & UKMO-HadGEM2 & Rumbold & $\begin{array}{l}2 \text {-stream PIFM }+\delta \text {-scaling (ES96), } c k \text {-D }\left(\mathrm{H}_{2} \mathrm{O}: \text { HITRAN 2003, } \mathrm{O}_{3} \text { :HITRAN92), } 6(2 / 3) \text {, }\right. \\
0.2-10 \mu \mathrm{m}, \mathrm{AGFL}\end{array}$ \\
\hline 25 & CAR-CAWCR & F. Zhang & 2-stream $\delta$-Ed (SES), ESFT (GENLN2), 9 (4/5) 0.2-5.0 $\mu \mathrm{m}$, AFGL \\
\hline 26 & CAR-CAM & F. Zhang & 2-stream $\delta$-Ed, ESFT (HITRAN2k), $19(8 / 11), 0.2-5.0 \mu \mathrm{m}$, AFGL \\
\hline 27 & ULAQ & Pitari, Di Genova & 2-stream $\delta$-Ed, ESFT (MPI-MAINZ + HITRAN92 for $\left.\mathrm{H}_{2} \mathrm{O}\right), 235(150 / 85), 0.1216-7 \mu \mathrm{m}, 570 \mathrm{~m}$ \\
\hline 28 & FORTH & $\begin{array}{l}\text { Vardavas, Hatzianastassiou } \\
\text { Matsoukas }\end{array}$ & 2-stream $\delta$-Ed, ESFT, 128 (115/13), 0.2-9.52 $\mu \mathrm{m}, 100$-layers \\
\hline 29 & CAR-GFDL & F. Zhang & $\delta$-Ed+adding, ESFT (HITRAN92), 18 (13/5) 0.173-20 $\mu \mathrm{m}$, AFGL \\
\hline 30 & MPI-MOM & Kinne & 10-streams Matrix-Operator adding-doubling, $c k$-D (LOWTRAN5+Vigroux), 8 (4/4), $\mu \mathrm{m}, 20$-layers \\
\hline 31 & MOMO & Doppler, Fischer & Matrix-Operator adding-doubling, non-correlated $k$ (HITRAN-2008), 97 (67/30), 0.2-100 $\mu \mathrm{m}$, AFGL \\
\hline
\end{tabular}

a See Appendix A for further model details. Appendix Table A1 provides additional information on gaseous transmission.

b Format: \#-streams and multiple-scattering scheme, gaseous transmittance scheme (transmission database), total \# bands (\# UV-Vis/\# Near-IR), full $\lambda$-range [ $\mu$ m], vertical resolution.

c Abbreviations: $\mathrm{RT}=$ radiative transfer, $\mathrm{LBL}=$ line-by-line, $\mathrm{DISORT}=$ discrete-ordinate method, PIFM $=$ Practical Improved Flux Method, Ed $=$ Eddington, $\delta$-Ed $=$ delta Eddington, ES96 = Edwards and Slingo (1996),

$\mathrm{SES}=$ Sun-Edwards-Slingo, $\mathrm{CS}=\mathrm{Chou}$ and Suarez, FL $=\mathrm{Fu}-$ Liou, $\mathrm{FLG}=\mathrm{Fu}-\mathrm{Liou}-\mathrm{Gu}, \mathrm{ESFT}=$ exponential sum fit transmission, $c k$-D $=$ correlated $k$-distribution, AFGL $=$ Air Force Geophysical Laboratory vertical resolution.

Halthore et al. (2005) and represents the fraction of TOA irradiance absorbed in the atmosphere:

$A=\frac{\left(F_{\mathrm{TOA}}^{\downarrow}-F_{\mathrm{TOA}}^{\uparrow}\right)-\left(F_{\mathrm{SFC}}^{\downarrow}-F_{\mathrm{SFC}}^{\uparrow}\right)}{F_{\mathrm{TOA}}^{\downarrow}}$

where arrows indicate the direction of the flux (positive down). Additionally, the surface albedo $(\alpha)$ is fixed to the same value for all wavelengths, allowing for the calculation of surface (SFC) aerosol RF $\left(F_{\mathrm{SFC}}^{\uparrow}=\alpha F_{\mathrm{SFC}}^{\downarrow}\right)$. Flux in the near-IR is computed as the difference between broadband and UV-VIS.

\subsection{Case 1: Rayleigh scattering atmosphere}

Only molecular scattering and absorption (Rayleigh atmosphere) occur in the aerosol- and cloud-free Case 1. Following Halthore et al. (2005), shortwave flux components were computed using two different standard atmospheric profiles for ozone $\left(\mathrm{O}_{3}\right)$ and water vapor $\left(\mathrm{H}_{2} \mathrm{O}\right)$ : the Air Force Geophysics Laboratory (AFGL; Anderson et al., 1986) subarctic winter (SAW, lower humidity) and tropical atmospheres (TROP, higher humidity). Figure 1 shows the prescribed $\mathrm{O}_{3}$ and $\mathrm{H}_{2} \mathrm{O}$ profiles. Modelers were given the standard atmospheres at $1-\mathrm{km}$ resolution from $0-26 \mathrm{~km}$ and $2-\mathrm{km}$ from $26-$ $120 \mathrm{~km}$ (corresponding pressure levels were also provided); it was up to the individual contributor to vertically interpolate these fields if needed (see Appendix A). Fluxes are analyzed at two solar zenith angles (SZA), ranging from low $\left(30^{\circ}\right)$ to high $\left(75^{\circ}\right)$, to provide a range of conditions that representative of tropical and high-latitude conditions, respectively. The wavelength-independent Lambertian surface albedo $(\alpha)$ was prescribed as 0.2 . This case only considers cloud- and aerosol-free conditions; it thus highlights the transmittance of the radiation schemes considered. Results from Case 1 are presented in Sect. 3.1. 
Table 2. Protocol summary.

\begin{tabular}{|c|c|c|c|}
\hline Experiment & Case 1 & Case $2 \mathrm{a}$ & Case $2 b$ \\
\hline Aerosol & None (Rayleigh) & Fixed & Fixed \\
\hline $\mathrm{AOD}(0.55 \mu \mathrm{m})$ & 0 & 0.2 & 0.2 \\
\hline Ångström & \multicolumn{3}{|c|}{ Spectral dependence of AOD: } \\
\hline Parameter & \multicolumn{3}{|c|}{$\mathrm{AOD}=\exp (-1.0 \times \ln (\lambda / 0.55)+\ln (0.2))$} \\
\hline $\begin{array}{l}\text { Asymmetry }(g) \\
\text { Parameter }^{\mathrm{a}}\end{array}$ & N/A & 0.7 & 0.7 \\
\hline $\mathrm{SSA}^{\mathrm{a}}$ & N/A & 1.0 & 0.8 \\
\hline Surface Albedo ${ }^{\mathrm{a}}$ & \multicolumn{3}{|c|}{0.2 , globally, spectrally uniform } \\
\hline Atmosphere $^{b}$ & \multicolumn{3}{|c|}{$\begin{array}{l}\text { AFGL "Tropical" (TROP) and } \\
\text { "Sub-Arctic Winter" (SAW) }\end{array}$} \\
\hline Clouds & \multicolumn{3}{|c|}{ NONE } \\
\hline Solar Zenith Angle & \multicolumn{3}{|c|}{$30^{\circ}, 75^{\circ}$ for each atmosphere } \\
\hline
\end{tabular}

a Solar-spectrally invariant.

b TROP has higher humidity $\left(\mathrm{H}_{2} \mathrm{O}\right.$ mixing ration) and ozone (see Fig. 1).

\section{AFGL Standard Atmospheres}

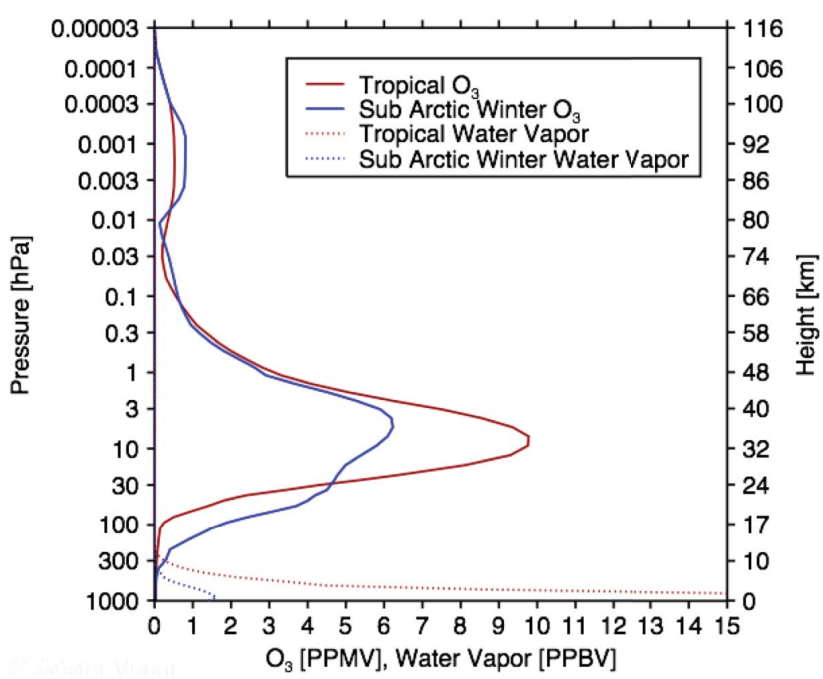

Fig. 1. Prescribed AFGL profiles of Ozone $\left(\mathrm{O}_{3}\right)$ and Water Vapor $\left(\mathrm{H}_{2} \mathrm{O}\right)$.

\subsection{Case 2a and 2b: cloud-free atmosphere with aerosols}

Case 2a (Scattering Aerosols) augments Case 1 by considering a simple prescription of purely scattering aerosols. $\mathrm{AOD}$ at $550 \mathrm{~nm}$ is prescribed at 0.2 and linearly distributed in the lowest $2 \mathrm{~km}$ of the host model. This corresponds roughly to the "high AOD" case considered by Halthore et al. (2005). The Ångström exponent is given as 1.0 at $550 \mathrm{~nm}$ such that at other wavelengths $(\lambda ; \mu \mathrm{m})$, $\mathrm{AOD}=\exp (-1.0 \times \ln (\lambda / 0.55)+\ln (0.2))$. The single scattering albedo (SSA) is solar-spectrally invariant and set equal to 1.0 for scattering aerosols. The asymmetry parameter $(g)$ is prescribed at 0.7 (forward-scattering) and is also solarspectrally invariant. In Case 2b (Absorbing Aerosols), we consider a simple prescription of more absorbing aerosols. Aerosol properties are as in Case 2a, however the single scattering albedo is prescribed at 0.8 (solar-spectrally invariant SSA). Note that in Case $2 \mathrm{~b}$ the aerosols both scatter and absorb solar radiation. These cloud-free aerosol cases shows how the models handle multiple scattering and atmospheric absorption by aerosols. Flux results from Case $2 \mathrm{a}$ and $2 \mathrm{~b}$ are presented in Sect. 3.2.

\subsection{Case 2a and 2b: aerosol direct radiative forcing}

The fluxes considered in Cases 1 and 2 provide the necessary information to calculate broadband aerosol direct radiative forcing (RF). Here, $\mathrm{RF}\left[\mathrm{W} \mathrm{m}^{-2}\right]$ is defined as the difference (down $\downarrow-$ up $\uparrow$ ) in flux $(F)$ with and without aerosols present in the atmosphere:

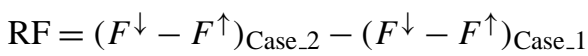

Defined in this way (positive down), negative values imply aerosol radiative cooling and positive values imply aerosol radiative warming of the climate system. We compute RF at the top-of-the-atmosphere (TOA) and the surface (SFC). The atmospheric forcing (ATM) is the difference between the two: ATM=TOA-SFC. Because aerosol RF is calculated as a difference in fluxes with and without aerosols holding atmospheric state constant, errors in the treatment of the Rayleigh atmosphere (Case 1) tend to be cancelled to first order. However, we examine aerosol RF because it is of primary interest to the AeroCom community and remains a major source of uncertainty in our understanding of anthropogenic climate change (Solomon et al., 2007). Because we consider harmonized surface and aerosol optical properties, these RF calculations should indicate differences in how models treat multiple-scattering, rather than how an individual model simulates aerosol properties (mass, lifetime, etc.) and their resulting direct RF. Note that global, diurnally-averaged results from the AeroCom Prescribed Experiment FIX2-FIX0 in clear-sky (cloud-free) conditions are comparable to Case 2a. However, in the Prescribed Experiment the surface albedo and gaseous absorbers are not fixed (Stier et el., 2012). Similarly, results from Case 2b are analogous to the global average FIX3-FIX0 clear-sky results in Stier et el. (2012). We examine aerosol RF in Sect. 3.3 and draw comparisons to other Phase II AeroCom studies in Sect. 3.4.

\section{Results}

Recall that results from each case are first normalized to the model-specific TOA downwards flux in the appropriate band (broadband or UV-VIS); the normalized fluxes are then scaled by the multi-model median TOA flux (see Fig. 2). We 

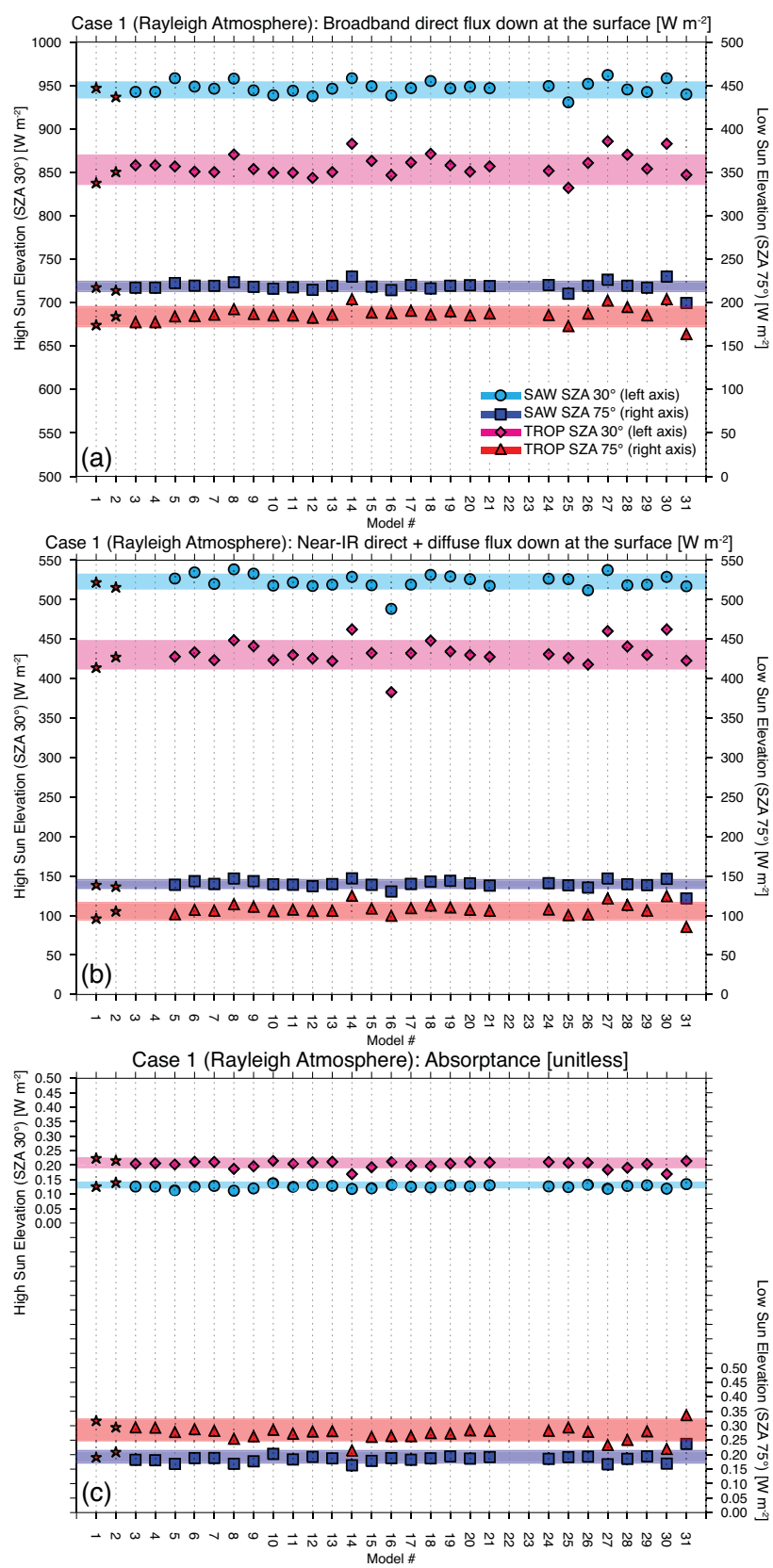

Fig. 2. Summary of results for Case 1 (Rayleigh Atmosphere) in $\mathrm{W} \mathrm{m}^{-2}$ : (a) direct broadband flux down at the surface, (b) total (direct plus diffuse) near-IR down at the surface (calculated as the difference between broadband and UV-VIS), and (c) broadband absorptance calculated as in Eq. (1). Line-by-line results (stars) and non-LBL results (non-stars) are given as a function of Model \# (Table 1). Shading represents the greater of \pm 1 standard deviation from the LBL or non-LBL mean. Normalized results were scaled by the following broadband (UV-VIS) TOA downwards fluxes: 1189.28 (563.38) $\mathrm{W} \mathrm{m}^{-2}$ for SZA $30^{\circ}$ and 355.43 (168.37) $\mathrm{W} \mathrm{m}^{-2}$ for SZA $75^{\circ}$. Note that the mean bias of TOA downward fluxes for nonLBL models relative to the LBL models was $2 \%$ in the broadband and $2.4 \%$ in the UV-VIS. Models 22-23 are omitted because they are the same as Models 20-21 in the clear-sky case. Models 3-4 did not provide UV-VIS fluxes. tabulate results separately for the line-by-line (LBL) benchmark codes (Models \#1 and 2) and the remaining non-LBL models. We calculate the relative standard deviation (RSD) in order to evaluate overall model diversity, where $\mathrm{RSD}=\left|\frac{\sigma}{\mu}\right|$, $\sigma$ is the standard deviation, and $\mu$ the mean value of the respective parameter. The RSD is calculated separately for the two LBL models and the non-LBL models. The average bias of the non-LBL models relative tho the average benchmark LBL results is expressed as a percent difference from the LBL-mean (i.e. $\left.100 \times\left(\mu_{\text {models }}-\mu_{\mathrm{LBL}}\right) / \mu_{\mathrm{LBL}}\right)$. To visualize non-LBL model diversity, we examine the individual model bias relative to the non-LBL model mean.

\subsection{Case 1 (Rayleigh atmosphere)}

Figure 2a shows the direct downwards broadband flux in cloud- and aerosol-free conditions for each solar zenith angle and standard atmosphere combination. While most models fall within the inter-model diversity (the greater of \pm 1 standard deviation from the LBL or non-LBL model mean; shading), models 14, 25, 27, 30, and 31 are often outliers and are not included in the summary statistics for the Rayleigh atmosphere case in Table 3. (Appendix Table A2 provides statistics including all models). Of these models, models 14 and 30 use the same gaseous transmission scheme (Appendix A). Note that models 22 and 23 are identical to models 20 and 21 for the Rayleigh atmosphere case and are thus omitted for Case 1 ; however they are included in Case 2 because they use different multiple-scattering schemes (Table 1).

The low value of RSD for both LBL and non-LBL models (Table 3) indicates the best agreement in direct broadband flux down at the surface when the water vapor slant path is at its lowest $\left(30^{\circ}\right.$ in the sub-Arctic winter). Inter-model differences increase both with increased solar zenith angle and increased water vapor (i.e. the tropical AFGL profile), with the former having a stronger impact on the RSD. This pattern of inter-model difference agrees with the findings of Halthore et al. (2005), and the agreement between models in this study is also generally better than $2 \%$. Our model diversity is within $\sim 30 \%$ of the broadband direct flux results for the 16 models considered in Halthore et al. (2005).

Relative to the LBL models, models in this study tend to overestimate the direct broadband radiation at the surface by $<2 \%$ under most conditions (Table 3 ). We note that in addition to prescribing the AFGL ozone and water vapor profiles, Halthore et al. (2005) also specified $\mathrm{N}_{2}$ and $\mathrm{O}_{2}$ abundances as a function of height from MODTRAN and fixed the $\mathrm{CO}_{2}$ mixing ratio at $360 \mathrm{ppm}$. In our results, individual modelers choose the specification of trace gasses excluding $\mathrm{O}_{3}$ and $\mathrm{H}_{2} \mathrm{O}$. A sensitivity study to the inclusion of additional gaseous absorbers was performed using the CAR ensemble modeling system (Liang and Zhang, 2012; Zhang et al., 2013), which provided results for seven of the radiation schemes considered here (Table 1). Addition of $\mathrm{N}_{2} \mathrm{O}$, $\mathrm{CH}_{4}$, and $\mathrm{CO}_{2}$ contributed to an additional $1 \%$ decrease in 
Table 3. Case 1: Summary of Statistics for the Rayleigh Atmosphere ${ }^{\mathrm{a}, \mathrm{b}, \mathrm{c}}$

\begin{tabular}{lcccc}
\hline & \multicolumn{2}{c}{ SAW } & \multicolumn{2}{c}{ TROP } \\
\hline & $30^{\circ} \mathrm{SZA}$ & $75^{\circ} \mathrm{SZA}$ & $30^{\circ} \mathrm{SZA}$ & $75^{\circ} \mathrm{SZA}$ \\
\hline \multicolumn{2}{c}{ Direct Broadband Downwards } & Flux at Surface \\
\hline LBL Avg & 942.4 & 216.2 & 844.5 & 179.6 \\
LBL RSD & $0.8 \%$ & $1.1 \%$ & $1.1 \%$ & $3.9 \%$ \\
Model Avg. & 946.8 & 218.6 & 856.3 & 186.3 \\
Avg. Bias & $0.5 \%$ & $1.1 \%$ & $1.4 \%$ & $3.7 \%$ \\
Model RSD & $0.6 \%$ & $1.0 \%$ & $0.9 \%$ & $2.1 \%$ \\
\hline
\end{tabular}

Diffuse Broadband Downwards Flux at Surface

\begin{tabular}{lllll}
\hline LBL Avg & 64.4 & 37.2 & 64.0 & 36.8 \\
LBL RSD & $0.9 \%$ & $1.5 \%$ & $0.4 \%$ & $0.5 \%$ \\
Model Avg. & 63.4 & 38.0 & 63.3 & 37.9 \\
Avg. Bias & $-1.5 \%$ & $2.1 \%$ & $-1.1 \%$ & $3.0 \%$ \\
Model RSD & $7.0 \%$ & $4.8 \%$ & $6.8 \%$ & $4.6 \%$
\end{tabular}

Diffuse Broadband Flux Up at TOA

\begin{tabular}{lllll}
\hline LBL Avg & 227.6 & 82.6 & 204.7 & 75.2 \\
LBL RSD & $1.3 \%$ & $1.5 \%$ & $1.3 \%$ & $1.8 \%$ \\
Model Avg. & 230.5 & 83.9 & 210.1 & 77.8 \\
Avg. Bias & $1.3 \%$ & $1.6 \%$ & $2.6 \%$ & $3.5 \%$ \\
Model RSD & $1.1 \%$ & $1.9 \%$ & $1.4 \%$ & $2.1 \%$
\end{tabular}

Total (Direct + Diffuse) UV-VIS Downwards Flux at Surface

\begin{tabular}{lllll}
\hline LBL Avg & 489.2 & 115.8 & 489.1 & 115.7 \\
LBL RSD & $0.7 \%$ & $1.3 \%$ & $0.2 \%$ & $0.3 \%$ \\
Model Avg. & 489.3 & 116.7 & 490.3 & 117.5 \\
Avg. Bias & $0.0 \%$ & $0.8 \%$ & $0.3 \%$ & $1.6 \%$ \\
Model RSD & $1.1 \%$ & $2.6 \%$ & $1.0 \%$ & $2.4 \%$ \\
\hline
\end{tabular}

\begin{tabular}{lllll}
\hline \multicolumn{5}{c}{ Total near-IR Downwards Flux at Surface } \\
\hline LBL Avg & 519.1 & 138.0 & 421.1 & 101.1 \\
LBL RSD & $0.8 \%$ & $1.0 \%$ & $2.3 \%$ & $6.5 \%$ \\
Model Avg. & 521.7 & 139.9 & 429.1 & 107.3 \\
Avg. Bias & $0.5 \%$ & $1.4 \%$ & $1.9 \%$ & $6.1 \%$ \\
Model RSD & $2.0 \%$ & $2.5 \%$ & $3.2 \%$ & $3.6 \%$ \\
\hline \multicolumn{5}{c}{ Broadband Absorptance } \\
\hline LBL Avg & 0.134 & 0.201 & 0.221 & 0.307 \\
LBL RSD & $7.2 \%$ & $6.4 \%$ & $2.5 \%$ & $5.1 \%$ \\
Model Avg. & 0.126 & 0.186 & 0.204 & 0.276 \\
Avg. Bias & $-5.7 \%$ & $-7.6 \%$ & $-7.5 \%$ & $-10.1 \%$ \\
Model RSD & $4.7 \%$ & $4.3 \%$ & $3.8 \%$ & $4.2 \%$ \\
\hline
\end{tabular}

a Flux units $\mathrm{W} \mathrm{m}^{-2}$; scaled normalized results as described in the text and Fig. 2. Statistics for non-LBL models excludes models 14, 25, 27, 30, and 31. Models 22 and 23 are excluded because they are the same as models 20 and 21 in the Rayleigh atmosphere. Table A2 gives statistics excluding models 22-23 only.

${ }^{\mathrm{b}}$ Line-by-line (LBL) benchmarks (Avg. of models \#1 and \#2) and non-LBL model results.

${ }^{c}$ Avg. Bias is expressed as a percentage of the LBL Avg. RSD = standard deviation as a percentage of mean.

d Near-IR is calculated as a difference between broadband and UV-VIS.

e Absorptance (Eq. 1) is derived assuming $\mathrm{F}_{\mathrm{SFC}}^{\uparrow}=\alpha \mathrm{F}_{\text {SFC }}^{\downarrow}$ and surface albedo $\alpha=0.2$.
Table 4. Statistics for diffuse flux down at surface with aerosols ${ }^{\mathrm{a}}$

\begin{tabular}{|c|c|c|}
\hline ATM and SZA & $\begin{array}{c}\text { Group } 1^{\mathrm{b}} \\
\text { Bias (RSD) }\end{array}$ & $\begin{array}{c}\text { Group } 2^{\mathrm{c}} \\
\text { Bias (RSD) }\end{array}$ \\
\hline \multicolumn{3}{|c|}{ Case 2a: Scattering Aerosols } \\
\hline SAW 30 & $-0.9 \%(3.5 \%)$ & $-36.6 \%(5.8 \%)$ \\
\hline SAW 75 & $2.3 \%(5.2 \%)$ & $-30.4 \%(3.7 \%)$ \\
\hline TROP 30 & $0.2 \%(3.7 \%)$ & $-35.3 \%(5.6 \%)$ \\
\hline TROP75 & $4.3 \%(5.4 \%)$ & $-27.1 \%(4.4 \%)$ \\
\hline \multicolumn{3}{|c|}{ Case 2b: Absorbing Aerosols } \\
\hline SAW 30 & $-0.3 \%(3.6 \%)$ & $-33.8 \%(4.4 \%)$ \\
\hline SAW 75 & $3.4 \%(5.5 \%)$ & $-26.5 \%(2.6 \%)$ \\
\hline TROP 30 & $1.0 \%(3.9 \%)$ & $-32.4 \%(4.4 \%)$ \\
\hline TROP 75 & $5.2 \%(5.8 \%)$ & $-23.1 \%(2.8 \%)$ \\
\hline
\end{tabular}

broadband downwards flux at the surface, with most of that due to carbon dioxide (F. Zhang, personal communication, 2012). We thus note that diversity in the treatment of other trace gas absorbers may contribute to some of the bias and diversity in our results.

Figure $2 \mathrm{~b}$ shows the total (direct plus diffuse) downwards flux in the near-IR (i.e. broadband minus UV-VIS). Deficiencies in the near-IR band indicate that models may not adequately treat absorption by water vapor. The statistics in Table 3 indicate increased model diversity (larger RSD) and increased bias relative to the LBL results as the slant-path of water vapor increases. Broadband absorptance calculated according to Eq. (1) is shown in Fig. 2c. Model diversity expressed as RSD is roughly $4 \%$ for broadband absorptance. In the tropical atmosphere, broadband absorptance RSD is slightly higher compared to the $\sim 3 \%$ diversity found in Halthore et al. (2005). This difference, however, is small considering that the spectral resolution of the models considered in Halthore et al. (2005) was generally much greater than the models in this study.

In the UV-VIS where gaseous absorption is influenced by the amount of ozone, the LBL models show good agreement (RSD $\lesssim 1 \%$; Table 3 ). However, the non-LBL RSD is higher by about a factor of $\sim 2$ for SAW (less $\mathrm{O}_{3}$ ) and a factor of 5-8 for TROP $\left(\right.$ more $\mathrm{O}_{3}$ ). The bias relative to the LBL calculations is low at $30^{\circ}$ and increases at $75^{\circ}$. Figure A1a shows the UV-VIS down at the surface expressed as a percent deviation from the non-LBL model mean (i.e. $\mu$ excluding only models 1-2 and 22-23). Models that performed well for the broadband may have deficiencies in the UV-VIS range, as exhibited by models such as 5 and 25, which over and underestimate the UV-VIS flux relative to the LBL results (see Fig. A2). Note that Model \#5 uses a one-parameter scaling approach to scale the absorption by atmospheric gases 


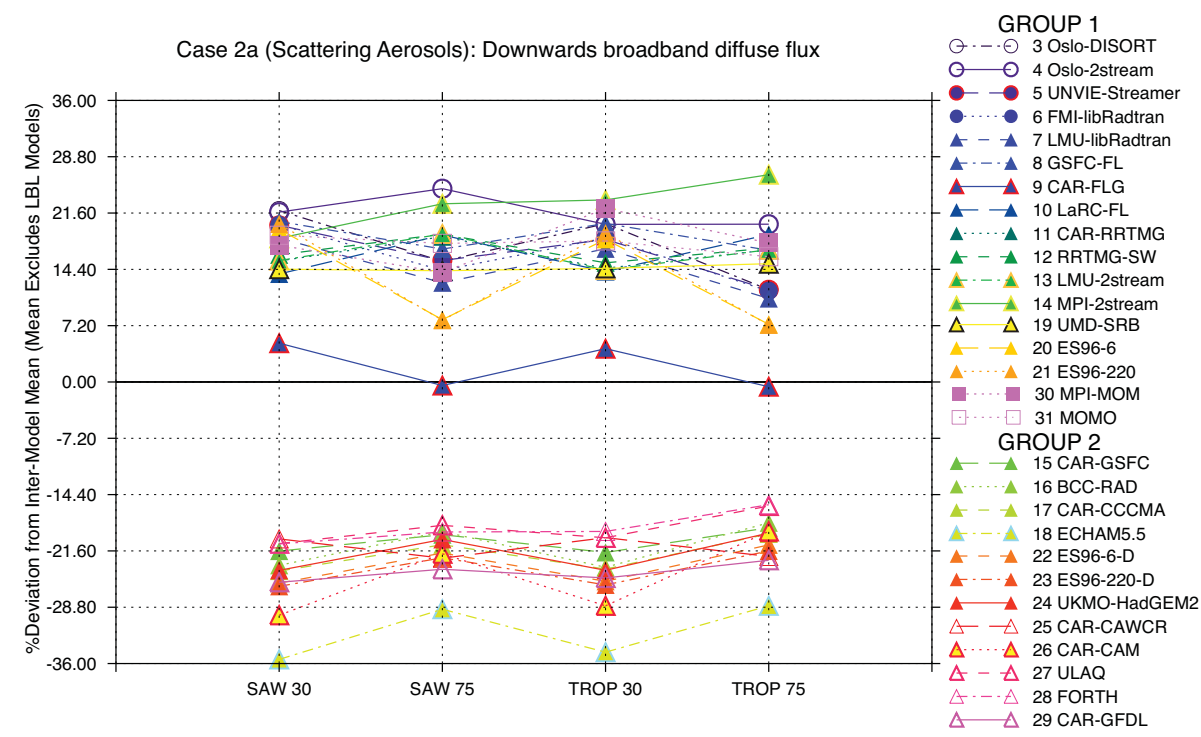

Fig. 3. As a function of standard atmosphere and solar zenith angle, the inter-model diversity in broadband diffuse flux down at the surface for Case 2a (Scattering Aerosols), expressed as a percent deviation from the non-LBL model mean (i.e. all models excluding \#1 and 2). Figure A4 shows the inter-model differences in broadband direct and diffuse flux down at the surface for Case $2 \mathrm{a}$ and $2 \mathrm{~b}$.

to different temperatures and pressures; this reduces the $\mathrm{O}_{3}$ absorption in the Rayleigh atmosphere case but is less important when calculating aerosol direct and indirect forcing as well as exoplanetary surface temperatures, the primary applications of this model.

The largest inter-model flux differences occur for broadband diffuse flux to the surface (Table 3, Figs. A1b and A3). The RSD is roughly equal for each SZA regardless of prescribed atmosphere, and it is greatest at $30^{\circ}$. Relative to LBL calculations, models generally under- and overestimate broadband diffuse flux at the surface at lower and higher solar zenith angle, respectively. Because much of the diffuse flux occurs in the UV-VIS, deficiencies in the broadband diffuse flux may point to issues in the treatment of ozone absorption. The model diversity for the diffuse flux down at the surface is comparable to Halthore et al. (2005) in the sub-Arctic winter; however, it is considerably ( $\sim 5$ times) less in the tropical atmosphere. The relatively good agreement in upwards broadband flux at the top-of-the atmosphere (RSD 2\%) is similar to the agreement found for the direct broadband flux to the surface as expected due to the prescribed surface albedo.

\subsection{Case 2 (fluxes with aerosols)}

Flux results for Case 2a (Scattering Aerosols) and Case $2 \mathrm{~b}$ (Absorbing Aerosols) are summarized in Appendix Tables A3 and A4, respectively. For all flux quantities, model disagreement (RSD) increases with solar zenith angle and, with the exception of downwards UV-VIS flux, is higher in the tropical atmosphere compared to the sub-Arctic winter. In both aerosol cases, models agree within $\lesssim 3 \%$ for all total (direct plus diffuse) flux quantities. For comparison, Halthore et al. (2005) found that model diversity with inclusion of nonabsorbing aerosols at high AOD (0.24) as generally within $1-2 \%$. Model diversity is similar with increased aerosol absorption (decreased SSA), but the magnitude of the bias relative to the LBL-benchmark is generally slightly higher for absorbing aerosols.

The worst model agreement for Case 2 occurs for the components of the total irradiance down at the surface, a finding in accord with Phase I of the Continual Intercomparison of Radiation Codes (CIRC; Oreopoulos et al., 2012). Figures 3 and A4 illustrate the inter-model differences in the diffuse and direct components of the downwards broadband flux. The models tend to fall into two separate groups: those which are approximately equal to the LBL-benchmark (Group 1, Models \#3-14, 19-21, 30-31), and those that underestimate it (Group 2; Models \#15-18, 22-29). Table 4 gives the statistics for each group relative to the LBL-mean. Despite the different biases in the two groups relative to the LBL-benchmark, the RSD shows that the model diversity is similar for each group ( $\sim 3-6 \%)$. Most multi-stream models (\#3, 5-9), which include all models that employ the DISORT algorithm for multiple-scattering (\#3-7), agree the best with the LBL-benchmarks (see the Appendix Fig. A5 and A6). Both LBL schemes also use DISORT and multiple streams (Table 1).

A sensitivity study using both a delta 2-stream and delta 4stream approximation was performed using Model \#9 (CARFLG; F. Zhang, personal communication, 2012). While Model \#9 is in Group 1 (Table 4) when run with a delta 4stream method, using only a delta 2 -stream method largely reduces the broadband diffuse flux to the surface such that it 

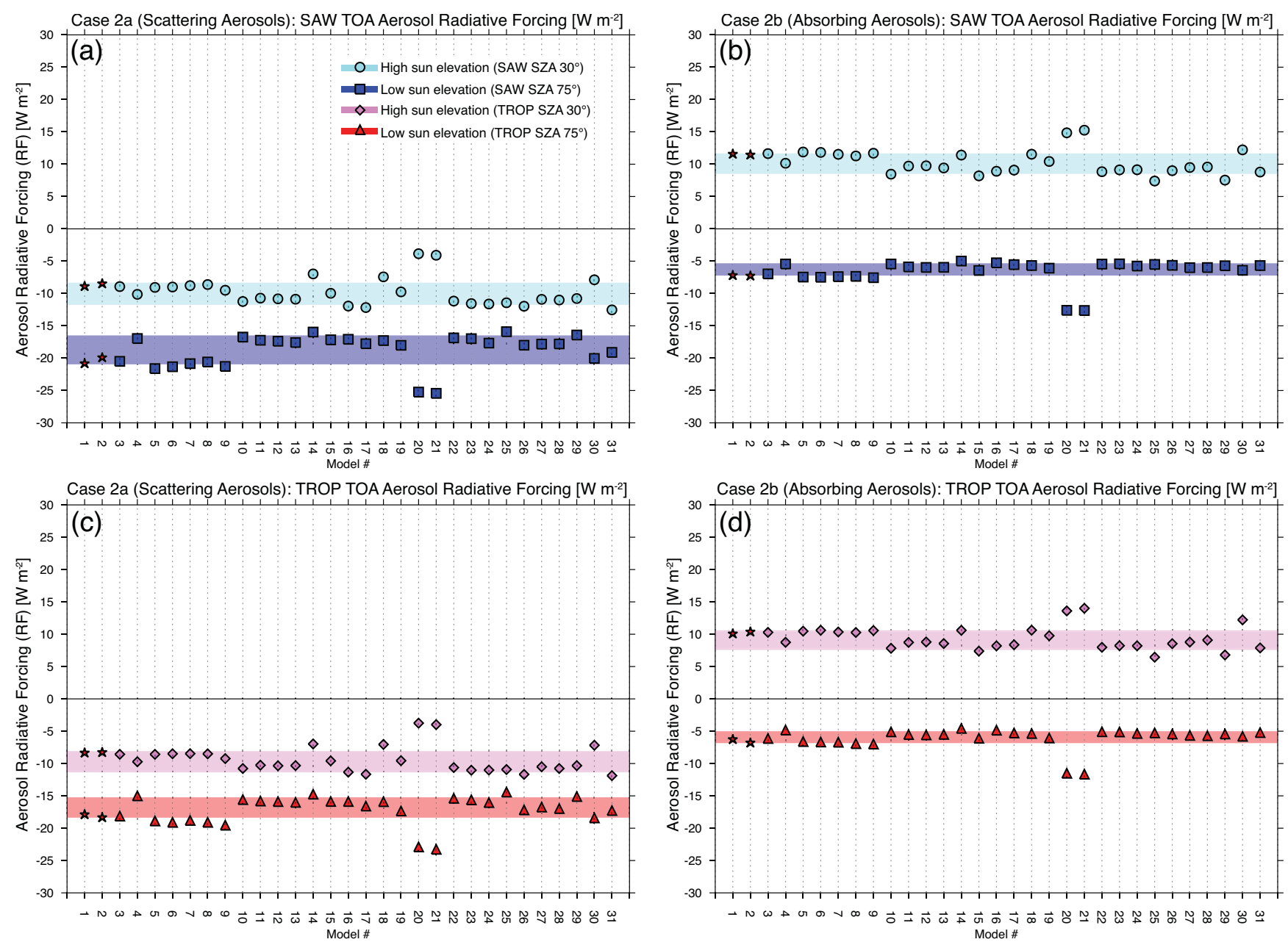

Fig. 4. Summary of results for top of the atmosphere aerosol radiative forcing (TOA RF) in $\mathrm{W} \mathrm{m}^{-2}$ : (a) Case 2a (Scattering Aerosols) SAW, (b) Case 2b (Absorbing Aerosols) SAW, (c) Case 2a (Scattering Aerosols) TROP, and (d) Case 2b (Absorbing Aerosols) TROP. Line-by-line results (stars) and non-LBL results (non-stars) are given as a function of Model \# (Table 1). Shading represents the greater of \pm 1 standard deviation from the LBL or non-LBL mean (excluding Models 20-21). RF was calculated from Eq. (2) using normalized flux results that were scaled by the broadband downwards fluxes given in Fig. 2.

is closer to the mean flux for Group 2. In the delta-rescaling, the fraction of scattered energy residing in the forward peak $(f)$ for the delta 2-stream and delta 4-stream approximations are $f=\tilde{\omega}_{2} / 5$ and $f=\tilde{\omega}_{4} / 9$, respectively, where $\tilde{\omega}_{2}$ and $\tilde{\omega}_{4}$ are the second and fourth coefficients of the phase function. Using the Henyey-Greenstein phase function, $\tilde{\omega}_{2}=5 g^{2}$ and $\tilde{\omega}_{4}=9 g^{4}$ where $g$ is the asymmetry factor. When $f$ decreases, more scattered energy is kept and there is an increase in diffuse flux at the surface. As the number of streams increase from two $\left(f \sim g^{2}\right)$ to four $\left(f \sim g^{4}\right), f$ decreases, and the diffuse flux down to the surface increases.

Models \#20-23, which employ the Practical Improved Flux Method (PIFM) for multiple scattering (Zdunkowski et al., 1980), illustrate that the same 2-stream method can be configured to either more accurately represent diffuse or total flux. In models \#22 and 23, $\delta$-rescaling provides more accurate total flux at the expense of the partitioning between the direct and diffuse fluxes because it increases the flux in the direct beam to account for strong forward aerosol scattering. However, while omitting $\delta$-rescaling (models \#20 and 21) improves the accuracy of the diffuse beam relative to the LBL-results (Figs. A5 and A6), as shown in Sect. 3.3, it impacts RF estimates.

\subsection{Aerosol direct radiative forcing from Case 2a and 2b}

Figure 4 shows the top of the atmosphere aerosol radiative forcing. Surface and atmospheric aerosol radiative forcing are shown in Fig. 5. Table 5 gives the multi-model statistics for the aerosol radiative forcing. Note that Models \#20-21 are outliers (see Fig. 4). Recall from Section 3.2 that these models are the same as Models \#22-23 except that they do not 
Table 5. Summary of statistics for aerosol radiative forcing $\mathrm{a}, \mathrm{b}, \mathrm{c}, \mathrm{d}$

\begin{tabular}{|c|c|c|c|c|}
\hline & \multicolumn{2}{|c|}{ Case 2a: Scattering Aerosols } & \multicolumn{2}{|c|}{ Case 2b: Absorbing Aerosols } \\
\hline & TOA RF & SFC RF & TOA RF & SFC RF \\
\hline \multicolumn{5}{|c|}{ Sub-Arctic Winter $30^{\circ} \mathrm{SZA}$} \\
\hline LBL Avg. & -8.6 & -9.7 & 11.6 & -42.1 \\
\hline LBL RSD & $3.4 \%$ & $4.2 \%$ & $0.7 \%$ & $1.4 \%$ \\
\hline Model Avg. & $-10.2(-10.6)$ & $-11.0(-11.2)$ & $9.9(9.4)$ & $-41.8(-41.6)$ \\
\hline Avg. Bias & $18.9 \%(23.2 \%)$ & $13.0 \%(15.9 \%)$ & $-14.2 \%(-18.5 \%)$ & $-0.7 \%(-1.2 \%)$ \\
\hline Model RSD & $14.7 \%(14.3 \%)$ & $13.3 \%(13.8 \%)$ & $14.3 \%(12.9 \%)$ & $4.1 \%(4.3 \%)$ \\
\hline \multicolumn{5}{|c|}{ Sub-Arctic Winter $75^{\circ} \mathrm{SZA}$} \\
\hline LBL Avg. & -20.3 & -21.5 & -7.2 & -37.8 \\
\hline LBL RSD & $3.2 \%$ & $3.8 \%$ & $0.7 \%$ & $2.9 \%$ \\
\hline Model Avg. & $-18.2(-17.4)$ & $-18.6(-17.5)$ & $-6.1(-5.7)$ & $-34.7(-33.5)$ \\
\hline Avg. Bias & $-10.3 \%(-14.2 \%)$ & $-13.8 \%(-18.7 \%)$ & $-15.0 \%(-20.1 \%)$ & $-8.1 \%(-11.2 \%)$ \\
\hline Model RSD & $9.6 \%(5.4 \%)$ & $11.8 \%(5.9 \%)$ & $12.6 \%(6.3 \%)$ & $7.3 \%(4.2 \%)$ \\
\hline \multicolumn{5}{|c|}{ Tropics $30^{\circ} \mathrm{SZA}$} \\
\hline LBL Avg. & -8.2 & -10.0 & 10.3 & -40.6 \\
\hline LBL RSD & $0.7 \%$ & $5.1 \%$ & $2.0 \%$ & $0.5 \%$ \\
\hline Model Avg. & $-9.8(-10.2)$ & $-10.9(-11.0)$ & $9.0(8.7)$ & $-40.4(-40.1)$ \\
\hline Avg. Bias & $19.2 \%(23.3 \%)$ & $8.3 \%(10.1 \%)$ & $-12.0 \%(-15.9 \%)$ & $-0.6 \%(-1.2 \%)$ \\
\hline Model RSD & $14.5 \%(14.2 \%)$ & $12.2 \%(13.3 \%)$ & $15.2 \%(15.1 \%)$ & $4.0 \%(4.2 \%)$ \\
\hline \multicolumn{5}{|c|}{ Tropics $75^{\circ} \mathrm{SZA}$} \\
\hline LBL Avg. & -18.0 & -18.9 & -6.5 & -33.6 \\
\hline LBL RSD & $1.8 \%$ & $0.1 \%$ & $5.8 \%$ & $0.8 \%$ \\
\hline Model Avg. & $-16.7(-16.1)$ & $-16.6(-15.7)$ & $-5.7(-5.4)$ & $-31.6(-30.7)$ \\
\hline Avg. Bias & $-7.4 \%(-10.9 \%)$ & $-12.3 \%(-17.0 \%)$ & $-12.4 \%(-16.9 \%)$ & $-5.8 \%(-8.6 \%)$ \\
\hline Model RSD & $8.9 \%(6.1 \%)$ & $11.8 \%(7.5 \%)$ & $11.6 \%(7.1 \%)$ & $8.3 \%(7.3 \%)$ \\
\hline \multicolumn{5}{|c|}{$\begin{array}{l}\text { Forcing units } \mathrm{W} \mathrm{m}^{-2} \text { calculated as in Eq. (2). We exclude Model \# } 20 \text { and } 21 \text { as described in the text. } \\
\text { n parenthesis, we also exclude the multi-stream models (Models \# } 3 \text { and 5-9) that agree well with LBL results. }\end{array}$} \\
\hline \multicolumn{5}{|c|}{$\begin{array}{l}\text { Line-by-line (LBL) benchmarks (Avg. of Models \#1 and \#2) and non-LBL model results. } \\
\text { Avg. Bias is expressed as a percentage of the LBL Avg. Positive values imply that models overestimate radiative cooling or radiative } \\
\text { warming. RSD = standard deviation as a percentage of mean. } \\
\text { Unless given, assumed } \mathrm{F}_{\mathrm{SFC}}^{\uparrow}=\alpha \mathrm{F}_{\mathrm{TOA}}^{\downarrow} \text { and } \alpha=0.2 \text { to calculate SFC RF. }\end{array}$} \\
\hline
\end{tabular}

include $\delta$-rescaling (and thus sacrifice accuracy in total flux to gain accuracy in diffuse flux). Models \#20-21 significantly over- and underestimate both the LBL-mean and the mean of all other models at $30^{\circ}$ and $75^{\circ}$, respectively; we thus exclude them from the RF statistics in Table 5. Models using multiple streams (\#3, 5-9, 30-31) generally show the best agreement with benchmark LBL calculations of TOA radiative forcing. If we exclude multi-stream models from the statistics in Table 5 (shown in parenthesis), the model bias gets larger but there is an improvement in model diversity (i.e. a reduction in RSD).

For scattering-only aerosols (Case 2a), the magnitude of aerosol cooling increases with solar zenith angle (Table 5). This is expected for an optically thin atmosphere; as the solar zenith angle increases so does the upscatter fraction, and decreases in incident irradiance are compensated by increased optical path length (Nemensure et al., 1995; Halthore et al.,
2005). Compared to benchmark LBL calculations (Table 5), models tend to overestimate top of the atmosphere radiative cooling at low SZA and underestimate radiative cooling at high SZA. The magnitude of this bias is less sensitive to the prescribed atmosphere than to solar zenith angle, and is on the order of $20 \%$ at 30 degrees and $10 \%$ at 75 degrees. Model diversity is largest at the lower zenith angle $(\sim 15 \%$ RSD at $30^{\circ}$ compared to $\sim 9 \%$ at $75^{\circ}$ ). As expected for nonabsorbing aerosols, the behavior of the surface radiative forcing in terms of bias and RSD is similar to the results at the TOA.

For more absorbing aerosols (Case $2 \mathrm{a}, \mathrm{SSA}=0.8$ ), TOA aerosol radiative forcing switches sign from positive to negative (radiative warming to cooling) as solar zenith angle increases. Models underestimate TOA radiative warming by $\sim 12-14 \%$ at $30^{\circ}$ and underestimate radiative cooling at $75^{\circ}$ by about $12-15 \%$ relative to the LBL benchmark. Model 

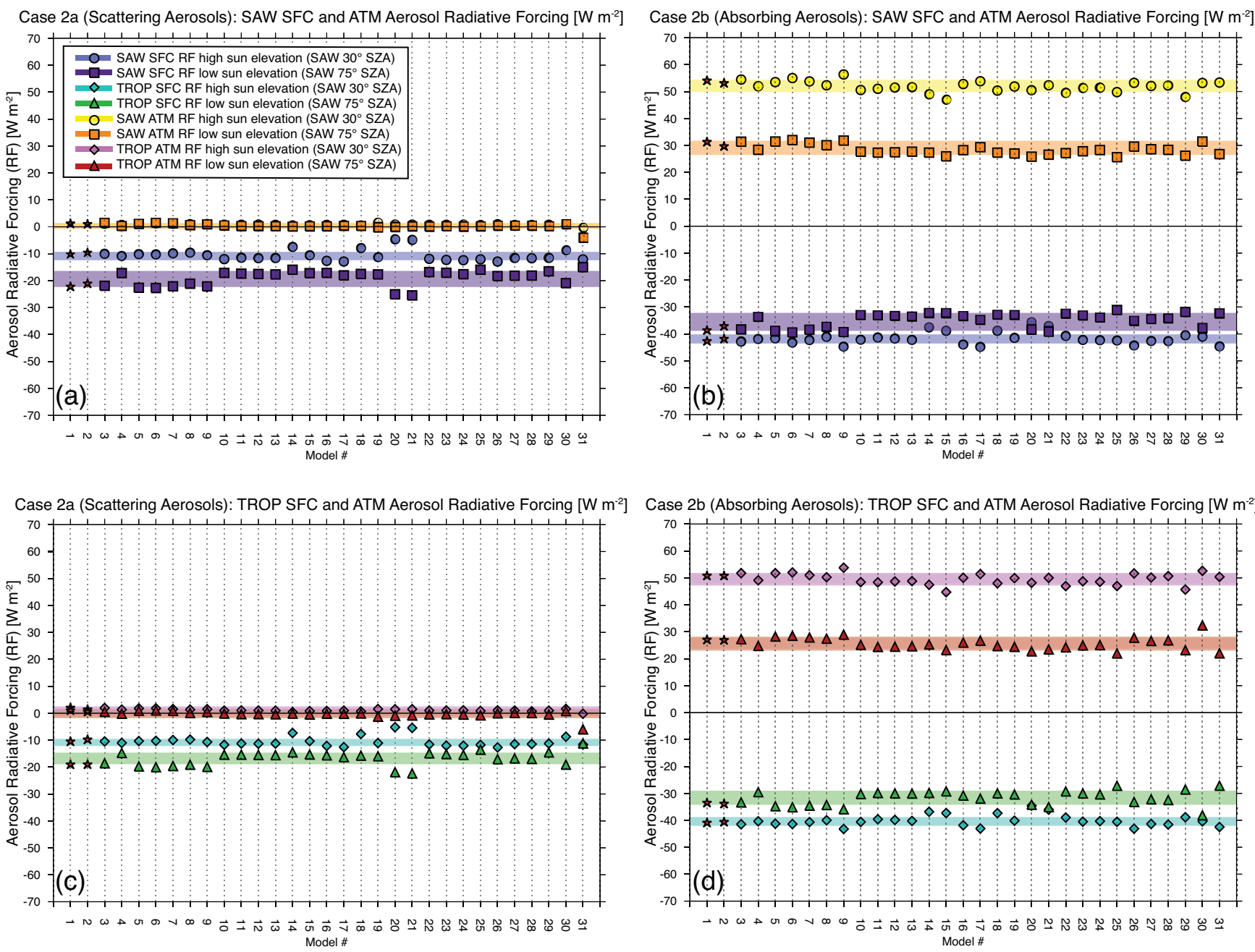

Fig. 5. Summary of results for surface and atmospheric aerosol radiative forcing (SFC and ATM RF) in W m ${ }^{-2}$ : (a) Case $2 \mathrm{a}$ (Scattering Aerosols) SAW, (b) Case 2b (Absorbing Aerosols) SAW, (c) Case 2a (Scattering Aerosols) TROP, and (d) Case 2b (Absorbing Aerosols) TROP. Line-by-line results (stars) and non-LBL results (non-stars) are given as a function of Model \# (Table 1). Shading represents the greater of \pm 1 standard deviation from the LBL or non-LBL mean. RF was calculated from Eq. (2) using normalized flux results that were scaled by the broadband TOA downwards fluxes given in Fig. 2. The ATM forcing is calculated as a residual from the TOA and SFC RF (i.e. $\mathrm{ATM} R F=$ TOA RF-SFC RF).

biases are slightly larger in magnitude for the sub-Arctic winter (lower humidity) compared to the tropics (higher humidity). Model diversity (RSD) is roughly $12-15 \%$ for all conditions considered. Surface radiative forcing for absorbing aerosols shows the least bias compared to the LBLbenchmark as well as the lowest model diversity.

Figure 6 shows bi-variate probability density functions (PDFs) of TOA aerosol radiative forcing for Case 2a (a-d) and Case $2 b(e-h)$. As a function of SZA for either the SAW (Fig. 6a and e) or TROP (Fig. 6b and f) atmospheric profile, the PDF indicates two main groups. Group M1 includes the LBL-models and most of the multi-stream models (\#3, 5-9) and group M2 includes the majority of the other models. The near-linear shape of the TOA RF PDFs as a function of atmosphere for SZA $30^{\circ}$ (Fig. 6c and g) and SZA $75^{\circ}$ (Fig. 6d and $\mathrm{h}$ ) indicate that the inter-model diversity in TOA RF has a stronger dependence on SZA than on trace-gas absorption, as expected. For absorbing aerosols (Case 2b), inter-model diversity decreases, and this results in less spread in the TOA RF PDF as a function of solar zenith angle for a given atmosphere (Fig. 6e-f). In Fig. 6i-1 we show bi-variate PDFs of TOA aerosol RF for each atmosphere-SZA combination for Case 2a (Scattering Aerosols) relative to Case 2b (Absorbing Aerosols). The PDFs are generally fairly linear but appear somewhat bi-modal, with the different modes corresponding to groups M1 and M2. Models 20-21 form a separate mode.

In Fig. 7 we show PDFs of the TOA, SFC, and ATM radiative forcing relative bias compared to the LBL-mean benchmark for all conditions. We see a strong dependence of model bias on solar zenith angle, which is somewhat stronger for 


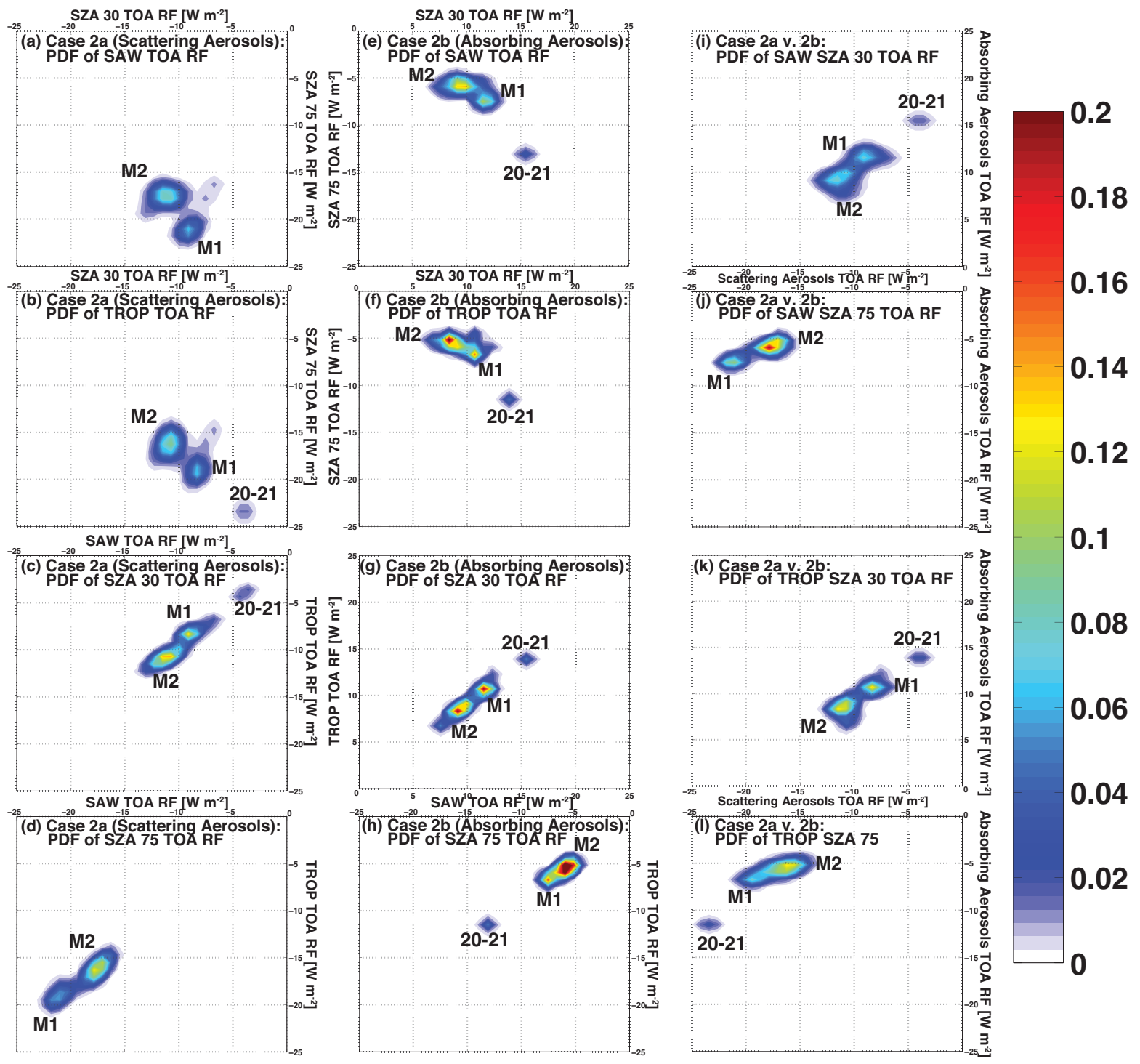

Fig. 6. Bi-variate probability density function (PDF) of TOA aerosol radiative forcing for Case 2a (Scattering Aerosols): (a) sub-Arctic winter as a function of solar zenith angle, (b) the tropics as a function of solar zenith angle, (c) SZA $30^{\circ}$ as a function of prescribed atmosphere, and (d) SZA $75^{\circ}$ as a function of prescribed atmosphere. PDFs of TOA RF for Case 2b (Absorbing Aerosols): (e) sub-Arctic winter as a function of solar zenith angle, (f) the tropics as a function of solar zenith angle, (g) SZA $30^{\circ}$ as a function of prescribed atmosphere, and (h) SZA $75^{\circ}$ as a function of prescribed atmosphere. PDFs of the effect of aerosol absorption (i.e. Case 2a vs. Case 2b) for given conditions: (i) SAW SZA $30^{\circ}$, (j) SAW SZA 75 , (k) TROP SZA $30^{\circ}$, and (l) TROP SZA 75 ${ }^{\circ}$. The PDFs are calculated such that the volume is normalized to unity. Red shading indicates a large concentration of models. Group M1 includes Models \#1-3, and 5-9. Group M2 includes most other models (except Models \#20-21).

non-absorbing aerosols. Compared to scattering aerosols, absorbing aerosols reduce model biases, particularly for SFC and ATM forcing at lower SZA. Note that the large biases for atmospheric forcing due to scattering aerosols are a consequence of the small value of this quantity $\left(<1 \mathrm{~W} \mathrm{~m}^{-2}\right)$.

\subsection{Comparison to other AeroCom Phase II experiments}

As noted in the introduction, two other Phase II AeroCom experiments examine the diversity in aerosol radiative forcing estimates in global models. Myhre et al. (2013) reports the direct aerosol RF for 16 global aerosol models, 8 of which use radiation schemes similar or identical to radiative transfer schemes examined in this work. Results from 

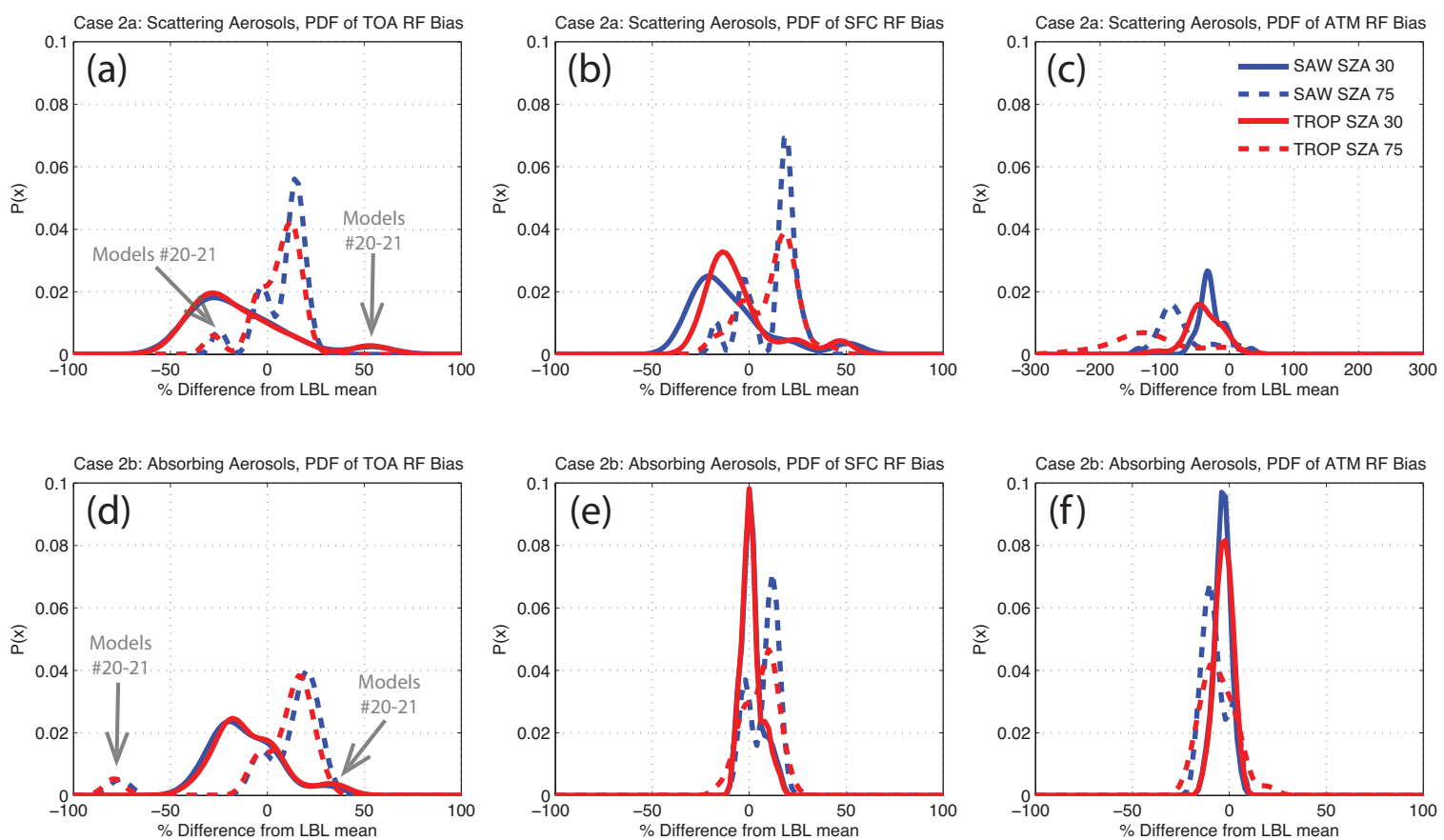

Fig. 7. For each solar zenith angle and prescribed atmosphere combination, the probability density function $\mathrm{P}(\mathrm{x})$ for (a) scattering aerosol (Case 2a) TOA RF bias, (b) scattering aerosol (Case 2a) SFC RF bias, (c) scattering aerosol (Case 2a) ATM RF bias, (d) absorbing aerosol (Case 2b) TOA RF bias, (e) absorbing aerosol (Case 2b) SFC RF bias, and (f) absorbing aerosol (Case 2b) ATM RF bias. Biases are calculated as the percent deviation of each non-LBL model from the LBL mean: Bias $=100 \times \frac{\mu_{\text {model }}-\mu_{\mathrm{LBL}}}{\mu_{\mathrm{LBL}}}$ where $\mu$ is the mean. Negative biases imply too much radiative cooling or too little radiative warming; positive biases imply too little radiative cooling (too much radiative warming). The small peaks in the PDF are from Models \#20 and 21 which use the Eddington approximation (as opposed to the $\delta$-Eddington approximate used in the counterpart Models \#22 and 23).

Myhre et al. (2013), reported as clear-sky (cloud-free) TOA and ATM normalized radiative forcing efficiency (NRF), can be compared to the results from this study for the absorbing aerosol case. Note that the results from Myhre et al. (2013) (a) are global averages (diurnal and zenith-angle averaged) and (b) have varying host-model treatment of, for example, surface albedo and atmospheric gases. The NRF is defined as TOA and SFC radiative forcing divided by AOD or the ATM radiative forcing divided by the absorption optical depth $(\mathrm{AAOD}=(1-\mathrm{SSA}) \times \mathrm{AOD})$. Clear-sky global average results from the AeroCom Prescribed Experiment (Stier et el., 2012), which included 8 models using similar or identical radiation schemes to those included in this study, are even more comparable to results reported here. Specifications for aerosol properties in FIX2-FIX0 and FIX3-FIX0 are identical to Case 2a (Scattering Aerosols) and Case 2b (Absorbing Aerosols), respectively. However, in Stier et el. (2012) surface albedo and Rayleigh scattering are different for each model, and results are for global average conditions (diurnal, solar-zenith angle averaged). Note that in both this study and Stier et el. (2012) AOD is 0.2 and and AAOD is 0.04; these optical properties varied by model in Myhre et al. (2013).

Figure 8 summarizes overlapping aerosol radiative forcing results from the AeroCom Phase II experiments. Models that use similar radiation schemes have the same colored bar, and the benchmark average LBL radiative forcing (black bars with \pm 1 standard deviation error bars) is given for this study. Table A5 gives the model name and number from this study and the corresponding model names from Stier et el. (2012) and Myhre et al. (2013).

Figure 8a and c summarize the TOA and SFC NRF for Case 2a (Scattering Aerosols) and its analog (FIX2-FIX0) from the Prescribed Experiment. The mean (RSD) of the eight models from the Prescribed Experiment (FIX2-FIX0) are $-36.6 \mathrm{~W} \mathrm{~m}^{-2}(6.0 \%)$ and $-37.7 \mathrm{~W} \mathrm{~m}^{-2}(8.4 \%)$ for TOA and SFC NRF, respectively. For these same radiation schemes in the current study, the mean TOA NRF ranges from $\sim-47$ to $-84 \mathrm{~W} \mathrm{~m}^{-2}$, increasing in magnitude with increased SZA. The RSD ranges from $\sim 8$ to $18 \%$, increasing with decreased SZA. As solar zenith angle increases, surface NRF increases in magnitude by a factor of 1.7 , and the RSD ranges are roughly the same as the TOA NRF.

For the scattering aerosol case, note that Fig. 8b shows the ATM RF, rather than the normalized atmospheric radiative forcing because $\mathrm{AAOD}=0$. Though aerosol absorption is defined as zero for the simulations considered here $(\mathrm{SSA}=1.0)$, aerosol scattering can enhance molecular absorption by increasing the photon path-length (Stier et el., 2012). For both 

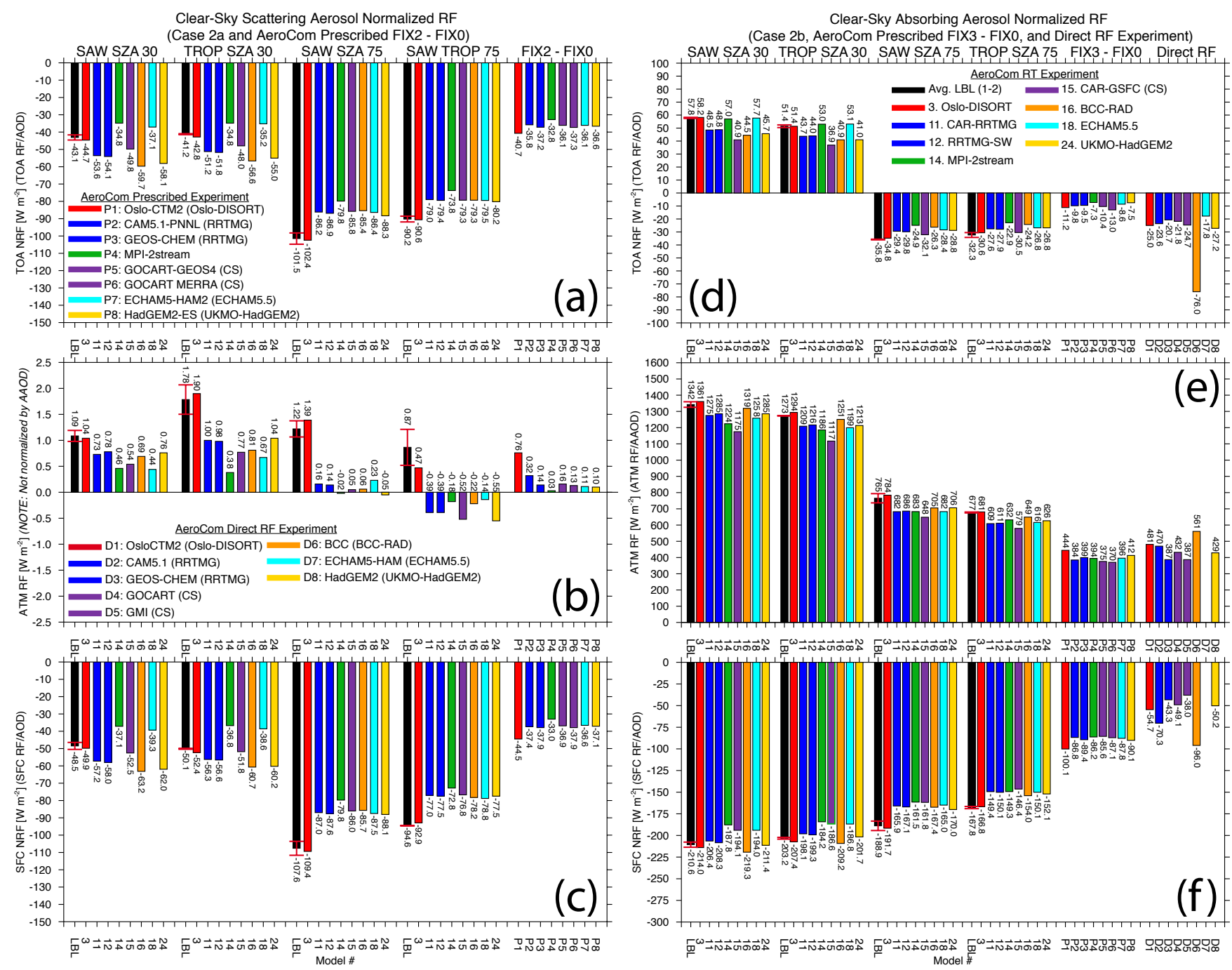

Fig. 8. Summary of clear-sky (cloud-free) aerosol direct normalized radiative forcing (NRF) from the present study (AeroCom Radiative Transfer Experiment), the AeroCom Prescribed Experiment (Stier et el., 2012), and the AeroCom Direct Radiative Forcing Experiment (Myhre et al., 2013). NRF is defined as the TOA and SFC RF divided by the AOD and the ATM RF divided by the absorption optical depth $($ AAOD $=(1-S S A) \times$ AOD $)$. Results from Stier et el. (2012) and Myhre et al. (2013) are from Table 3 of each study. Models which use similar radiative transfer schemes have the same color bar. (a) Comparison of TOA NRF results from Case 2a (Scattering Aerosols) versus the FIX2-FIX0 (Stier et el., 2012); aerosol properties in these two studies are identical (AOD = 0.2, SSA = 1.0) except in Stier et el. (2012) host models simulate their own surface albedo and gaseous absorbers. Also, the results for FIX2-FIX0 are global and diurnal average results. (b) Comparison of ATM RF results from Case 2a (Scattering Aerosols) versus FIX2-FIX0. Note: We do not show normalized atmospheric radiative forcing because the AAOD is zero in the scattering aerosol case. Non-zero ATM RF in the scattering case results from enhanced molecular absorption due to aerosol scattering as described in the text. (c) Comparison of SFC NRF from Case 2a and FIX2-FIX0. (d-f) Comparison of TOA, ATM, and SFC NRF results from Case 2b (Absorbing Aerosols) versus the global average result from FIX3-FIX0 (Stier et el., 2012), which also has the same specified aerosol optical properties (but not the same albedo or gaseous absorbers; AOD $=0.2$, AAOD $=0.04$ ). We also include results from the AeroCom Direct Radiative Forcing Experiment (Myhre et al., 2013). Note that in the global and diurnally averaged results in Myhre et al. (2013), models are run in their standard configuration, simulating all included aerosol processes. The mean SSA for the eight models here was 0.941 with a standard deviation of 0.02 , and the mean global AOD was 0.0245 with a standard deviation of 0.008 (Table 3; Myhre et al., 2013). 
studies, the RSD in atmospheric radiative forcing is largest (e.g. $47 \%$ at $30^{\circ}$ ). In this study, the mean ATM RF is slightly positive (more positive at lower SZA) for the eight models overlapping with Stier et el. (2012). Stier et el. (2012) indicates a mean ATM RF of $0.2 \mathrm{~W} \mathrm{~m}^{-2}$ with a large RSD.

In both this study and the Prescribed Experiment, OsloDISORT (Model \#3, OsloCTM2 in Stier et el., 2012) exhibits the strongest absorption enhancement in the scatteringonly aerosol case. However, the ATM RF of Model \#3 (a multi-stream model) has the best agreement with the mean LBL result. In the two-stream version of this model (Oslo2stream, Model \#4; see Fig. 5), the ATM NRF is reduced by roughly 30 to $110 \%$ at lower and higher SZA, respectively. We also note that Oslo-DISORT has a low spectral resolution (4 shortwave bands, Table 1), and enhanced molecular absorption due to $\mathrm{O}_{3}$ may be larger as a result (Stier et el., 2012).

The mean (RSD) of the eight models from the Prescribed Experiment (FIX3-FIX0) are $-9.7 \mathrm{~W} \mathrm{~m}^{-2}(19.7 \%$ ), $397 \mathrm{~W} \mathrm{~m}^{-2}(5.9 \%)$, and $-89.1 \mathrm{~W} \mathrm{~m}^{-2}(5.3 \%)$ for TOA, ATM, and SFC NRF, respectively. Note that in Stier et el. (2012), models can have different surface albedos, and differences in the resulting path-length can contribute to the diversity in atmospheric absorption at the TOA. For the analog Case 2b (Absorbing Aerosols; Fig. 8d-f), the TOA NRF RSD for these same eight radiation schemes ranges 10 to $14 \%$, increasing with decreased SZA. The mean TOA NRF is $48.6 \mathrm{~W} \mathrm{~m}^{-2}$ at $30^{\circ}$ and $-28.7 \mathrm{~W} \mathrm{~m}^{-2}$ at $75^{\circ}$. In this study, atmospheric NRF averages $659 \mathrm{~W} \mathrm{~m}^{-2}$ at $75^{\circ}$ and $1236 \mathrm{~W} \mathrm{~m}^{-2}$ at $30^{\circ}$. The RSD for ATM NRF ( 8 and $5 \%$ at each of these solar zenith angles, respectively) is lower compared to the scattering-only case, consistent with the results of Stier et el. (2012). The RSD for SFC NRF in Case $2 b$ is roughly equivalent to the atmospheric values.

We now consider radiation schemes that were also involved in the AeroCom Direct Radiative Forcing Experiment (Myhre et al., 2013). While it is generally difficult to scale the uncertainties in aerosol radiative forcing under idealized conditions to uncertainties in diurnal-averaged global estimates of aerosol radiative effects, this comparison allows us to examine how these radiation schemes perform at given solar zenith angles and atmospheric conditions that may be representative of daily averaged forcing for a given region. Considering schemes also used in Myhre et al. (2013), the TOA normalized forcing diversity (RSD) is roughly 10 to $14 \%$ for Case $2 \mathrm{~b}$ (Absorbing Aerosols) and the mean TOA NRF is $\sim 47$ and $-29 \mathrm{~W} \mathrm{~m}^{-2}$ at lower and higher SZA, respectively. SFC and ATM NRF model diversity ranges between 5 and $8 \%$ (increasing with $\mathrm{SZA}$ ). We compare Case $2 \mathrm{~b}$ results to clear-sky results from the Direct RF experiment, which have an average SSA of 0.94 (i.e. less absorbing than Case 2b). After having first simulated the full aerosol life-cycle, the Direct RF models exhibits relatively good agreement in atmospheric normalized radiative forcing (RSD $14 \%$; mean $450 \mathrm{~W} \mathrm{~m}^{-2}$ ). However, there is a large range in TOA NRF
( $\sim-18$ to $-76 \mathrm{~W} \mathrm{~m}^{-2}$; mean $-29.6 \mathrm{~W} \mathrm{~m}^{-2}$; RSD $\left.64 \%\right)$ and SFC NRF $\left(\sim-38\right.$ to $-96 \mathrm{Wm}^{-2}$; mean $-57.4 \mathrm{~W} \mathrm{~m}^{-2}$; RSD $35 \%$ ). Thus all three AeroCom studies indicate lower inter-model diversity in simulating atmospheric absorption when more absorbing aerosols are considered. The higher RSD in surface NRF in Myhre et al. (2013) may reflect the use of geographic and model-dependent surface albedo.

\section{Conclusions}

In this study we examine the performance of multi- and two-stream radiative transfer schemes used in global climate models relative to reference data from high spectral resolution multi-angular methods. We examine the models in a controlled sense by prescribing both gaseous absorbers (water vapor and ozone) and simple aerosol optical properties (separately, scattering-only and more absorbing aerosols) with fixed surface albedo. Results are compared as a function of solar zenith angle and increasing trace gas amount.

Comparisons in clear-sky (aerosol- and cloud-free) Rayleigh atmosphere conditions of solar atmospheric transmissions indicate significant model bias from the reference line-by-line calculation (up to $6 \%$ at high solar zenith angle in humid conditions for the near-IR). This identifies deficiencies particularly in the representation of absorption by atmospheric water vapor. Diversity amongst models, quantified as the standard deviation as a percentage of the mean or relative standard deviation, is on the order of 2 to $4 \%$ for wavelengths where gaseous absorption is prominent (near-IR), and this diversity increases as water vapor slant path increases (or, as SZA increases). In the Rayleigh atmosphere case, the largest model diversity occurs in the partitioning of total flux into direct and diffuse components.

In order to isolate the treatment of multiple scattering and absorption by aerosols, we computed the broadband solar top of the atmosphere aerosol radiative forcing. In the computation of forcing, a second call is made to the radiation models, now with prescribed aerosol optical properties, and fluxes at the TOA are differenced relative to the Rayleigh atmosphere case. The diversity amongst models in the TOA forcing is largest for purely scattering aerosols at low SZA $(15 \%)$ and decreases with increasing SZA. Increased aerosol absorption decreases the diversity in atmospheric and surface radiative forcing. This indicates that the treatment of multiple scattering contributes to the large inter-model diversity in top of the atmosphere aerosol radiative forcing, and this diversity may be important given the regionally diverse absorption characteristics of global aerosols.

When considering solar top of the atmosphere (TOA) radiative forcing by aerosols, deficiencies in gaseous transmission are less important than the treatment of multiple scattering. Relative to benchmark multi-directional line-by-line results, when scattering-only aerosols are considered, simpler two stream models over- and underestimate TOA aerosol 
radiative cooling as SZA increases. Two-stream models underestimate the magnitude of radiative warming and cooling at lower and higher SZA when absorbing aerosols are considered. The bias in aerosol radiative forcing for the models in this study is on the order of $10-20 \%$, with the highest bias occurring when considering scattering aerosols at lower SZA.

We considered solar zenith angles more representative of the tropics $\left(30^{\circ}\right)$ and high latitudes $\left(75^{\circ}\right)$ following Halthore et al. (2005). A previous study (Russell et al., 1997) indicated that aerosol radiative forcing may peak somewhere in between these angles (specifically, around $60^{\circ}$ for mostly scattering aerosol due to the competition between path length and available sun energy). Thus, biases reported in this study may be mitigated in the global average. Indeed, the intermodel diversity reported in this study for the two specific zenith angles is generally higher than those reported for global, diurnally-averaged conditions (Myhre et al., 2013) even when the same aerosol optical properties are prescribed (Stier et el., 2012). Though biases may be larger when considering specific zenith angles, we note that all three AeroCom studies indicate decreased inter-model diversity in atmospheric radiative forcing as aerosol absorption increases. Further, both Stier et el. (2012) and this work show that atmospheric absorption is enhanced when considering scatteringonly aerosol because the increased photon path-length increases molecular absorption, particularly by ozone.

For daily forcing simulations, biases in radiative forcing indicate that there is a tendency by the two-stream models to under- and overestimate the magnitude of aerosol forcing for absorbing and scattering-only aerosols, respectively, at low latitudes (with predominantly low solar zenith angles during the day). At high latitudes (with predominantly high solar zenith angles during the day), scattering-only and absorbing aerosols both underestimate the magnitude of aerosol radiative cooling. It is important to note that computational limitations often prevent the use of multi-stream radiative transfer schemes in global aerosol modeling. Delta-scaling serves to somewhat mitigate the accuracy sacrificed by two-stream models in their representation of the phase function. Furthermore, from a climatological perspective, daily biases introduced by two-stream schemes may partially compensate one another when computing a global average radiative forcing. However, regionally and seasonally they may introduce systematic errors that can significantly impact aerosol climate effects.

This study has presented an intercomparison of global aerosol model radiative transfer schemes using common idealized aerosol properties. We have shown that, assuming aerosol properties are perfectly known, the bias in aerosol radiative forcing is sensitive to the solar zenith angle. Yet, it is expected that inter-model differences in simulating aerosol properties (e.g. AOD, SSA) would likely introduce biases in radiative forcing of greater magnitude than presented here. Global observations of AOD have served to reduce inter- model diversity in simulated AOD (e.g. Textor et al., 2006, 2007). An observing system that helps to better constrain the diurnal variation of aerosol optical properties would enable global aerosol models to converge to a better representation of these properties as a function of zenith angle and hence a better estimate of aerosol radiative forcing. The smaller biases introduced by the use of two-stream radiation schemes can be mitigated by future advances in computational power that will allow multi-stream schemes to operate on-line within global aerosol models.

\section{Appendix A}

\section{Radiative transfer scheme descriptions}

We provide brief descriptions of the models used in this intercomparison; model characteristics are summarized in Table 1 and Appendix Table A1. We refer the reader to seminal works for details on radiative transfer theory and methods for solving the transfer equation (e.g., Chandrasekhar, 1960; van de Hulst, 1980; Lenoble, 1985; Liou, 1992). Models in the appendix are arranged by model \# from Table 1 with the names of contributing investigators given in parenthesis.

\section{A1 Models \#9, 11, 15, 17, 25, 26 and 29: Cloud-Aerosol- Radiation model (CAR; $F$. Zhang)}

The Cloud-Aerosol-Radiation (CAR) Ensemble Modeling System currently incorporates 7 major cloud-aerosol radiation packages used in major research institutions worldwide: CAM (NCAR), RRTMG (NCEP, ECMWF, and future NCAR), GFDL (NOAA), GSFC (NASA), CCCMA (Canada), CAWCR (Australia), and FLG (popular for DOE/ARM). A general model description and basic skill evaluation of the CAR system is found in Liang and Zhang (2012); Zhang et al. (2013) and can also be found at http: //car.umd.edu. For each radiative transfer code, radiative processes such as gaseous absorption and absorption and scattering by clouds and aerosol particles can be easily included or excluded depending on the aim of the study. Strikingly, cloud and aerosol properties can be decoupled from the radiative transfer calculation, making CAR a useful tool for the intercomparison of different cloud, aerosol and radiation schemes. See additional descriptions of each radiation scheme in CAR used in this intercomparison according to model number from Table 1 .

\section{A2 Model \#1 GENLN2-DISORT (G. Myhre)}

GENLN2-DISORT is the GENLN2 (Edwards, 1992) lineby-line (LBL) model coupled to a discrete-ordinate method (DISORT; Stamnes et al., 1988) for calculation of radiative fluxes. The model has been used for radiative transfer calculation in the solar spectrum previously (Myhre et. al., 2002) and in an intercomparison study (Forster et al., 2011). The 
Table A1. Gaseous transmission schemes: \#k- or ESFT terms for ozone and water vapor ${ }^{\mathrm{a}}$

\begin{tabular}{|c|c|c|c|c|}
\hline Model \# & Model Name & Type & $\# \mathrm{O}_{3}$ & $\# \mathrm{H}_{2} \mathrm{O}$ \\
\hline 1 & GENLN2-DISORT & LBL & - & - \\
\hline 2 & RFM DISORT (RFMD) & LBL & - & - \\
\hline 3 & Oslo-DISORT & ESFT & 2 & $2-3$ \\
\hline 4 & Oslo-2Stream & ESFT & 2 & $2-3$ \\
\hline 5 & UNIVIE-Streamer & ESFT & 0-30 terms/band & $0-30$ terms/band \\
\hline 6 & FMI-libRadtran & $c k-\mathrm{D}$ & 123 & 30 \\
\hline 7 & LMU-libRadtran & $c k-\mathrm{D}$ & 123 & 30 \\
\hline 8 & GSFC-FL & $c k-\mathrm{D}$ & 10 & 54 \\
\hline 9 & CAR-FLG & $c k-\mathrm{D}$ & 10 & 44 \\
\hline 10 & LaRC-FL & $c k-\mathrm{D}$ & 10 & 60 \\
\hline 11 & CAR-RRTMG & $c k-\mathrm{D}$ & 28 & 92 \\
\hline 12 & RRTMG-SW & $c k-\mathrm{D}$ & 28 & 92 \\
\hline 13 & LMU-2stream & $c k-\mathrm{D}$ & 123 & 30 \\
\hline 14 & MPI-2stream & $c k-\mathrm{D}$ & 9 & 41 \\
\hline 15 & CAR-GSFC & $k$-distribution & 8 & 31 \\
\hline 16 & BCC-RAD & $c k-\mathrm{D}$ & 15 & 13 \\
\hline 17 & CAR-CCCMA & $c k-\mathrm{D}$ & 9 & 23 \\
\hline 18 & ECHAM5.5 & Padé approximation & 1 & 1 \\
\hline 19 & UMD-SRB & $k$-distribution for $\mathrm{H}_{2} \mathrm{O}$ & - & 40 \\
\hline & & Lacis and Hansen (1974) for $\mathrm{O}_{3}$ & & \\
\hline 20 & ES96-6 & $c k-\mathrm{D}$ & 6 & 15 \\
\hline 21 & ES96-220 & $c k-\mathrm{D}$ & $0-24 /$ band & $0-25 /$ band \\
\hline 22 & ES96-6-D & $c k-\mathrm{D}$ & 6 & 15 \\
\hline 23 & ES96-220-D & $c k-\mathrm{D}$ & $0-24 /$ band & $0-25 /$ band \\
\hline 24 & UKMO-HadGEM2 & $c k-\mathrm{D}$ & 6 & 15 \\
\hline 25 & CAR-CAWCR & ESFT & 8 & 13 \\
\hline 26 & CAR-CAM & ESFT & 7 & 7 \\
\hline 27 & ULAQ & ESFT & 150 & 85 \\
\hline 28 & FORTH & ESFT & $\begin{array}{l}\text { high spectral resolution } \\
\text { for } \mathrm{O}_{3} \text { photolysis rates }\end{array}$ & 67 \\
\hline 29 & CAR-GFDL & ESFT & 14 & 25 \\
\hline 30 & MPI-MOM & $c k-\mathrm{D}$ & 9 & 41 \\
\hline 31 & MOMO & non-correlated $k$ & 120 & 3000 \\
\hline
\end{tabular}

a Abbreviations: LBL = line-by-line, DISORT = discrete-ordinate method, ES96 = Edwards and Slingo (1996), ESFT = exponential sum fit transmission, $c k$ - $\mathrm{D}=$ correlated $k$-distribution

GENLN2 LBL code is updated with absorption data from the HITRAN-2008 database (Rothman et al., 2009). Absorption by $\mathrm{H}_{2} \mathrm{O}, \mathrm{CO}_{2}, \mathrm{O}_{3}, \mathrm{O}_{2}$, and $\mathrm{CH}_{4}$ has been included in the simulations. The spectral resolution in the computations was $0.02 \mathrm{~cm}^{-1}$. The extraterrestrial spectral solar irradiance had a $1 \mathrm{~nm}$ resolution from Lean et al (2005) in simulations and the full spectral region considered has been from $0.2 \mu \mathrm{m}$ to $5.0 \mu \mathrm{m}$. For this intercomparison the radiative fluxes were computed using 16 streams in the DISORT code.

\section{A3 Model \#2 RFM DISORT (RFMD; E. Highwood, C. Ryder, B. Harris)}

RFM DISORT is the Reference Forward Model (RFM), a line-by-line radiative transfer model, coupled to a discrete ordinate method (DISORT; Stamnes et al., 1988) for scattering calculations. RFM has been developed at Oxford University, UK (http://www.atm.ox.ac.uk/RFM/) and is based on the GENLN2 model (Edwards, 1992). The spectral resolution used was $1 \mathrm{~cm}^{-1}$, covering wavelengths from 0.2 to 10 microns with 4 streams in DISORT. The HITRAN 2004 database (Rothman et al., 2005) is used for gaseous absorption coefficients.

\section{A4 Model \#3 Oslo-DISORT (G. Myhre)}

The Oslo-DISORT code uses the discrete-ordinate method (DISORT) (Stamnes et al., 1988) specifically designed for calculations of atmospheric aerosols. The model has a high number of streams (8), but a low spectral resolution 
Case 1 (Rayleigh Atmosphere): Inter-model diversity in downwards VIS total (direct + diffuse) flux

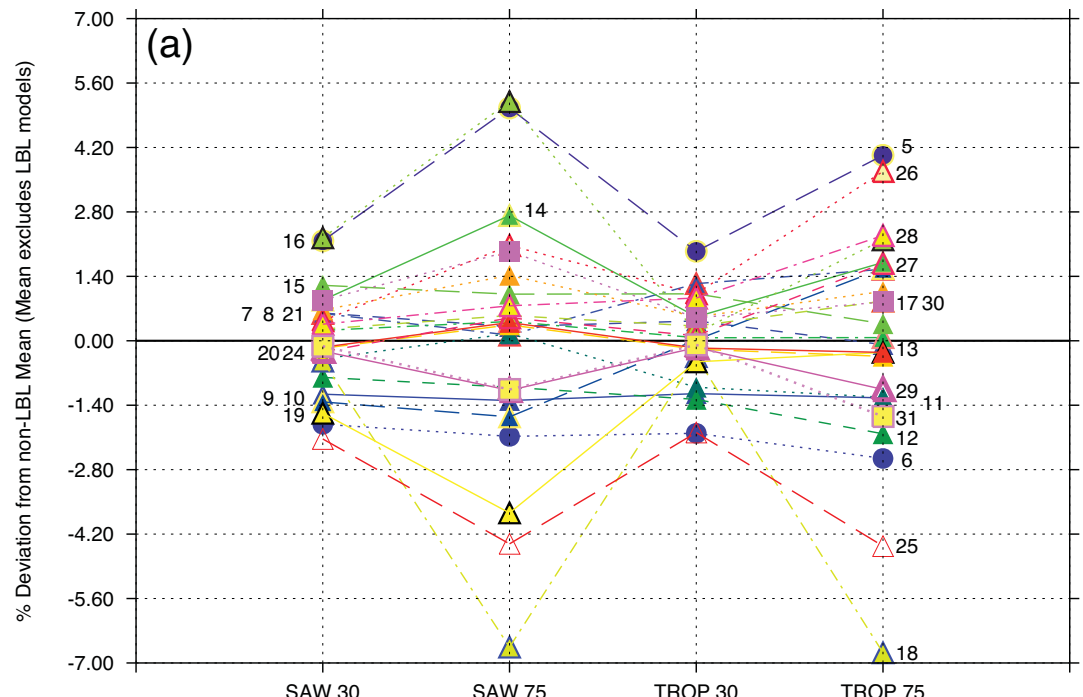

Case 1 (Rayleigh Atmosphere): Inter-model diversity in downwards broadband diffuse flux

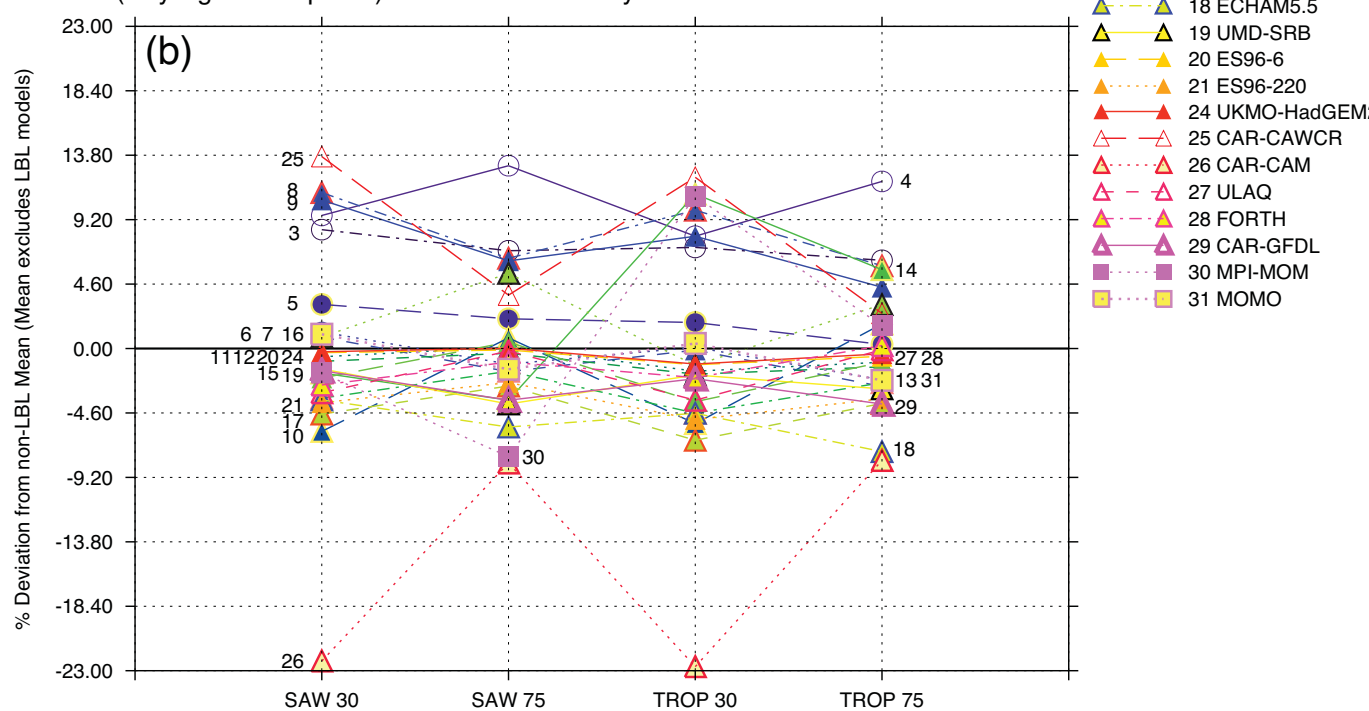

Fig. A1. Inter-model diversity in UV-VIS and broadband diffuse flux down at the surface for the Rayleigh atmosphere (Case 1) expressed as a percent deviation from the non-LBL model mean (i.e. the mean from all models excluding \#1, 2, 22 and 23). Note that Models \#22-23 are the same as \#20-21 in Case 1. As a function of standard atmosphere and solar zenith angle: (a) downwards UV-VIS at the surface and (b) downwards diffuse broadband flux. Appendix Figures A2 and A3 show the bias of UV-VIS and broadband diffuse down fluxes relative to the LBL benchmarks, respectively.

(4 bands), with the main emphasis on wavelengths below $1.5 \mu \mathrm{m}$. The spectral regions are $0.3-0.5 \mu \mathrm{m}, 0.5-0.85 \mu \mathrm{m}$, $0.85-1.5 \mu \mathrm{m}$, and $1.5-4.0 \mu \mathrm{m}$. The absorption by water vapor and ozone is taken into account by the exponential-sum fitting method (ESFT, Wiscombe and Evans, 1977). The number of exponential-sum fitting terms for each spectral region is two or three. Higher accuracy can be obtained with a higher number of exponential-sum fitting terms, but this increases the computational time. The GENLN2 line-by-line model (Edwards, 1992) is used to calculate the transmission data for water vapor with spectroscopic data from the
HITRAN92 database (Rothman et al., 1992). Cross-sections for ozone in the ultraviolet and visible region are from WMO (1985). Oslo-DISORT has been validated against the GENLN2-DISORT LBL model for various cases for aerosols with agreement within 10\% (Myhre et. al., 2002).

\section{A5 Model \#4 Oslo-2stream (G. Myhre)}

2-stream version of Oslo-DISORT (Model \#3; see above). 

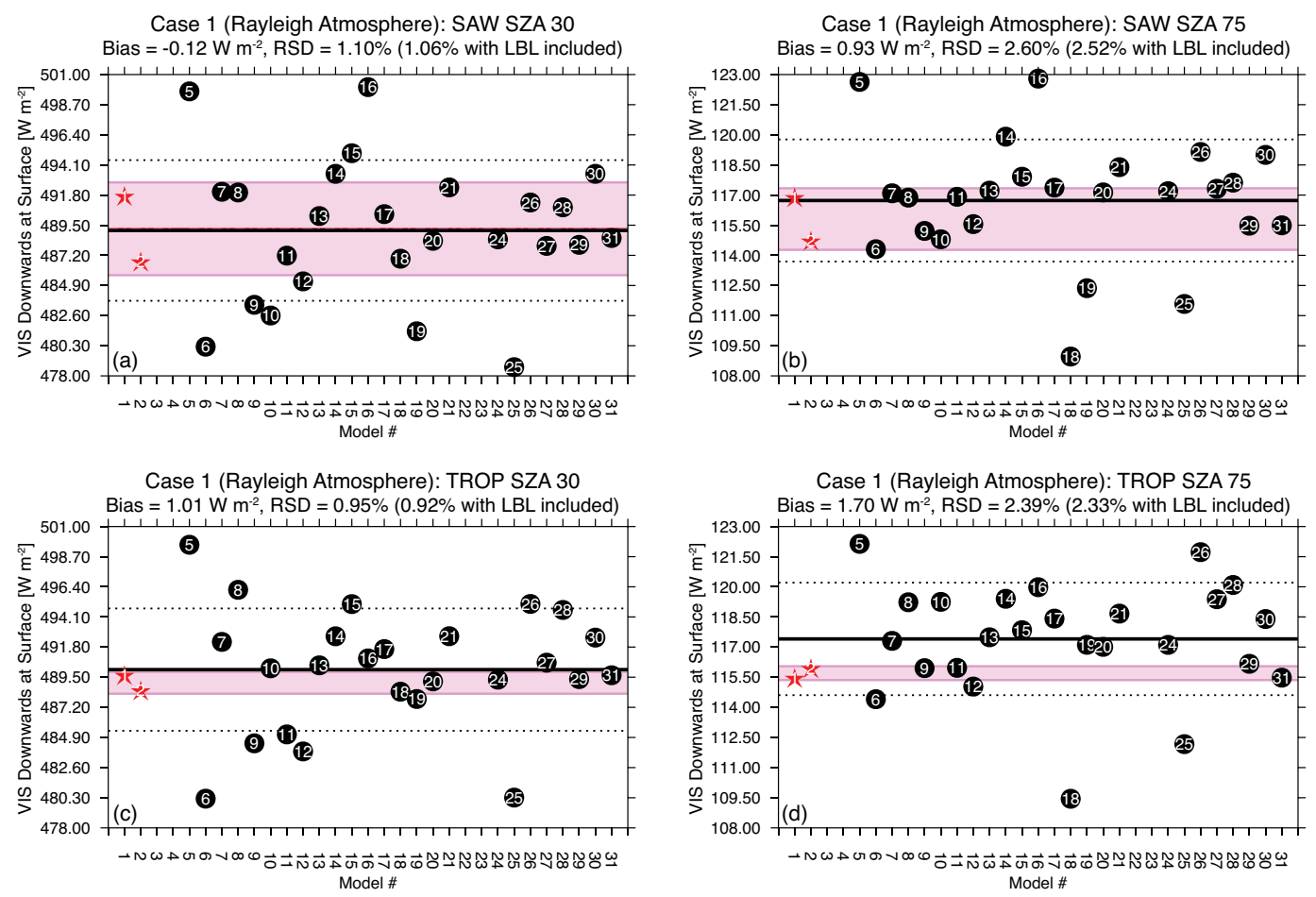

Fig. A2. UV-VIS flux down at the surface in Case 1 (Rayleigh atmosphere) for (a) SAW $30^{\circ}$, (b) SAW $75^{\circ}$, (c) TROP $30^{\circ}$, and (d) TROP $75^{\circ}$. LBL results are given as stars; non-LBL models are black circles. The pink shading indicates \pm 1 standard deviation from the LBL mean. The non-LBL mean is given as the thick black line with \pm 1 standard deviation indicated by dotted black lines. The model bias relative to the LBL-mean is given as well as the relative standard deviation (RSD) excluding (and in parenthesis including) the LBL models. See Appendix Table A2 for additional statistics.

\section{A6 Model \#5 UNIVIE-Streamer (D. Neubauer, R. Hitzenberger)}

Streamer (Key and Schweiger, 1998) is a radiative transfer model employing the discrete-ordinate (DISORT) method (Stamnes et al., 1988) to solve the radiative transfer equation. We have modified Streamer to increase the spectral range for radiative transfer calculations and to include additional scattering and absorbing gases (Neubauer et al., 2011). The modified model UNIVIE-Streamer accounts for absorption by atmospheric gases using exponential fits (Wiscombe and Evans, 1977) to the LOWTRAN7 (Kneizys et al., 1988) and LBLRTM (Clough et al., 2005) transmittances. In all cases 8 streams and 24 unequal spectral intervals in the solar range $0.2-5.0 \mu \mathrm{m}$ and 10 bands in the UV/visible range $0.2-0.69 \mu \mathrm{m}$ were used for computing fluxes. Aerosol optical properties were computed separately using Mie theory for 60 wavelengths ( 7 in the UV/visible range). Note that the number of ESFT terms varies between 0 and 30 for each spectral band and each atmospheric gas.

\section{A7 Model \#6 FMI-libRadtran (J. Huttunen)}

The Finnish Meteorological Institute version of libRadtran (FMI-libRadtran, Mayer and Kylling, 2005) uses 8-streams and the DISORT2 solver. Delta-M scaling is switched on. Solar spectral irradiance is taken from Gueymard (2004).

\section{A8 Model \#7 LMU-libRadtran (B. Mayer)}

The Ludwig-Maximilians-Universitaet version of libRadtran (Mayer and Kylling, 2005) uses 6-streams, the discreteordinate method (DISORT2) for calculation of radiative fluxes, and a plane-parallel atmosphere assumption. Molecular absorption is treated with a $k$-distribution of 32 bands (Kato et al., 1999). The shortwave (SW) bands are the sum of bands 1-32 (240.1-4605.7 nm). The visible (VIS) bands are the sum of 16 bands (204.1-704.4 nm).

\section{A9 Model \#8 GSFC Fu-Liou Radiative Transfer Model (GSFC-FL; $\mathrm{H}$. Yu)}

The Fu-Liou model used by the NASA Goddard Space Flight Center (GSFC) group is a broadband radiative transfer model with a delta-four-stream approximation (Fu and Liou, 1992, 1993). The model accounts for solar radiation over $0.2-4.0 \mu \mathrm{m}$ range with 6 bands. The first band in the UV-visible $(0.2-0.7 \mu \mathrm{m})$ is divided into 10 subintervals where the spectral dependences of $\mathrm{O}_{3}$ absorption and aerosol optical properties are incorporated explicitly. Absorption data for $\mathrm{H}_{2} \mathrm{O}, \mathrm{O}_{2}$, and $\mathrm{CO}_{2}$ are taken from HITRAN82 

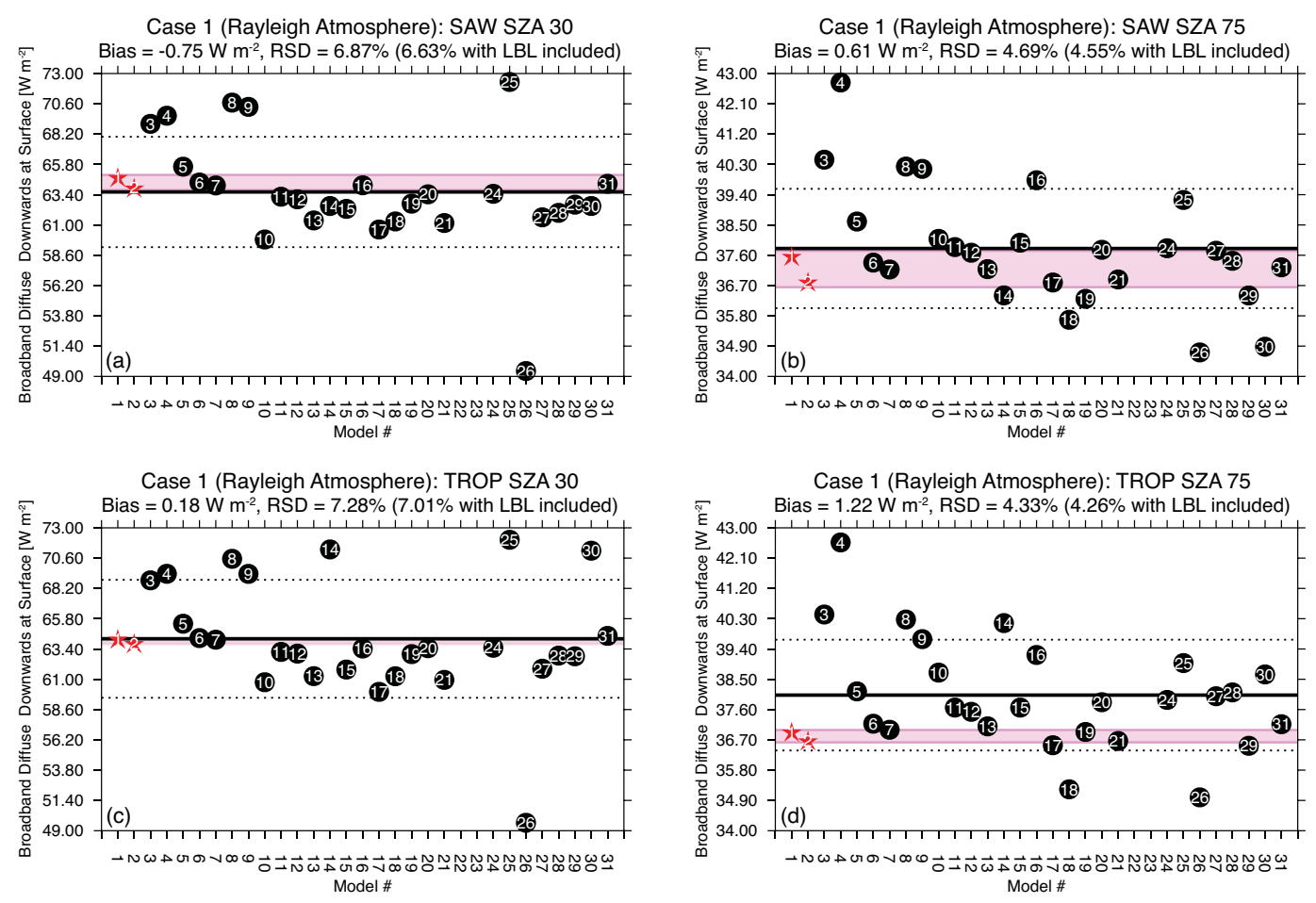

Fig. A3. The same as Fig. A2 except for broadband diffuse flux down at the surface in the Rayleigh atmosphere (Case 1). See Appendix Table A2 for additional statistics.
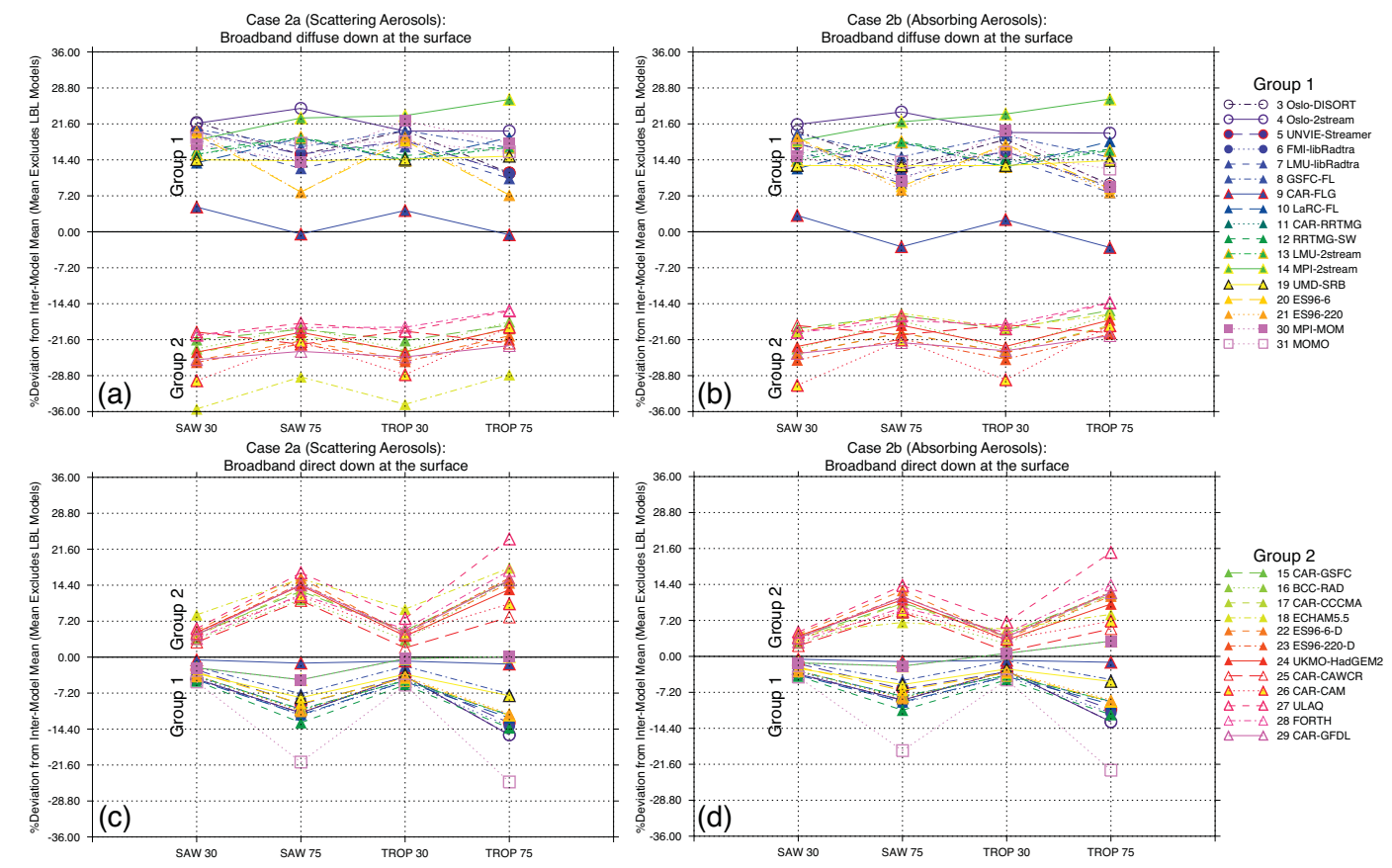

Fig. A4. Inter-model diversity in broadband diffuse and direct flux down at the surface expressed as a percent deviation from the non-LBL model mean (i.e. $\mu$ from all models excluding \#1 and 2). As a function of standard atmosphere and solar zenith angle the broadband diffuse flux down at the surface is given for: (a) Case 2a (Scattering Aerosols) and (b) Case 2b (Absorbing Aerosols). Corresponding diversity for the broadband direct flux down at the surface is given for: (c) Case 2a (Scattering Aerosols) and (d) Case 2a (Absorbing Aerosols). Note that Fig. A4a is the same as Fig. 3. 


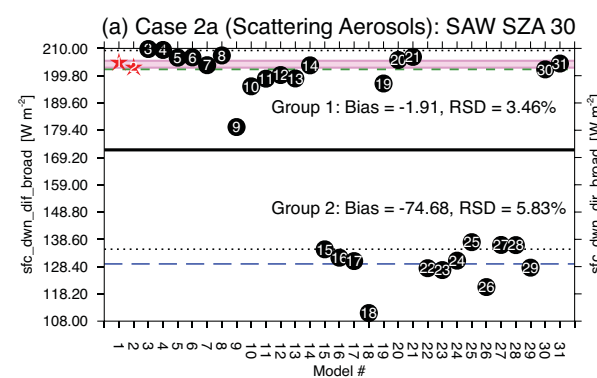

Model \#
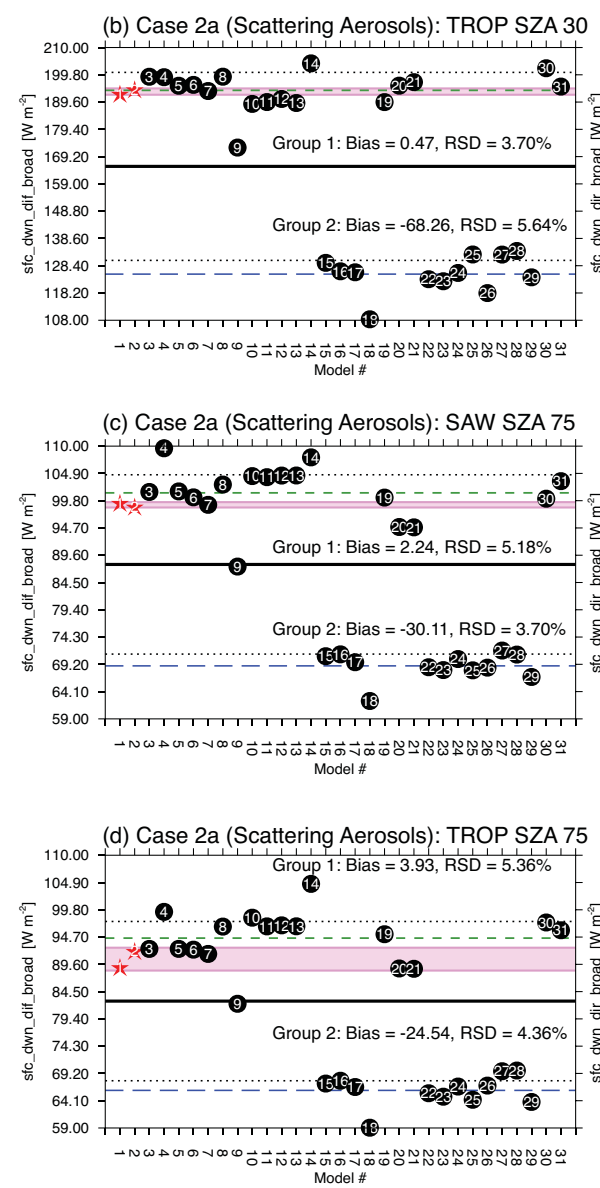

(e) Case 2a (Scattering Aerosols): SAW SZA 30

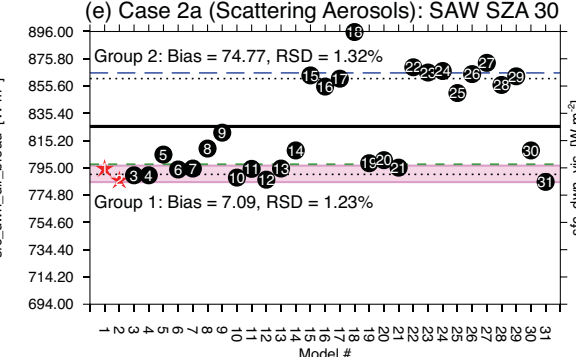

Model \#

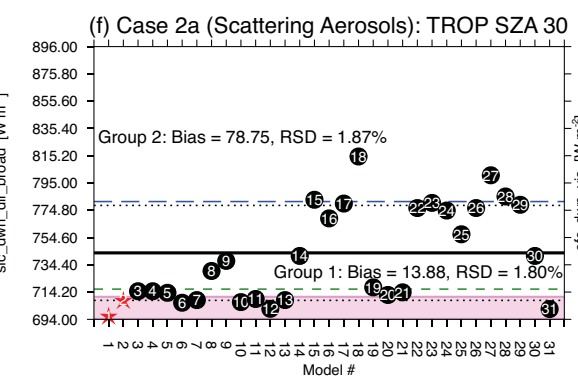

(g) Case 2a (Scattering Aerosols): SAW SZA 75

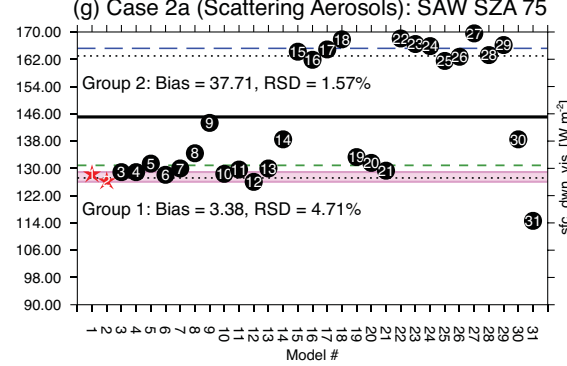

Model \#

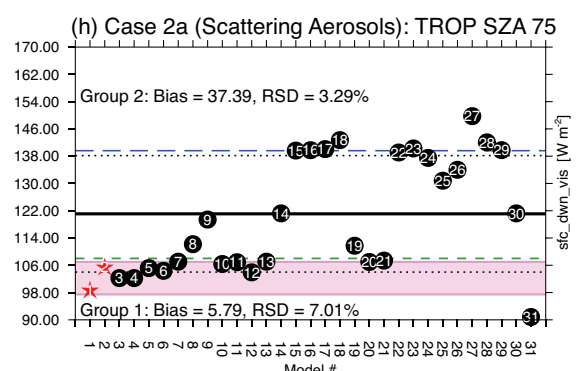

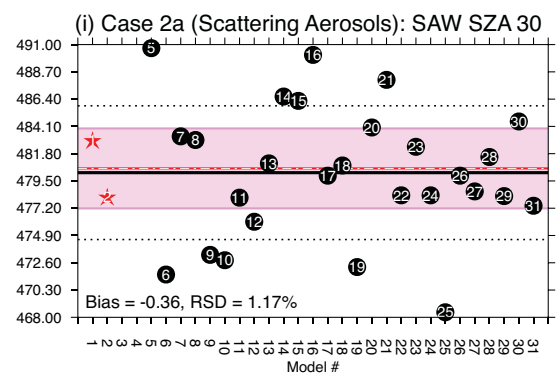

Model \#

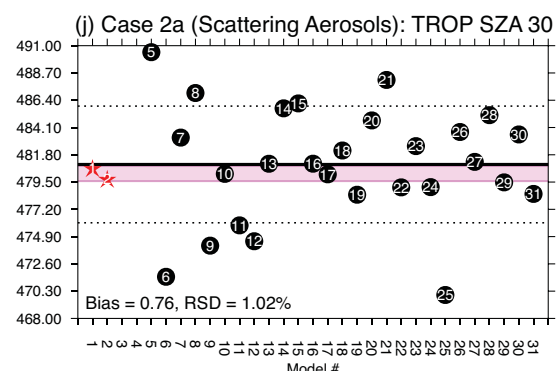

Model \#
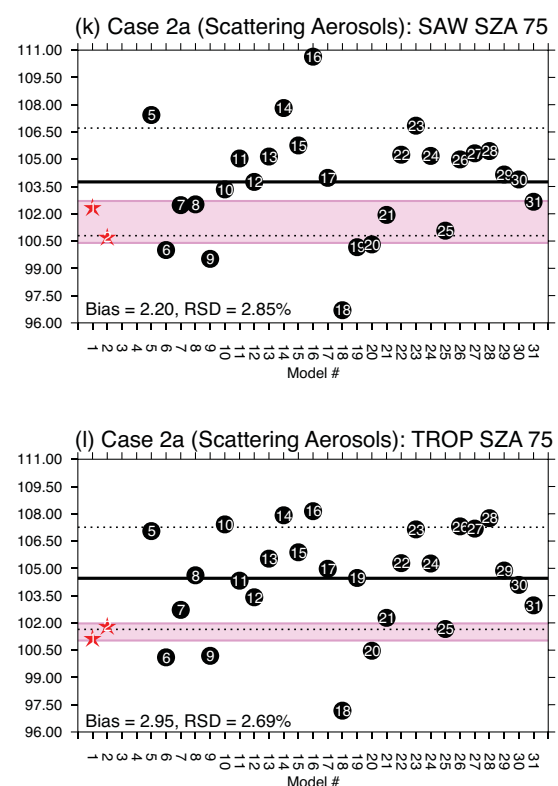

Fig. A5. Broadband diffuse (a-d), broadband direct (e-h), and UV-VIS (direct + diffuse) (i-l) flux down at the surface in Case 2a (Scattering Aerosols) as a function of atmosphere and solar zenith angle. LBL results are given as stars; non-LBL models are black circles. The pink shading indicates \pm 1 standard deviation from the LBL mean. The non-LBL mean is given as the thick black line with \pm 1 standard deviation indicated by dotted black lines. For UV-VIS fluxes, the absolute model bias relative to the LBL-mean is given as well as the RSD excluding the LBL models. Green and blue lines indicate the multi-model averages for the groups described in Table 4 for broadband fluxes; statistics are given for each group. Group 1 (green) includes Models \# 3-14, 19-21, and 30-31; Group 2 (blue) includes Models \#15-18 and 22-29.

(Rothman et al., 1983) and that for $\mathrm{O}_{3}$ are based on Howard et al. (1961). Rayleigh scattering is parameterized according to Slingo and Schrecker (1982). For this experiment, a total of 73 vertical layers are used, with a resolution of $1 \mathrm{~km}$ below $25 \mathrm{~km}$ and $2 \mathrm{~km}$ for altitudes of $26-120 \mathrm{~km}$.

\section{A10 Model \#9 Fu-Liou-Gu radiation scheme (CAR-FLG, F. Zhang)}

The Fu-Liou-Gu scheme ( $\mathrm{Gu}$ et al., 2010, 2011; Liou et al., 2008) is a modified and improved version based on the original Fu-Liou scheme (Fu and Liou, 1992, 1993). The model calculates SW flux in a vertically inhomogeneous scattering-absorbing atmosphere using either a 
(a) Case 2b (Absorbing Aerosols): SAW SZA 30

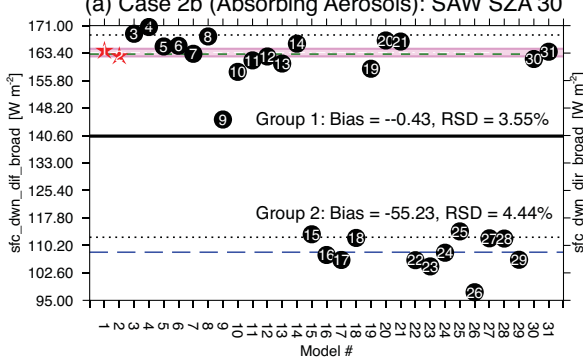

(b) Case 2b (Absorbing Aerosols): TROP SZA 30
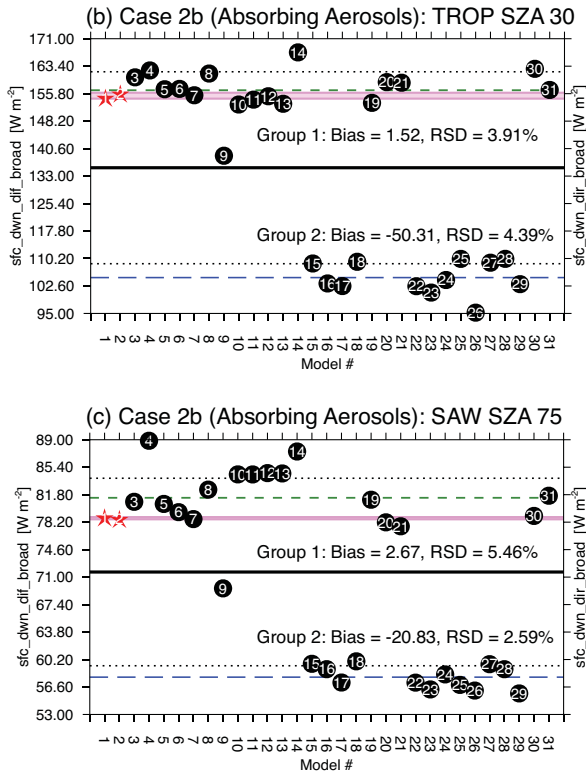

(d) Case 2b (Absorbing Aerosols): TROP SZA 75

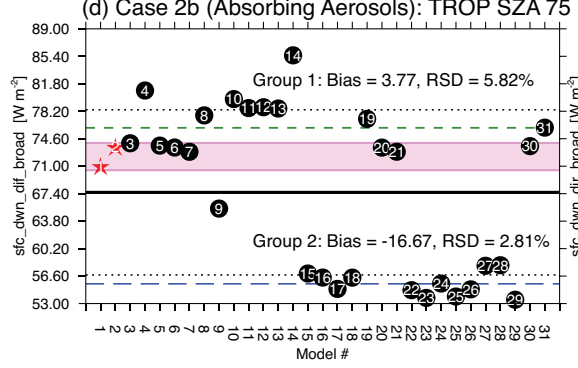

(e) Case 2b (Absorbing Aerosols): SAW SZA 30

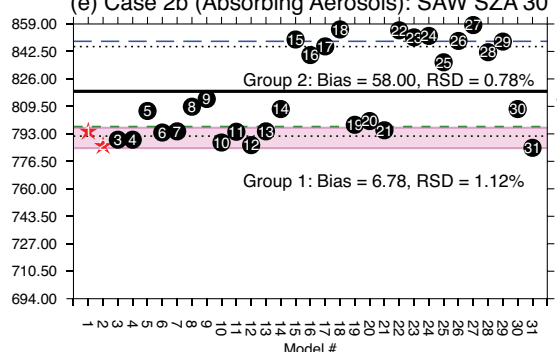

Model \#

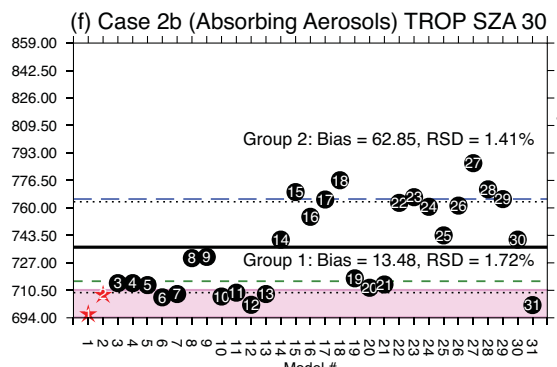

Model \#

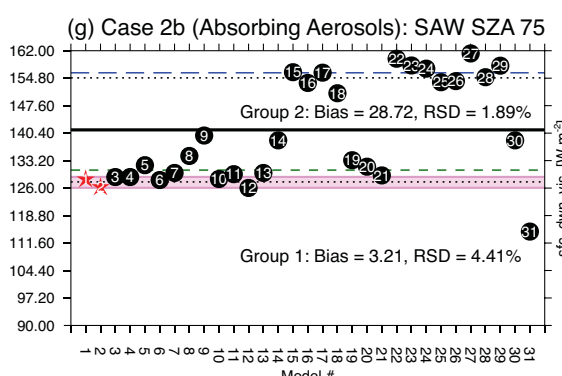

Model \#

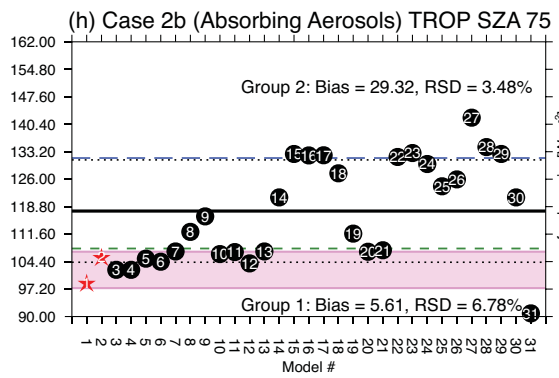

(i) Case $2 \mathrm{~b}$ (Absorbing Aerosols): SAW SZA 30

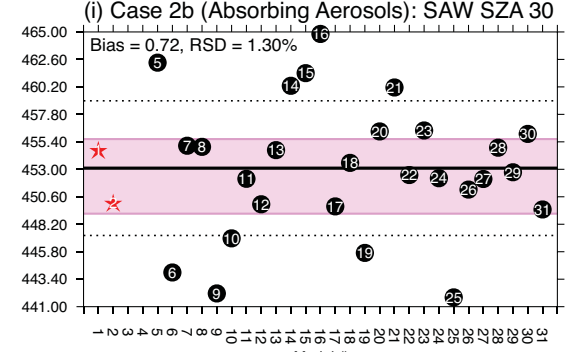

Model \#

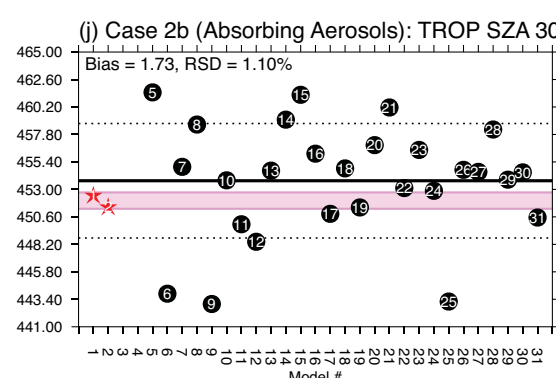

(k) Case 2b (Absorbing Aerosols): SAW SZA 75
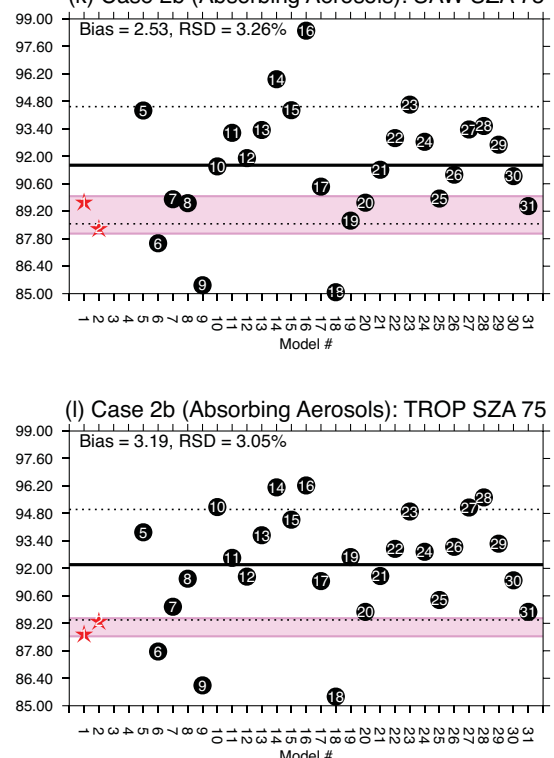

Fig. A6. The same as Fig. A5 except for Case 2b (Absorbing Aerosols).

delta-four-stream approximation or a delta-two-stream (Eddington) approximation. It and accounts for the absorption of all radiatively important gases using the correlated- $k$ distribution method ( $c k-\mathrm{D}$ ) fits to the 1982 version of the AFGL data type (Fu and Liou, 1992) with some updates fits to HITRAN 2000 (Zhang et al., 2005). There are 6 solar bands with total 54 sub-spectra over $0.2 \sim 4.0 \mu \mathrm{m}$. Modeled molecular absorbers in the solar bands are $\mathrm{H}_{2} \mathrm{O}$ (including $\mathrm{H}_{2} \mathrm{O}$ continuum absorption), $\mathrm{O}_{3}, \mathrm{CO}_{2}, \mathrm{CH}_{4}, \mathrm{~N}_{2} \mathrm{O}, \mathrm{CO}$ and $\mathrm{O}_{2}$. Here, the four-stream method is used for this intercomparison.

\section{A11 Model \#10 NASA LaRC Fu-Liou RTM (LaRC-FL; F. G. Rose, S. Kato)}

The NASA Langley (LaRC) Fu-Liou Radiative Transfer Model is a modified version based on the original Fu-Liou scheme (Fu and Liou, 1992, 1993). This scheme uses a twostream delta-Eddington approximation to calculate shortwave flux and the correlated- $k$ distribution method ( $c k-\mathrm{D})$ for gas absorption (coefficients based on HITRAN 2000 including SW continuum absorption). There are 18 shortwave bands (10 visible, 8 near-infrared) spanning the wavelength range $0.17-4.0 \mu \mathrm{m}$. The visible to near-IR split is located 
Table A2. Case 1: summary of statistics for the Rayleigh atmo-

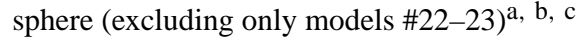

\begin{tabular}{|c|c|c|c|c|}
\hline & \multicolumn{2}{|c|}{ SAW } & \multicolumn{2}{|c|}{ TROP } \\
\hline & $30^{\circ} \mathrm{SZA}$ & $75^{\circ} \mathrm{SZA}$ & $30^{\circ} \mathrm{SZA}$ & $75^{\circ} \mathrm{SZA}$ \\
\hline \multicolumn{5}{|c|}{ Direct Broadband Downwards Flux at Surface } \\
\hline LBL Avg & 942.4 & 216.2 & 844.5 & 179.6 \\
\hline LBL RSD & $0.8 \%$ & $1.1 \%$ & $1.1 \%$ & $3.9 \%$ \\
\hline Model Avg. & 947.4 & 218.8 & 858.1 & 186.9 \\
\hline Avg. Bias & $0.5 \%$ & $1.2 \%$ & $1.6 \%$ & $4.0 \%$ \\
\hline Model RSD & $0.8 \%$ & $2.6 \%$ & $1.5 \%$ & $4.6 \%$ \\
\hline \multicolumn{5}{|c|}{ Diffuse Broadband Downwards Flux at Surface } \\
\hline LBL Avg & 64.4 & 37.2 & 64.0 & 36.8 \\
\hline LBL RSD & $0.9 \%$ & $1.5 \%$ & $0.4 \%$ & $0.5 \%$ \\
\hline Model Avg. & 63.6 & 37.8 & 64.2 & 38.0 \\
\hline Avg. Bias & $-1.2 \%$ & $1.6 \%$ & $0.3 \%$ & $3.3 \%$ \\
\hline Model RSD & $6.9 \%$ & $4.7 \%$ & $7.3 \%$ & $4.3 \%$ \\
\hline \multicolumn{5}{|c|}{ Diffuse Broadband Flux Up at TOA } \\
\hline LBL Avg & 227.6 & 82.6 & 204.7 & 75.2 \\
\hline LBL RSD & $1.3 \%$ & $1.5 \%$ & $1.3 \%$ & $1.8 \%$ \\
\hline Model Avg. & 230.8 & 84.0 & 211.4 & 78.4 \\
\hline Avg. Bias & $1.4 \%$ & $1.7 \%$ & $3.3 \%$ & $4.2 \%$ \\
\hline Model RSD & $1.1 \%$ & $1.8 \%$ & $2.5 \%$ & $3.2 \%$ \\
\hline
\end{tabular}

Total (Direct + Diffuse) UV-VIS Downwards Flux Down at Surface

\begin{tabular}{lllll}
\hline LBL Avg & 489.2 & 115.8 & 489.1 & 115.7 \\
LBL RSD & $0.7 \%$ & $1.3 \%$ & $0.2 \%$ & $0.3 \%$ \\
Model Avg. & 489.1 & 116.7 & 490.1 & 117.4 \\
Avg. Bias & $0.0 \%$ & $0.8 \%$ & $0.2 \%$ & $1.5 \%$ \\
Model RSD & $1.1 \%$ & $2.6 \%$ & $1.0 \%$ & $2.4 \%$ \\
\hline
\end{tabular}

Total near-IR Downwards Flux at Surface ${ }^{\mathrm{d}}$

\begin{tabular}{lllll}
\hline LBL Avg & 519.1 & 138.0 & 421.1 & 101.1 \\
LBL RSD & $0.8 \%$ & $1.0 \%$ & $2.3 \%$ & $6.5 \%$ \\
Model Avg. & 522.9 & 139.9 & 432.6 & 108.2 \\
Avg. Bias & $0.7 \%$ & $1.4 \%$ & $2.7 \%$ & $7.0 \%$ \\
Model RSD & $1.9 \%$ & $3.9 \%$ & $3.8 \%$ & $7.5 \%$ \\
\hline
\end{tabular}

\begin{tabular}{lcccc}
\hline \multicolumn{5}{c}{ Broadband Absorptance $^{\mathrm{e}}$} \\
\hline LBL Avg & 0.134 & 0.201 & 0.221 & 0.307 \\
LBL RSD & $7.2 \%$ & $6.4 \%$ & $2.5 \%$ & $5.1 \%$ \\
Model Avg. & 0.126 & 0.186 & 0.201 & 0.273 \\
Avg. Bias & $-6.1 \%$ & $-7.6 \%$ & $-8.8 \%$ & $-11.1 \%$ \\
Model RSD & $4.9 \%$ & $7.6 \%$ & $6.2 \%$ & $8.9 \%$ \\
\hline
\end{tabular}

${ }^{a}$ Flux units $\mathrm{W} \mathrm{m}^{-2}$; scaled normalized results as described in the text and Fig. 2. Only Models 22 and 23 are excluded because they are the same as Models 20 and 21 in the Rayleigh atmosphere.

${ }^{\mathrm{b}}$ Line-by-line (LBL) benchmarks (Avg. of Models \#1 and \#2) and non-LBL model results.

${ }^{c}$ Avg. Bias is expressed as a percentage of the LBL Avg. RSD = standard deviation as a percentage of mean.

$\mathrm{d}$ Near-IR is calculated as a difference between broadband and UV-VIS

e Absorptance (Eq. 1) is derived assuming $\mathrm{F}_{\mathrm{SFC}}^{\uparrow}=\alpha \mathrm{F}_{\mathrm{SFC}}^{\downarrow}$ and surface albedo $\alpha=0.2$.

at $14500 \mathrm{~cm}^{-1}(0.6896 \mu \mathrm{m})$. The code was modified from the original Fu-Liou code to improve treatment of Rayleigh scattering and gas absorption. While two-streams were used for this intercomparison, the code can also be configured for four-streams and gamma-weighted two-streams. The vertical resolution was 32 layers, with $1-\mathrm{km}$ resolution in the troposphere (below $25 \mathrm{~km}$ ). Between 25 and $65 \mathrm{~km}$, we interpolated online to $5 \mathrm{~km}$ vertical resolution using the natural log of pressure.

\section{A12 Models \#11 CAR-RRTMG (F. Zhang) and \#12 RRTMG-SW (L. Oreopoulos, D. Lee)}

RRTMG-SW (http://rtweb.aer.com/rrtm_frame.html) is a solar radiative transfer model that utilizes the correlated- $k(c k$ D) approach to treat gaseous absorption and to calculate shortwave fluxes and heating rates efficiently and accurately in a large-scale model environment (Clough et al., 2005; Iacono et al., 2008). Modeled sources of extinction are water vapor, carbon dioxide, ozone, methane, oxygen, nitrogen, aerosols, clouds, and Rayleigh scattering. The solar spectrum, $0.2-12 \mu \mathrm{m}$, is divided into 14 bands and spectral extinction integration within each band is accomplished using a variable number of g-points that add to $112 \mathrm{~g}$-points for the entire solar spectrum. Absorption coefficient data for $c k$ $\mathrm{D}$ are obtained directly from the line-by-line radiative transfer model, LBLRTM, which has been extensively validated against observations, principally at the ARM SGP site. Scattering is treated using the delta-Eddington flavor (Joseph et al., 1976) of the two-stream approximation (Meador and Weaver, 1980; Oreopoulos and Barker, 1999).

The last solar band $820-2600 \mathrm{~cm}^{-1}$ is coded out of sequence to preserve spectral continuity with the longwave bands. For the visible/UV calculations of this paper the normalized fluxes either included band $9\left(12850-16000 \mathrm{~cm}^{-1}\right.$ or $0.625-0.778 \mu \mathrm{m}$ ) or were only integrated up to $0.625 \mu \mathrm{m}$; contributors Oreopoulos and Lee (Model \#12) provide results for both, which are averaged in the intercomparison.

\section{A13 Model \#13 LMU-2stream (B. Mayer)}

This is a version of libRadtran that uses a two-stream deltaEddington radiative transfer solver rather than DISORT. Gaseous transmission is the same as in LMU-libRadtran (Model \#7).

\section{A14 Model \#14 MPI-2stream (S. Kinne)}

The Max Plank Institute for Meteorology model computes radiative fluxes with a two-stream method (e.g., Meador and Weaver, 1980) for the solar and infrared spectral region. This necessitates repeated applications (ca. 120 times) to properly approximate the spectral variability of atmospheric particle properties (via 8 solar and 12 infrared spectral sub-bands) and of major trace-gases $\left(\mathrm{O}_{3}, \mathrm{CO}_{2}, \mathrm{CO}, \mathrm{N}_{2} \mathrm{O}\right.$, and $\mathrm{CH}_{4}$ through a number of exponential terms in each of the subbands). The trace gas absorption (including water vapor) in the near-IR is based on LOWTRAN-5 data and ozone absorption data are based on Vigroux (1953). Trace-gases were 
Table A3. Case 2a: summary statistics for scattering aerosols ${ }^{\mathrm{a}, \mathrm{b}, \mathrm{c}}$

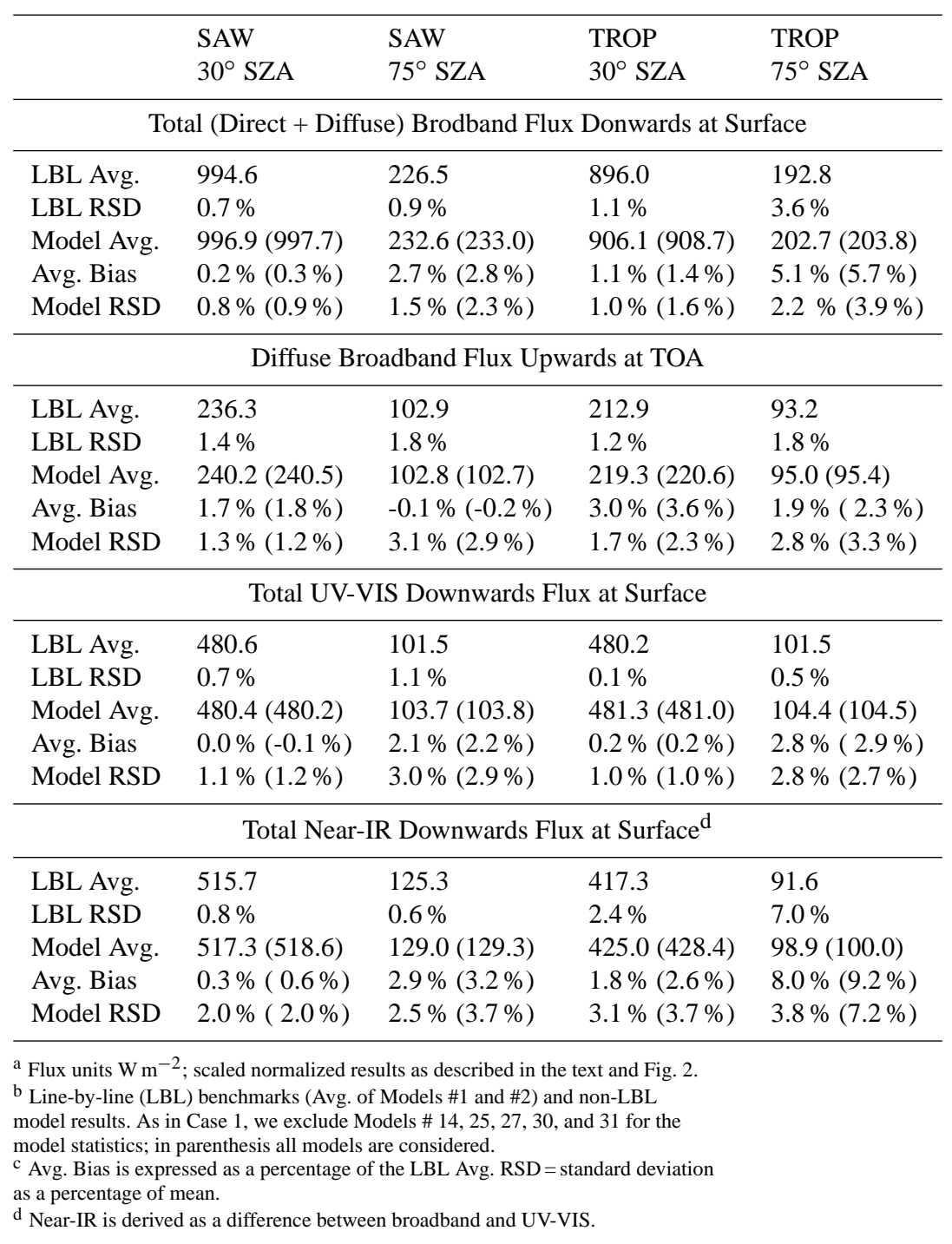

interpolated to the model resolution in the vertical using the $\log$ of pressure.

\section{A15 Modle \#15 GSFC radiation scheme (CAR-GSFC, F. Zhang)}

The NASA GSFC radiation scheme includes the absorption due to water vapor, $\mathrm{O}_{3}, \mathrm{O}_{2}, \mathrm{CO}_{2}$, clouds, and aerosols. Interactions among the absorption and scattering by clouds, aerosols, molecules (Rayleigh scattering), and the surface are fully taken into account. There are total $11 \mathrm{SW}$ bands with 38 sub-spectra from $0.175 \mu \mathrm{m}$ to $10 \mu \mathrm{m}$ (Chou and Suarez, 1999). Depending upon the nature of absorption, different approaches are applied to different absorbers. In the ultraviolet (UV) and photosynthetically active (PAR) region, the spectrum is divided into 8 bands, and a single $\mathrm{O}_{3}$ absorption coefficient and Rayleigh scattering coefficient are used for each band. In the infrared, the spectrum is divided into 3 bands, and the $k$-distribution method is applied with ten absorption coefficients used in each band. The flux reduction due to $\mathrm{O}_{2}$ is derived from a simple function, while the flux reduction due to $\mathrm{CO}_{2}$ is derived from precomputed tables. Reflection and transmission of a cloud and aerosol-laden layer are computed using the delta-Eddington approximation. Fluxes are then computed using the two-stream adding approximation. A special feature of this model is that absorption due to a number of minor absorption bands is included. Individually the absorption in those minor bands is small, but collectively the effect is large, $\sim 10 \%$ of the atmospheric heating. 
Table A4. Case 2b: summary of statistics for absorbing serosols ${ }^{\mathrm{a}, \mathrm{b}, \mathrm{c}}$

\begin{tabular}{|c|c|c|c|c|}
\hline & $\begin{array}{l}\text { SAW } \\
30^{\circ} \mathrm{SZA}\end{array}$ & $\begin{array}{l}\text { SAW } \\
75^{\circ} \mathrm{SZA}\end{array}$ & $\begin{array}{l}\text { TROP } \\
30^{\circ} \mathrm{SZA}\end{array}$ & $\begin{array}{l}\text { TROP } \\
75^{\circ} \mathrm{SZA}\end{array}$ \\
\hline \multicolumn{5}{|c|}{ Total (Direct + Diffuse) Brodband Flux Donwards at Surface } \\
\hline LBL Avg. & 954.1 & 206.2 & 857.7 & 174.5 \\
\hline LBL RSD & $0.8 \%$ & $0.8 \%$ & $1.1 \%$ & $3.8 \%$ \\
\hline Model Avg. & $958.2(959.0)$ & $212.6(212.9)$ & $869.2(871.7)$ & $184.4(185.2)$ \\
\hline Avg. Bias & $0.4 \%(0.5 \%)$ & $3.1 \%(3.3 \%)$ & $1.3 \%(1.6 \%)$ & $5.7 \%(6.2 \%)$ \\
\hline Model RSD & $0.8 \%(0.9 \%)$ & $1.4 \%(2.4 \%)$ & $1.0 \%(1.6 \%)$ & $2.3 \%(4.1 \%)$ \\
\hline \multicolumn{5}{|c|}{ Diffuse Broadband Flux at Upwards at TOA } \\
\hline LBL Avg. & 216.1 & 89.8 & 194.4 & 81.7 \\
\hline LBL RSD & $1.4 \%$ & $1.3 \%$ & $1.3 \%$ & $2.1 \%$ \\
\hline Model Avg. & $220.0(220.4)$ & $90.6(90.5)$ & $200.5(201.8)$ & $83.9(84.3)$ \\
\hline Avg. Bias & $1.8 \%(2.0 \%)$ & $0.9 \%(0.8 \%)$ & $3.1 \%(3.8 \%)$ & $2.8 \%(3.3 \%)$ \\
\hline Model RSD & $1.3 \%(1.3 \%)$ & $2.8 \%(2.6 \%)$ & $1.7 \%(2.5 \%)$ & $2.6 \%(3.2 \%)$ \\
\hline \multicolumn{5}{|c|}{ Total UV-VIS Downwards Flux at Surface } \\
\hline LBL Avg. & 452.4 & 89.0 & 452.0 & 89.0 \\
\hline LBL RSD & $0.7 \%$ & $1.1 \%$ & $0.2 \%$ & $0.5 \%$ \\
\hline Model Avg. & $453.4(453.1)$ & $91.5(91.5)$ & $454.1(453.4)$ & $92.1(92.2)$ \\
\hline Avg. Bias & $0.2 \%(0.2 \%)$ & $2.8 \%(2.9 \%)$ & $0.5 \%(0.4 \%)$ & $3.5 \%(3.6 \%)$ \\
\hline Model RSD & $1.3 \%(1.3 \%)$ & $3.4 \%(3.3 \%)$ & $1.1 \%(1.1 \%)$ & $3.1 \%(3.1 \%)$ \\
\hline \multicolumn{5}{|c|}{ Total Near-IR Downwards Flux at Surface ${ }^{d}$} \\
\hline LBL Avg. & 503.2 & 117.5 & 407.2 & 85.8 \\
\hline LBL RSD & $0.8 \%$ & $0.5 \%$ & $2.4 \%$ & $7.1 \%$ \\
\hline Model Avg. & $505.8(507.0)$ & $121.3(121.5)$ & $415.3(418.6)$ & $92.9(93.6)$ \\
\hline Avg. Bias & $0.5 \%(0.7 \%)$ & $3.2 \%(3.4 \%)$ & $2.0 \%(2.8 \%)$ & $8.3 \%(9.2 \%)$ \\
\hline Model RSD & $2.0 \%(1.9 \%)$ & $2.4 \%(3.7 \%)$ & $3.0 \%(3.7 \%)$ & $3.8 \%(7.0 \%)$ \\
\hline $\begin{array}{l}\text { Flux units W m } \\
\text { Line-by-line (LB } \\
\text { Ve exclude Model } \\
\text { onsidered. } \\
\text { Avg. Bias is expr } \\
\text { hean. } \\
\text { Near-IR is derive }\end{array}$ & $\begin{array}{l}\text { scaled normalized i } \\
\text { ) benchmarks (Avg. } \\
\text { ssed as a percentage }\end{array}$ & $\begin{array}{l}\text { lts as described in } \\
\text { Models \#1 and \#2) } \\
\text { for the model stati } \\
\text { the LBL Avg. RSD }\end{array}$ & $\begin{array}{l}\text { text and Fig. } 2 \text {. } \\
\text { d non-LBL model r } \\
\text { cs; in parenthesis al } \\
\text { standard deviation a }\end{array}$ & $\begin{array}{l}\text { ults. } \\
\text { nodels are } \\
\text { a percentage of }\end{array}$ \\
\hline
\end{tabular}

\section{A16 Model \#16 Beijing Climate Center (BCC-RAD; H. Zhang, P. Lu)}

The Beijing Climate Center radiation transfer model (BCCRAD) uses the correlated $k$-distribution $(c k$-D) algorithm adopted by Zhang et al. (2003, 2006a,b) and the 2-stream Eddington algorithm of radiative transfer. The $10-49000 \mathrm{~cm}^{-1}$ spectral range $(0.204-1000 \mu \mathrm{m})$ is divided into 17 bands $(8$ longwave and 9 shortwave). Eight major GHGs including $\mathrm{H}_{2} \mathrm{O}, \mathrm{CO}_{2}, \mathrm{O}_{3}, \mathrm{~N}_{2} \mathrm{O}, \mathrm{CH}_{4}$, and Chlorofluorocarbons (CFCs) are considered. The HITRAN2000 database (Rothman et al., 2003) was used to give line parameters and cross sections; CKD_2.4 (Zhang et al., 2003) generated continuum absorption coefficients due to water vapor, $\mathrm{CO}_{2}, \mathrm{O}_{3}$, and $\mathrm{O}_{2}$. The effective absorption coefficients of $c k$-D were calculated based on LBLRTM (Clough and Iacono, 1995) with a spectral interval of $1 / 4$ of the mean spectral line half-width and with a $25 \mathrm{~cm}^{-1}$ cutoff for line wings over each band (Clough et al., 1992; Clough and Iacono, 1995). Modeled molecular absorbers in the solar bands are $\mathrm{H}_{2} \mathrm{O}$ (including continuum absorption), $\mathrm{O}_{3}$ and $\mathrm{O}_{2}$. Nominally, cloud optical properties are from Nakajima et al. (2000) and aerosol optical properties are calculated by Wei and Zhang (2011) and Zhang et al. (2012).

\section{A17 Model \#17 CCCMA radiation scheme (CAR-CCCMA, F. Zhang)}

The Canadian Climate Center radiation scheme calculates SW flux in a vertically inhomogeneous scattering-absorbing atmosphere using a delta-Eddington approximation and adding method (Li et al., 2005). It accounts for the absorption of all radiatively important gases using the correlated $k$-distribution method ( $c k$-D) with fits to the HITRAN 96 (Li and Barker, 2005). There are 4 solar bands with a total of 35 
Table A5. Synergy across Aerocom Phase II Aerosol Radiative Forcing Experiments*

\begin{tabular}{clll}
\hline Model \# & $\begin{array}{l}\text { Radiative Transfer Experiment } \\
\text { this work }\end{array}$ & $\begin{array}{l}\text { Aerocom Prescribed } \\
\text { (Stier et el., 2012) }\end{array}$ & $\begin{array}{l}\text { Aerocom Direct RF } \\
\text { (Myhre et al., 2013) }\end{array}$ \\
\hline 3 & Oslo-DISORT & OsloCTM2 & OsloCTM2 \\
11 & CAR-RRTMG & CAM-PNNL and GEOS-CHEM & CAM5.1 and GEOS-CHEM \\
12 & RRTMG-SW & CAM-PNNL and GEOS-CHEM & CAM5.1 and GEOS-CHEM \\
14 & MPI-2stream & MPI-2stream & - \\
15 & CAR-GSFC & GOCART GEOS-4 and GOCART MERRA & GOCART and GMI \\
16 & BCC-RAD & - & BCC \\
18 & ECHAM5.5 & ECHAM-HAM2 & ECHAM5-HAM \\
24 & UKMO-HadGEM2 & HadGEM2-ES & HadGEM2 \\
\hline
\end{tabular}

* Radiation scheme, Model \#, and name from this work and corresponding model names in Stier et el. (2012) and Myhre et al. (2013) which use the same or similar radiation schemes.

sub-spectra for pressure layers $>1 \mathrm{mb}$ or 40 sub-spectra for pressure layers $<1 \mathrm{mb}$ over the range $0.2 \sim 4.0 \mu \mathrm{m}$. Modeled molecular absorbers in the solar bands are $\mathrm{H}_{2} \mathrm{O}, \mathrm{O}_{3}, \mathrm{CO}_{2}$, and $\mathrm{O}_{2}$. This model contains a proper treatment of spectral overlap between solar and infrared radiation. The effect of the additional solar energy $\left(\sim 12 \mathrm{~W} \mathrm{~m}^{-2}\right.$ in $\left.0-2500 \mathrm{~cm}^{-1}\right)$ is also included simply by imposing this energy onto the infrared downward flux for the appropriate infrared bands $(\mathrm{Li}$ and Barker, 2005). A new parameterization for the effects of atmospheric spherical curvature and refraction and their impact on radiative transfer has been incorporated ( $\mathrm{Li}$ and Shibata, 2006). This rigorous scheme enables variations in both the path length and the gaseous amount along a solar direct beam. These variations can then be accurately evaluated in the radiative transfer process, and we find better results in flux and heating rates when compared to other parameterizations.

\section{A18 Model \#18 ECHAM5.5 (J. Quaas, S. Kinne, P. Stier)}

The ECHAM5.5 general circulation model (Roeckner et al., 2003) used in several contributions to the AeroCom project applies a solar radiative transfer scheme based on Fouquart and Bonnel (1980). In a two-stream approximation, scattering and absorption by molecules and aerosols are taken into account. Since the update by Cagnazzo et al. (2007), six bands are used, with intervals between $0.185 \mu \mathrm{m}, 0.25 \mu \mathrm{m}$, $0.44 \mu \mathrm{m}, 0.69 \mu \mathrm{m}, 1.19 \mu \mathrm{m}, 2.38 \mu \mathrm{m}$ and $4.0 \mu \mathrm{m}$. The range $0.185-0.69 \mu \mathrm{m}$ is considered the visible range, the range $0.69-4.0 \mu \mathrm{m}$, the near-infrared. We use the off-line radiation code extracted by Klocke et al. (2011) and take into account the effects of water vapor, ozone, methane and $\mathrm{N}_{2} \mathrm{O}$ from the prescribed profiles, as well as of carbon dioxide with a constant mixing ratio of 348 ppmv. Carbon monoxide is not considered in the radiation, and the mixing ratios of chloroflourocarbons are set to zero.

The configuration is considered as an open ocean surface, and the vertical resolution is chosen as in the input files, where the boundary of the lowest surface is set to $0 \mathrm{~km}$, and the layer-mean values are the averages of the layer interfaces. The uppermost layer-mean values are considered the same as at its lower boundary, with the temperature at the upper boundary as at the lower one, the pressure at the upper boundary $0 \mathrm{hPa}$, and the layer-mean pressure half the pressure at the lower boundary. For the aerosols, the Angström exponent is used to extrapolate the $550 \mathrm{~nm}$ optical depth to the other bands considering the band-average wavelength. The single-scattering albedo is assumed spectrally constant.

\section{A19 Model \#19 UMD-SRB (Y. Ma and R. T. Pinker)}

The radiative transfer model used in the prescribed tests is part of the University of Maryland Surface Radiative Budget (UMD-SRB) module for satellite retrieval of shortwave (SW) fluxes. It calculates broadband SW fluxes in a planeparallel, vertically inhomogeneous, scattering and absorbing atmosphere. The model accounts for (1) absorption by water vapor and ozone; (2) Rayleigh scattering; (3) scattering and absorption by aerosols and cloud droplets; and (4) multiple reflection between the atmosphere and surface. Radiative transfer is dealt with the delta-Eddington approximation. In the prescribed AeroCom experiments, SW fluxes are computed in 7 broadband intervals $(0.2-0.4,0.4-0.5,0.5-$ $0.6,0.6-0.7,0.7-1.19,1.19-2.38$ and $2.38-4.00 \mu \mathrm{m})$. Water vapor absorption is accounted for in the $0.7-4.0 \mu \mathrm{m}$ spectral interval; ozone is accounted for in the $0.2-0.4 \mu \mathrm{m}$ (UV) and in $0.5-0.6 \mu \mathrm{m}$ (VIS) spectral intervals. For water vapor and water vapor continuum, we use the $k$-distribution method proposed by Chou and Lee (1996) and further advanced by Tarasova and Fomin (2000). Reference transmission database is HITRAN96. Ozone parameterization follows Lacis and Hansen (1974). The model is configured with variable number of layers $(>31)$, depending on presence of aerosol and/or clouds. More details can be found in Wang and Pinker (2009). For this study $1 \mathrm{~km}$ resolution was used below $25 \mathrm{~km}$; above this level, the vertical resolution for ozone and water vapor profiles is $5 \mathrm{~km}$. 


\section{A20 Models \#20-23 University of Reading Edwards and Slingo (ES96, E. Highwood, C. Ryder, B. Harris)}

The Edwards and Slingo radiation scheme (ES96) is a flexible radiative transfer model as described by Edwards and Slingo (1996) with updates from Walters et al. (2011). Results using the offline version released by the Met Office on 21 December 2009 are presented using a two stream practical improved flux method (PIFM, Zdunkowski et al., 1980). The user is able to define the number of spectral bands and model vertical levels. The spectral resolution is set by an external spectral file. The user is able to use (and adjust) spectral files supplied with the code, or create new versions. Here we provide results using standard supplied versions of spectral files with either 6 or 220 spectral bands covering wavelengths of 0.2 to 10 microns. The spectral file supplies details of atmospheric radiative properties such as gaseous absorption which may differ between spectral files. Therefore each subsequent description of ES96 makes reference to a specific spectral file and differences therein.

Water vapor terms are updated based on the HITRAN 2001 database (Rothman et al., 2003) for gaseous absorption coefficients, with updates up to 2003. For all other gases absorption is based on HITRAN92. Gaseous absorption is represented according to Cusack et al. (1999) using a correlated$k$ method.

ES96 allows the user to select whether delta-rescaling is implemented for particle scattering (ES96-D). Deltarescaling provides more accurate total flux measurements at the expense of the partitioning between the direct and diffuse fluxes since delta-rescaling effectively increases the flux in the direct beam to account for strong forward aerosol scattering.

Results are presented using ES96 with 6 and 220 spectral bands (Model \#20 ES96-6 and Model \#21 ES96-220), using the spectral files "sp_sw_hadgem1_3r" and "sp_sw_220_r", respectively. Aerosol properties in the spectral files are adjusted to represent AeroCom protocol requirements. Particle scattering is presented both for cases where no delta rescaling is included (model \#20 ES96-6 and model \#21 ES96-220) and where delta rescaling is included (model \#22 ES96-6-D and model \#23 ES96-220-D).

Absorption due to $\mathrm{CO}_{2}$ and $\mathrm{O}_{2}$ concentrations are set to $0.579 \mathrm{~g} \mathrm{~kg}^{-1}$ and $231 \mathrm{~g} \mathrm{~kg}^{-1}$ which are constant with altitude, absorption due to $\mathrm{H}_{2} \mathrm{O}$ and $\mathrm{O}_{3}$, are included as prescribed by AeroCom. $\mathrm{N}_{2} \mathrm{O}$ and $\mathrm{CH}_{4}$ are included from the AFGL standard atmospheres in the 220 band cases (ES96220) but are excluded in the 6 band cases (ES96-6). CO is not included.

\section{A21 Model \#24 UKMO HadGEM2 GCM (S. T. Rumbold)}

The online radiation code in HadGEM2 is consistent with the offline version of ES96 by design and is maintained as such at the UK Met Office (UKMO). A description of the online implementation can be found in Martin et al. (2011). For the UKMO-HadGEM2 contribution to this intercomparison, the offline code is used and is configured in an identical manner to that of the HadGEM2 online radiation. This configuration is as in ES96-6-D (Model \#22), but with vertical profiles of gases interpolated to mid-levels linearly in the logarithm of pressure. All AeroCom prescribed gases are used apart from $\mathrm{N}_{2} \mathrm{O}, \mathrm{CO}$ and $\mathrm{CH}_{4}$ as they are not included in the shortwave part of the online radiation scheme. Where needed, aerosol was prescribed at constant mass mixing ratio in the two lower most model layers (zero elsewhere) to achieve the correct optical depth.

\section{A22 Model \#25 CAWCR radiation scheme (CAR-CAWCR, F. Zhang)}

The Center for Australian Weather and Climate Research (CAWCR) Sun-Edwards-Slingo radiation scheme (SES2) is a model used in numerical weather prediction (NWP) and climate models (Sun and Rikus, 1999; Sun, 2008) and is based on the Edwards and Slingo (1996) radiation scheme. The model calculates SW flux in a vertically inhomogeneous scattering-absorbing atmosphere using a delta-two-stream algorithm, and accounts for the absorption of all radiatively important gases using the exponential sum fitting transmission method (ESFT). The line-by-line radiative transfer model (GENLN2) (Edwards, 1992) provides the absorption coefficients for the ESFT method. The accuracy of these absorption coefficients has been established by comparison of GENLN2 with other line-by-line models such as LBLRTM (Clough et al., 1992) and measurements from ARM (Stokes and Schwartz, 1994). Modeled molecular absorbers in the solar bands are $\mathrm{H}_{2} \mathrm{O}$ (including continuum effects), $\mathrm{O}_{3}, \mathrm{CO}_{2}$, $\mathrm{CH}_{4}, \mathrm{~N}_{2} \mathrm{O}$, and $\mathrm{O}_{2}$. There are 9 solar bands with total 27 sub-spectra over $0.2 \sim 5.0 \mu \mathrm{m}$. The radiation code has two novel features: one is the flexible spectral resolution of the code, and the second is that the same spectral framework for both the longwave and shortwave components. This makes the code easy to maintain and develop. In this scheme, the effect of the additional solar energy (about $12 \mathrm{Wm}^{-2}$ in 0 $2500 \mathrm{~cm}^{-1}$ ) is also included simply by imposing this energy onto the infrared downward flux for the appropriate infrared bands (Li and Barker, 2005).

\section{A23 Model \#26 CAM radiation scheme (CAR-CAM, F. Zhang)}

The NCAR CAM model (Collins et al., 2004) calculates SW flux in a vertically inhomogeneous scattering-absorbing 
atmosphere using a delta-two-stream algorithm. The solar spectrum is divided into 19 discrete spectral and pseudospectral intervals: 7 for $\mathrm{O}_{3}, 1$ for the visible, 7 for $\mathrm{H}_{2} \mathrm{O}$ including water-vapor continuum, 3 for $\mathrm{CO}_{2}$, and 1 for the near-infrared following Collins (1998). The solar absorption by water vapor between 1000 and $18000 \mathrm{~cm}^{-1}$ is treated using seven pseudo-spectral intervals with a constant specific extinction specified for each interval. These extinctions have been adjusted to minimize errors in heating rates and flux divergences relative to line-by-line (LBL) calculations for reference atmospheres (Anderson et al., 1986) using GENLN3 (Edwards, 1992) combined with the radiative transfer solver DISORT2 (Stamnes et al., 1988). This parameterization is essentially an exponential sum fit (e.g., Wiscombe and Evans, 1977). LBL calculations are performed with the HITRAN 2000 line database (Rothman et al., 2003) and the Clough, Kneizys, and Davies (CKD) model version 2.4.1 (Clough et al., 1989). The Rayleigh scattering optical depths in the seven pseudo-spectral intervals have been changed for consistency with LBL calculations of the variation of water-vapor absorption with wavelength. Modeled molecular absorbers in the solar bands are $\mathrm{H}_{2} \mathrm{O}$ (including continuum absorption), $\mathrm{CO}_{2}$, and $\mathrm{O}_{3}$.

\section{A24 Modle \#27 ULAQ (G. Pitari, G. Di Genova)}

The University of L'Aquila radiative transfer module, operating on-line in the climate-chemistry coupled model ULAQCCM, is a two-stream delta-Eddington approximation model (Toon et al., 1989) used for chemical species photolysis rate calculation in UV-visible wavelengths and for solar heating rates and radiative forcing in UV-VIS-NIR bands. Species cross sections are updated using JPL (2011) recommendations from the MPI-MAINZ database, while water vapor absorption data are derived from HITRAN92. SchumannRunge bands are treated following the parameterization of Minschwaner et al. (1993) based on (fixed-T) ODF formulation. Diurnal averages are calculated with a 5 point Gaussian quadrature.

Top-of-atmosphere solar fluxes are taken from SUSIMSL2 and LOWTRAN7 and are carefully integrated on the wavelength bins used in the model: they are in total 150 in the UV and visible range and 100 in the NIR, covering the solar spectrum from Lyman-alpha up to $7 \mu \mathrm{m}$. Sun-earth distance is calculated daily as a function of orbit eccentricity and the solar cycle is included. Sphericity is treated by means of Chapman functions (Dahlback and Stames, 1991). Refraction is taken into account with an iterated ray-tracing technique in a simple exponential refraction model.

Absorption/scattering optical depths take into account Rayleigh scattering, absorption from $\mathrm{O}_{3}, \mathrm{O}_{2}, \mathrm{NO}_{2}, \mathrm{SO}_{2}$, $\mathrm{H}_{2} \mathrm{O}, \mathrm{CO}_{2}$ and scattering/absorption from aerosol particles. Aerosol extinction values are passed daily from the ULAQCCM aerosol module to the radiative transfer module, with appropriate wavelength-dependent values of Q-ext, $g$, and single scattering albedo, given the calculated size distribution of the particles. Surface albedo is nominally taken from MERRA 2D hourly averaged data.

The native vertical resolution of our model is $570 \mathrm{~m}$. For this study, we linearly interpolate both AFGL $\mathrm{O}_{3}$ and $\mathrm{H}_{2} \mathrm{O}$ concentrations to this higher resolution using the calculated column values on the AFGL vertical grid as a constraint for both species (i.e. the calculated vertical columns after interpolation are re-normalized to the original values).

\section{A25 Model \#28 FORTH (I. Vardavas, N. Hatzianstassiou, C. Matsoukas)}

The incoming solar irradiance conforms to the spectral profile of Gueymard (2004). The model apportions $69.48 \%$ of the incoming spectral irradiance to the ultra violet-visiblenear infrared (UV-Vis-NIR) part $(0.20-1 \mu \mathrm{m})$ and $30.52 \%$ to the near infrared-infrared (NIR-IR) part $(1-10 \mu \mathrm{m})$. The radiative transfer equations are solved for 118 separate wavelengths for the UV-Vis-NIR part and for 10 bands for the NIR-IR part, using the delta-Eddington method as modified by Joseph et al. (1976). For a more detailed model description the reader is referred to Hatzianastassiou et al. (2004a,b, 2007a); Hatzianastassiou et a. (2007b) and Vardavas and Taylor (2007). The model takes into account clouds, Rayleigh scattering due to atmospheric gas molecules, absorption from $\mathrm{O}_{3}, \mathrm{O}_{2}, \mathrm{CO}_{2}, \mathrm{H}_{2} \mathrm{O}$, and $\mathrm{CH}_{4}$, and scattering and absorption due to aerosols. The model output includes downwelling and upwelling fluxes at the top of atmosphere, at the surface and at any atmospheric height. For this study we interpolated the AFGL water-vapor and ozone profiles to our model vertical resolution linearly in $\log$ (pressure)-log(gas concentration) space.

\section{A26 Model \#29 GFDL radiation scheme (CAR-GFDL, F. Zhang)}

The NOAA GFDL radiation scheme (Freidenreich and Ramaswamy, 1999) uses the exponential-sum-fit technique (ESFT) to develop the parameterization of water vapor transmission in the main absorbing bands. An absorptivity approach is used to represent the heating contributions by $\mathrm{CO}_{2}$ and $\mathrm{O}_{2}$, and a spectral averaging of the continuumlike properties is used to represent the $\mathrm{O}_{3}$ heating. Spectral line data for $\mathrm{H}_{2} \mathrm{O}, \mathrm{CO}_{2}, \mathrm{O}_{3}, \mathrm{CH}_{4}$ and $\mathrm{N}_{2} \mathrm{O}$ are now based on the HITRAN92 catalog (Rothman et al., 1992). The delta-Eddington method is used to solve for the reflection and transmission, while the "adding" method is used to combine the layers. The single-scattering properties can account for all types of scattering and absorbing constituents (molecules, drops, ice particles, and aerosols), given their respective single-scattering properties and mass concentrations. There are 18 solar bands with total 38 sub-spectra over $0.173 \sim 20.0 \mu \mathrm{m}$. 


\section{A27 Model \#30 MPI-MOM (S. Kinne)}

The Max Plank Institute for Meteorology MPI-MOM scheme combines the matrix-operator (Plass et al., 1973) and adding doubling method. The method was prepared for atmospheric broadband sold radiative transfer calculation by Grassl (1978). The trace gas absorption (including water vapor) in the near-IR is based on LOWTRAN-5 data and ozone absorption data are based on Vigroux (1953). Trace-gases were interpolated to the model resolution in the vertical using the log of pressure.

\section{A28 Model \#31 Matrix-Operator Model (MOMO; J. Fischer, L. Doppler)}

MOMO is a radiation transfer code for radiance and irradiance computations in the ocean and atmosphere (Fell and Fischer, 2001; Fischer and Grassl, 1984). Its spectral range is $0.2-100 \mu \mathrm{m}$. MOMO combines the matrix-operator (Plass et al., 1973) and adding doubling method. The gas transmission is computed using a code CGASA, derived from XTRA (Rathke and Fischer, 2000). CGASA combines the water-vapor continuum model of Clough et al. (1992) with Voigt line computations. Line properties are taken from the HITRAN-2008 spectral database (Rothman et al., 2009). A $k$-distribution method is used, following Bennartz and Fischer (2000). This $k$-distribution is exact (we do not make the correlated approximation). For this study, we computed MOMO simulations within 55 UV bands and 12 VIS bands, in order to consider the high variation of Rayleigh optical depth. 30 bands have been defined to model the near-IR radiation. $3000 \mathrm{k}$-intervals have been needed to model water vapor, ozone and mixed gas absorption lines with accuracy. The vertical resolution was $1 \mathrm{~km}$ from 0 to $26 \mathrm{~km}$ and $2 \mathrm{~km}$ from 26 to $100 \mathrm{~km}$. Within aerosols layers, the adding-doubling method divided the layers in $2 \mathrm{n}$ sub-layers in order to consider multi-scattering.

Acknowledgements. C. Randles was supported by the NASA Atmospheric Composition Modeling and Analysis (ACMAP) Program Grant NNX11AK20G under R. Eckman. G. Myhre was supported by the projects SLAC (Short Lived Atmospheric Components) and EarthClim funded by the Norwegian Research Council. M. Schulz acknowledges support under the EU ECLIPSE project, contract No. 282688. J. Huttunen was supported by Graduate school in Physics, Chemistry, Biology and Meteorology of Atmospheric Composition and Climate Change: From Molecular Processes to Global Observations and Models. D. Neubauer and R. Hitzenberger acknowledge financial funding from the University of Vienna, FPF 234 and thank Warren Wiscombe (Goddard Space Flight Center) for the ESFT program. D. Neubauer gratefully acknowledges the support by research fellowship F-369, University of Vienna. L. Oreopoulos and D. Lee acknowledge support from NASA's Modeling Analysis and Prediction program managed by D. Considine. The work of R. T. Pinker and Y. Ma was supported under grant NNX11AF54G through the NASA Science of Terra and
Aqua Program and grant NNX08AN40A from the NASA Science Mission Directorate-Division of Earth Science. S. T. Rumbold was supported by the Joint DECC and Defra Integrated Climate Programme (GA01101). H. Yu was supported by NASA ACMAP, managed by R. Eckman. F. Zhang was supported by US DOE office of Biological and Environmental Research (BER) DESC0001683. H. Zhang was funded and supported by the "Strategic Priority Research Program - Climate Change: Carbon Budget and Relevant Issues" (XDA05040200) and "National High-tech Research and Development (863) Project (2011AA12A104)". P. Lu was supported by National Basic Research Program of China (2011CB403405). The authors thank Q. Fu, Jun Wang, and one anonymous reviewer for their helpful comments that helped to improve the manuscript.

Edited by: Q. Fu

\section{References}

Anderson, G. P., Clough, S. A., Kneizys, F. X., Chetwynd, J. H., and Shettle, E. P.: AFGL atmospheric constituent profiles (0$120 \mathrm{~km}$ ). Technical Report AFGL-TR-86-0110, AFGL (OPI), Hanscom AFB, MA. 01736, 1986.

Arking, A.: Effects of bias in solar radiative transfer codes on global model simulations, Geophys. Res. Lett., 32, L20717, doi:10.1029/2005GL023644, 2005.

Bennartz, R. and Fischer, J. A.: A modified k-distribution approach applied to narrow band water vapor and oxygen absorption estimates in the near infrared, J. Quant. Spectrosc. Radiat. Transfer, 66, 539-553, 2000.

Boucher, O., Schwartz, S. E., Ackerman, T. P., Anderson, T. L., Bergstrom, B., Bonnel, B., Chýlek, P., Dahlback, A., Fouquart, Y. Fu, Q. Halthore, R. N., Haywood, J. M., Iversen, T., Kato, S., Kinne, S., Kirkevåg, A., Knapp, K. R., Lacis, A., Laszlo, I., Mischenko, M. I., Nemensure, S., Ramaswamy, V., Roberts, D. L., Russell, P., Schlesinger, M. E., Stephens, G. L., Wagener, R., Wang, M., Wong, J., and F. Yang: Intercomparison of models representing direct shortwave radiative forcing by sulfate aerosols, J. Geophys. Res., 103, 16979-16998, 1998.

Cagnazzo, C., Manzini, E., Giorgetta, M. A., Forster, P. M. De F., and Morcrette, J. J.: Impact of an improved shortwave radiation scheme in the MAECHAM5 General Circulation Model, Atmos. Chem. Phys., 7, 2503-2515, doi:10.5194/acp-7-2503-2007, 2007.

Chandrasekhar, S.: Radiative Transfer, Dover, Mineola, NY, USA, 393 pp., 1960.

Chou, M.-D. and Lee, K. T.: Parameterizations for the absorption of solar radiation by water vapor and ozone, J. Atmos. Sci., 53, 1203-1208, 1996.

Chou, M.-D. and Suarez, M. J.: A solar radiation parameterization for atmospheric studies, (last revision on March 2002) Technical Report Series on Global Modeling and Data Assimilation, edited by: M. J. Suarez, NASA/TM-1999-104606, Vol. 15, Goddard Space Flight Center, Greenbelt, MD, 42 pp., 1999.

Chýlek, P. and Coakley, J. A.: Aerosols and Climate, Science, 183, 75-77, 1974.

Clough, S. A. and Iacono, M. J.: Line-by-line calculation of atmospheric fluxes and cooling rates 2. Application to carbon dioxide, 
ozone, methane, nitrous oxide and the halocarbons, J. Geophys. Res., 100, 16519-16535, 1995.

Clough, S. A., Kneizys, F. X., and Davies, R. W.: Line shape and the water vapor continuum, Atmos. Res., 23, 229-241, 1989.

Clough, S. A., Iacono, M. J., and J. L. Moncet: Line-by-line calculations of atmospheric fluxes and cooling rates: Application to water vapor. J. Geophys. Res., 97, 15761-15785, 1992.

Clough, S. A., Shephard, M. W., Mlawer, E. J., Delamere, J. S., Iacono, M. J., Cady-Pereira, K., Boukabara, S., and Brown, P. D.: Atmospheric radiative transfer modeling: a summary of the AER codes. J. Quant. Spectrosc. Radiat. Transf., 91, 233-244, doi:10.1016/j.jqsrt.2004.05.058, 2005.

Collins, W. D.: A global signature of enhanced shortwave absorption by clouds, J. Geophys. Res., 103, 31669-31679, 1998.

Collins, W. D., Rasch, P. J., Boville, B. A., Hack, J. J., McCaa, J. R., Williamson, D. L., Kiehl, J. T., Briegleb, B., Bitz, C., Lin, S.-J., Zhang, M., and Dai, Y.: Description of the NCAR Community Atmosphere Model (CAM 3.0), NCAR Technical Note, NCAR/TN-464+STR, 226 pp., 2004.

Cusack, S., Edwards, J., and Crowther, J.: Investigating $\mathrm{k}$ distribution methods for paramterizing gaseous absorption in the Hadley Centre Climate Model, J. Geophys. Res., 104, 20512057, doi:10.1029/1998JD200063, 1999.

Dahlback, A. and Stamnes, K.: A new spherical model for computing the radiation field available for photolysis and heating at twilight, Planet. Space Sci., 39, 671-683, 1991.

Edwards, D. P.: GENLN2: A general line-by-line atmospheric transmittance and radiance model. Technical Report NCAR/TN367+STR, NCAR, P.O. Box 3000, Boulder, Colorado, 803073000, 147 pp., 1992.

Edwards, J. M. and Slingo, A.: Studies with a flexible new radiation code. I: Choosing a configuration for a large-scale model, Q. J. Roy. Meteor. Soc., 122, 689-719, 1996.

Fell, F. and Fischer, J.: Numerical simulation of the light field in the atmosphere-ocean system using the matrix-operator method, J. Quant. Spectrosc. Radiat. Transf., 69, 351-388, 2001.

Fischer, J. and Grassl, H.: Radiative transfer in an atmosphereocean system: an azimuthally dependent matrix-operator approach. Appl. Opt., 23, 1032-1039, 1984.

Forster, P., Ramaswamy, V., Artaxo, P., Berntsen, T., Betts, R., Fahey, D. W., Haywood, J., Lowe, J., Myhre, G., Nganga, J., Prinn, R., Raga, G., Schulz, M., and Dorland, R. V.: Climate Change 2007: The Physical Science Basis: Contribution of Working Group I to the Fourth Assessment Report of the Intergovernmental Panel on Climate Change, Chap. Changes in Atmospheric Constituents and in Radiative Forcing, Cambridge University Press, Cambridge, UK and New York, NY, USA, 2007.

Forster, P. M., V. I. Fomichev, E. Rozanov, C. Cagnazzo, A. I. Jonsson, U. Langematz, B. Fomin, M. J. Iacono, B. Mayer, E. Mlawer, G. Myhre, R. W. Portmann, H. Akiyoshi, V. Falaleeva, N. Gillett, A. Karpechko, J. Li, P. Lemennais, O. Morgenstern, S. Oberländer, M. Sigmond, and K. Shibata: Evaluation of radiation scheme performance within chemistry climate models, J. Geophys. Res., 116, D10302, doi:10.1029/2010JD015361, 2011.

Fouquart, Y. and Bonnel, B.: Computations of solar heating of the Earth's atmosphere: A new parameterization, Beitr. Phys. Atmos., 53, 35-62, 1980.

Fouquart, Y., Bonnel, B., and Ramaswamy, V.: Intercomparing shortwave radiation codes for climate studies, J. Geophys. Res.,
96, 8955-8968, 1991.

Freidenreich, S. M. and Ramaswamy, V.: A new multiple-band solar radiative parameterization for general circulation models. J. Geophy. Res., 104, 31389-31409, 1999.

$\mathrm{Fu}$, Q. and Liou, K. N.: On the correlated k-distribution method for radiative transfer in nonhomogeneous atmospheres. J. Atmos. Sci., 49, 2139-2156, 1992.

Fu, Q. and Liou, K. N.: Parameterization of the radiative properties of cirrus clouds, J. Atmos. Sci., 50, 2008-2025, 1993.

Gu, Y., Liou, K. N., Chen, W., and Liao, H.: Direct climate effect of black carbon in China and its impact on dust storms, J. Geophys. Res., 115, D00K14, doi:10.1029/2009JD01342, 2010.

Gu, Y., Liou, K. N., Ou, S. C., and Fovell, R.: Cirrus cloud simulations using WRF with improved radiation parameterization and increased vertical resolution. J. Geophys. Res., 116, D06119, doi:10.1029/2010JD014574, 2011.

Gueymard, C. A.: The sun's total and spectral irradiance for solar energy applications and solar radiation models, Sol. Energy, 76, 423-453, 2004.

Grassl, H.: Strahlung in getrübten Atmosphären und in Wolken, Contr. Atmos. Phys., 49, 225-236, 1978.

Halthore, R. N., Crisp, D., Schwartz, S. E., Anderson, G. P., Berk, A., Bonnel, B., Boucher, O., Chang, F.-L., Chou, M.-D., Clothiaux, E. E., Dubuisson, P., Fomin, B., Fouquart, Y., Freidenreich, S., Gautier, C., Kato, S., Laszlo, I., Li, Z., Mather, J. H., Plana-Fattori, A., Ramaswamy, V., Ricchiazzi, P., Shiren, Y., Trishchenko, A., and Wiscombe, W.: Intercomparison of shortwave radiative transfer codes and measurements, J. Geophys. Res., 110, D11206, doi:10.1029/2004JD005293, 2005.

Hatzianastassiou, N., Katsoulis, B., and Vardavas, I.: Global distribution of aerosol direct radiative forcing in the ultraviolet and visible arising under clear skies, Tellus, 56B, 51-71, doi:10.1111/j.1600-0889.2004.00085.x, 2004a.

Hatzianastassiou, N., Matsoukas, C., Hatzidimitriou, D., Pavlakis, C., Drakakis, M., and Vardavas, I.: Ten-year radiation budget of the Earth: 1984-1993, Int. J. Climatol., 24, 1785-1802, doi:10.1002/joc.1110, 2004b.

Hatzianastassiou, N., Matsoukas, C., Drakakis, E., Stackhouse, P. W., Koepke, P., Fotiadi, A., Pavlakis, K. G., and Vardavas, I.: The direct effect of aerosols on solar radiation based on satellite observations, reanalysis datasets, and spectral aerosol optical properties from Global Aerosol Data Set (GADS), Atmos. Chem. Phys., 7, 2585-2599, doi:10.5194/acp-7-2585-2007, 2007a.

Hatzianastassiou, N., Matsoukas, C., Fotiadi, A., P. W. Stackhouse Jr., Koepke, P., Pavlakis, K. G., and Vardavas, I.: Modelling the direct effect of aerosols in the solar near-infrared on a planetary scale, Atmos. Chem. Phys., 7, 3211-3229, doi:10.5194/acp-73211-2007, 2007b.

Howard, J. N., King, J. I. F., and Gast, P. R.: Thermal radiation, Handbook of Geophysics, 16, 16:1-16:32, Macmillan, Indianapolis, Indiana, 1961.

Iacono, M. J., Delamere, J. S., Mlawer, E. J., Shephard, M. W., Clough, S. A., and Collins, W. D: Radiative forcing by long-lived greenhouse gases: Calculations with the AER radiative transfer models, J. Geophys. Res., 113, D13103, doi:10.1029/2008JD009944, 2008.

Joseph, J. H., Wiscombe, W. J., and Weinman, J. A.: The DeltaEddington Approximation for Radiative Flux Transfer. J. Atmos. Sci., 33, 2452-2459, 1976. 
JPL: Chemical Kinetics and Photochemical Data for Use in Atmospheric Studies, Evaluation Number 17, JPL Publication 10-6, 2011.

Kato, S., Ackerman, T. P. and Mather, J. H. and Clothiaux, E. E.: The k-distribution method and correlated-k approximation for a shortwave radiative transfer model, J. Quant. Spectrosc. Radiat. Transfer, 62, 109-121, 1999.

Key, J. and Schweiger, A. J.: Tools for atmospheric radiative transfer: Streamer and FluxNet, Comput. Geosci., 24, 443-451, doi:10.1016/S0098-3004(97)00130-1, 1998.

Kinne, S., Schulz, M., Textor, C., Guibert, S., Balkanski, Y., Bauer, S. E., Berntsen, T., Berglen, T. F., Boucher, O., Chin, M., Collins, W., Dentener, F., Diehl, T., Easter, R., Feichter, J., Fillmore, D., Ghan, S., Ginoux, P., Gong, S., Grini, A., Hendricks, J., Herzog, M., Horowitz, L., Isaksen, I., Iversen, T., Kirkevåg, A., Kloster, S., Koch, D., Kristjansson, J. E., Krol, M., Lauer, A., Lamarque, J. F., Lesins, G., Liu, X., Lohmann, U., Montanaro, V., Myhre, G., Penner, J., Pitari, G., Reddy, S., Seland, Ø., Stier, P., Takemura, T., and Tie, X.: An AeroCom initial assessment - optical properties in aerosol component modules of global models, Atmos. Chem. Phys., 6, 1815-1834, doi:10.5194/acp-6-1815-2006, 2006.

Klocke, D., Pincus, R., and Quaas, J.: On constraining estimates of climate sensitivity with present day observations through model weighting, J. Clim., 24, 6092-6099, doi:10.1175/2011JCLI4193.1, 2011.

Kneizys F. X., Shettle E. P., Abreu L. W., Chetwynd J. H., Anderson G. P., Gallery W. O., Selby J. E. A., and S. A. Clough: Report AFGL-TR-88-0177, Air Force Geophysics Laboratory, Hanscom AFB, Massachusetts, USA, 1988.

Koch, D., Schulz, M., Kinne, S., McNaughton, C., Spackman, J. R., Balkanski, Y., Bauer, S., Berntsen, T., Bond, T. C., Boucher, O., Chin, M., Clarke, A., De Luca, N., Dentener, F., Diehl, T., Dubovik, O., Easter, R., Fahey, D. W., Feichter, J., Fillmore, D., Freitag, S., Ghan, S., Ginoux, P., Gong, S., Horowitz, L., Iversen, T., Kirkevåg, A., Klimont, Z., Kondo, Y., Krol, M., Liu, X., Miller, R., Montanaro, V., Moteki, N., Myhre, G., Penner, J. E., Perlwitz, J., Pitari, G., Reddy, S., Sahu, L., Sakamoto, H., Schuster, G., Schwarz, J. P., Seland, Ø., Stier, P., Takegawa, N., Takemura, T., Textor, C., van Aardenne, J. A., and Zhao, Y.: Evaluation of black carbon estimations in global aerosol models, Atmos. Chem. Phys., 9, 9001-9026, doi:10.5194/acp-9-9001-2009, 2009.

Lacis, A. A. and Hansen, J. E.: Parameterization for absorption of solar-radiation in earths atmosphere, J. Atmos. Sci., 31, 118-133, 1974.

Lacis A. A. and Oinas, V. A.: Description of the correlated kdistribution method, J. Geophys. Res.; 96, 9027-9064, 1991.

Lean, J., Rottman, G., Harder, J., and G. Kopp: SOURCE contributions to new understanding of global change and solar variability, Solar Phys., 230, 27-53, 2005.

Lenoble, J.: Radiative Transfer in Scattering and Absorbing Atmospheres: Standard Computational Procedures, A. Deepak, Hampton, VA, USA, 1985.

Li, J. and Barker, H. W.: A radiation alogorithm with Correlated-k Distribution. Part I: Local thermal equilibrium. J. Atmos. Sci., 62, 286-309, 2005.

Li, J. and Shibata, K.: On the effective solar pathlength, J. Atmos. Sci., 63, 1365-1373, doi:10.1175/JAS3682.1, 2006.
Li, J., Dobbie, S., Risnen, P., and Min, Q.: Accounting for unresolved clouds in a 1-D solar radiative-transfer model, Q. J. Roy. Meteorol. Soc., 131, 1607-1629, 2005.

Liang, X.-Z. and F. Zhang: Cloud-Aerosol-Radiation (CAR) Ensemble Modeling System. J. Geophys. Res., submitted, 2012.

Liou, K.-N.: Radiation and Cloud Processes in the Atmosphere, Oxford Univ. Press, New York, USA, 1992.

Liou, K. N., Gu, Y., Yue, Q., and McFarguhar, G.: On the correlation between ice water content and ice crystal size and its application to radiative transfer and general circulation models. Geophys. Res. Lett., 35, L13805, doi:10.1029/2008GL033918, 2008.

The HadGEM2 Development Team: G. M. Martin, Bellouin, N., Collins, W. J., Culverwell, I. D., Halloran, P. R., Hardiman, S. C., Hinton, T. J., Jones, C. D., McDonald, R. E., McLaren, A. J., O'Connor, F. M., Roberts, M. J., Rodriguez, J. M., Woodward, S., Best, M. J., Brooks, M. E., Brown, A. R., Butchart, N., Dearden, C., Derbyshire, S. H., Dharssi, I., Doutriaux-Boucher, M., Edwards, J. M., Falloon, P. D., Gedney, N., Gray, L. J., Hewitt, H. T., Hobson, M., Huddleston, M. R., Hughes, J., Ineson, S., Ingram, W. J., James, P. M., Johns, T. C., Johnson, C. E., Jones, A., Jones, C. P., Joshi, M. M., Keen, A. B., Liddicoat, S., Lock, A. P., Maidens, A. V., Manners, J. C., Milton, S. F., Rae, J. G. L., Ridley, J. K., Sellar, A., Senior, C. A., Totterdell, I. J., Verhoef, A., Vidale, P. L., and Wiltshire, A.: The HadGEM2 family of Met Office Unified Model climate configurations, Geosci. Model Dev., 4, 723-757, doi:10.5194/gmd-4-723-2011, 2011.

Mayer, B. and Kylling, A.: Technical note: The libRadtran software package for radiative transfer calculations - description and examples of use, Atmos. Chem. Phys., 5, 1855-1877, doi:10.5194/acp-5-1855-2005, 2005.

Meador, W. E. and Weaver, W. R.: Two-Stream Approximations to Radiative Transfer in Planetary Atmospheres: A Unified Description of Existing Methods and a New Improvement, J. Atmos. Sci., 37, 630-643, 1980.

Minschwaner, K., Salawitch, R. J., and McElroy, M. B.: Absorption of Solar Radiation by $\mathrm{O}_{2}$ : Implications for $\mathrm{O}_{3}$ and Lifetimes of $\mathrm{N}_{2} \mathrm{O}, \mathrm{CFCl} 3$, and CF2Cl2, J. Geophys. Res., 98, 10543-10561, doi:10.1029/93JD00223, 1993.

Myhre, G., Samset, B. H., Schulz, M., Balkanski, Y., Bauer, S., Berntsen, T. K., Bian, H., Bellouin, N., Chin, M., Diehl, T., Easter, R. C., Feichter, J., Ghan, S. J., Hauglustaine, D., Iversen, T., Kinne, S., Kirkevåg, A., Lamarque, J.-F., Lin, G., Liu, X., Lund, M. T., Luo, G., Ma, X., van Noije, T., Penner, J. E., Rasch, P. J., Ruiz, A., Seland, Ø., Skeie, R. B., Stier, P., Takemura, T., Tsigaridis, K., Wang, P., Wang, Z., Xu, L., Yu, H., Yu, F., Yoon, J.-H., Zhang, K., Zhang, H., and Zhou, C.: Radiative forcing of the direct aerosol effect from AeroCom Phase II simulations, Atmos. Chem. Phys., 13, 1853-1877, doi:10.5194/acp-13-18532013, 2013.

Myhre, G., Jonson, J. E., Bartnicki, J., Stordal, F., and Shine, K. P.: Role of spatial and temporal variations in the computation of radiative forcing due to sulphate aerosols: A regional study, Q. J. Roy. Meterol. Soc., 128, 973-989, 2002.

Nakajima, T., Tsukamoto, M., Tsushima, Y., Numafuti, A., and Kimura, T.: Modeling of radiative process in an atmospheric general circulation model, Appl. Opt., 39, 4869-4878, 2000.

Nemensure, S., Wagener, R., and Schwartz, S. E.: Direct shortwave forcing of climate by the anthropogenic sulfate aerosol: Sensitivity to particle size, composition, and relative humidity, J. Geo- 
phys. Res., 100, 26105-26116.

Neubauer, D., Vrtala, A., Leitner, J. J., Firneis, M. G., and Hitzenberger, R.: Development of a model to compute the extension of life supporting zones for Earth-like exoplanets, Orig. Life Evol. Biosph. 41, 545-552, doi:10.1007/s11084-011-9259-9, 2011.

Oreopoulos, L. and Barker, H. W.: Accounting for subgrid-scale cloud variability in a multi-layer 1-D solar radiative transfer algorithm, Q. Roy. Meteor. Soc., 125, 301-330, 1999.

Oreopoulos, L., Mlawer, E., Delamere, J., Shippert, T., Cole, J., Fomin, B., Iacono, M., Jin, Z., Li, J., Manners, J., Räisänen, P., Rose, F., Zhang, Y., and Wilson, M. J.: The Continual Intercomparison of Radiation Codes: Results from Phase I, J. Geophys. Res., 117, D06118, doi:10.1029/2011JD016821, 2012.

Plass, G., Kattawar, G., and Catchings, F.: Matrix-operator theory of radiative transfer. 1: Rayleigh scattering, Appl. Opt., 12, 314329, 1973.

Rathke, C. and Fischer, J.: Retrieval of cloud microphysical properties from thermal infrared observations by a fast iterative radiance 1tting method, J. Atmos. Ocean Technol., 17, 1509-1524, 2000.

Roeckner, E., Bäuml, G., Bonaventura, L., Brokopf, R., Esch, M., Giorgetta, M., Hagemann, S., Kirchner, I., Kornblueh, L., Manzini, E., Rhodin, A., Schlese, U., Schulzweida, U., and Tompkins, A.: The atmospheric general circulation model ECHAM5. Part I: Model description, Max Planck Institute for Meteorology Rep. 349, 127 pp., 2003.

Rothman, L. S., Gamache, R. R., Barbe, A., Goldman, A., Gillis, J. R., Brown, L. R., Toth, R. A., Falud, J. M., and Camypeyret, C.: AFGL atmospheric absorption-line parameters compilation 1982 edition, Appl. Optics, 22, 2247-2256, 1983.

Rothman, L. S., Gamache, R. R., Tipping, R. H., Rinsland, C. P., Smith, M. A. H., Benner, D. C., Devi, V. M., Flaud, J.-M., CamyPeyret, C., and Perrin, A.: The HITRAN molecular database: Editions of 1991 and 1992, J. Quant. Spectrosc. Radiat. Transfer, 48, 469-507, 1992.

Rothman, L. S., Barbe, A., Benner, D. C., Brown, L. R., CamyPeyret, C., Carleer, M. R., Chance, K., Clerbaux, C., Dana, V., Devi, V. M., Fayt, A., Flaud, J.-M., Gamache, R. R., Goldman, A., Jacquemart, D., Jucks, K. W., Lafferty, W. J., Mandin, J.-Y., Massie, S. T., Nemtchinov, V., Newnham, D. A., Perrin, A., Rinsland, C. P., Schroeder, J., Smith, K. M., Smith, M. A. H., Tang, K., Toth, R. A., Auwera, J. V., Varanasi, P., and Yoshino, K.: The HITRAN molecular spectroscopic database: Edition of 2000 including updates of 2001. J. Quant. Spectrosc. Radiat. Transfer, $82,5-44,2003$.

Rothman, L. S., Jacquemart, D., Barbe, A., Chris Benner, D., Birk, M., Brown, L. R., Carleer, M. R., Chackerian, C., Chance, K., Coudert, L. H., Dana, V., Devi, V. M., Flaud, J.-M., Gamache, R. R., Goldman, A., Hartmann, J.-M., Jucks, K. W., Maki, A. G., Mandin, J.-Y, Massie, S. T., Orphal, J., Perrin, A., Rinslad, C. P., Smigh, M. A. H., Tennyson, J., Tolchenov, R. N., Toth, R. A., Vander Auwera, J., Varanasi, P., and G. Wagner: The HITRAN 2004 molecular spectroscopic database, J. Quant. Spectrosc. Radiat. Transfer, 96, 139-204, doi:10.1016/j.jqsrt.2004.10.008, 2005.

Rothman, L. S., Gordon, I. E., Barbe, A., Benner, D. C., Bernath, P. F., Birk, M., Boudon, V., Brown, L. R., Campargue, A., Champion, J.-P., Chance, K., Coudert, L. H., Dana, V., Devi, V. M., Fally, S., Flaud, J.-M., Gamache, R. R., Goldman, A., Jacque- mart, D., Kleiner, I., Lacome, N., Lafferty, W. J., Mandin, J.Y., Massie, S. T., Mikhailenko, S. N., Miller, C. E., MoazzenAhmadi, N., Naumenko, O. V., Nikitin, A. V., Orphal, J., Perevalov, V. I., Perrin, A., Predoi-Cross, A., Rinsland, C. P., Rotger, M., Šimečcková, M., Smith, M. A. H., Sung, K., Tashkun, S. A., Tennyson, J., Toth, R. A., Vandaele, A. C., and Vander Auwera, J.: The HITRAN 2008 molecular spectroscopic database, J. Quant. Spectrosc. Radiat. Transfer, 110, 533-572, 2009.

Russell, P. B., S. A. Kinne, and R. W. Bergstrom: Aerosol climate effects: Local radiative forcing and column closure experiments, J. Geophys. Res., 102, 9397-9408, 1997.

Schulz, M., Textor, C., Kinne, S., Balkanski, Y., Bauer, S., Berntsen, T., Berglen, T., Boucher, O., Dentener, F., Guibert, S., Isaksen, I. S. A., Iversen, T., Koch, D., Kirkevåg, A., Liu, X., Montanaro, V., Myhre, G., Penner, J. E., Pitari, G., Reddy, S., Seland, Ø., Stier, P., and Takemura, T.: Radiative forcing by aerosols as derived from the AeroCom present-day and pre-industrial simulations, Atmos. Chem. Phys., 6, 5225-5246, doi:10.5194/acp-65225-2006, 2006.

Schulz, M., Chin, M., and Kinne S.: The Aerosol Model Comparison Project, AeroCom, Phase II: Clearing Up Diversity, IGAC Newsletter, No 41, May 2009.

Slingo, A. and Schrecker, H. M.: On the shortwave radiative properties of stratiform water clouds, Q. J. Roy. Meteor. Soc., 108, 407-426, 1982.

Solomon, S., Qin, D., Manning, M., Marquis, M., Averyt, K., Tignor, M., Miller, H., and Chen, Z.: Technical summary, in Climate Change 2007: The Physical Science Basis. Contribution of Working Group I to the Fourth Assessment Report of the Intergovernmental Panel on Climate Change, edited by: Solomon, S., Qin, D., Manning, M., Marquis, M., Averyt, K., Tignor, M., Miller, H., and Chen, Z., 19-94, Cambridge Univ. Press, Cambridge, UK, 2007.

Stamnes, K., Tsay, S. C., Wiscombe, W., and Jayaweera, K.: A numerically stable algorithm for discrete-ordinate-method radiative transfer in multiple scattering and emitting layered media. Appl. Opt., 27, 2502-2509, 1988.

Stier, P., Schutgens, N. A. J., Bian, H., Boucher, O., Chin, M., Ghan, S., Huneeus, N., Kinne, S., Lin, G., Myhre, G., Penner, J. E., Randles, C., Samset, B., Schulz, M., Yu, H., and Zhou, C.: Host model uncertainties in aerosol radiative forcing estimates: results from the AeroCom prescribed intercomparison study, Atmos. Chem. Phys. Discuss., 12, 25487-25549, doi:10.5194/acpd-1225487-2012, 2012.

Stokes, G. M. and Schwartz, S. E.: The Atmospheric Radiation Measurement (ARM) Program: Programmatic background and design of the cloud and Radiation Testbed, B. Amer. Meteor. Soc., 75, 1201-1221, 1994.

Sun, Z.: Development of the Sun-Edwards-Slingo Radiation Scheme (SES2). CAWCR Technical Report No. 009, Centre for Australian Weather and Climate Research, Australian Bureau of Meteorology, 94 pp., 2008.

Sun, Z. and Rikus, L.: Improved application of exponential sum fitting transmissions to inhomogeneous atmosphere, J. Geophy. Res., 104, 6291-6303, 1999.

Tarasova, T. A. and Fomin, B. A.: Solar radiation absorption due to water vapor: Advanced broadband parameterizations, J. Appl. Met., 39, 1947-1951, 2000. 
Textor, C., Schulz, M., Guibert, S., Kinne, S., Balkanski, Y., Bauer, S., Berntsen, T., Berglen, T., Boucher, O., Chin, M., Dentener, F., Diehl, T., Easter, R., Feichter, H., Fillmore, D., Ghan, S., Ginoux, P., Gong, S., Grini, A., Hendricks, J., Horowitz, L., Huang, P., Isaksen, I., Iversen, I., Kloster, S., Koch, D., Kirkevåg, A., Kristjansson, J. E., Krol, M., Lauer, A., Lamarque, J. F., Liu, X., Montanaro, V., Myhre, G., Penner, J., Pitari, G., Reddy, S., Seland, Ø., Stier, P., Takemura, T., and Tie, X.: Analysis and quantification of the diversities of aerosol life cycles within AeroCom, Atmos. Chem. Phys., 6, 1777-1813, doi:10.5194/acp-6-1777-2006, 2006.

Textor, C., Schulz, M., Guibert, S., Kinne, S., Balkanski, Y., Bauer, S., Berntsen, T., Berglen, T., Boucher, O., Chin, M., Dentener, F., Diehl, T., Feichter, J., Fillmore, D., Ginoux, P., Gong, S., Grini, A., Hendricks, J., Horowitz, L., Huang, P., Isaksen, I. S. A., Iversen, T., Kloster, S., Koch, D., Kirkevåg, A., Kristjansson, J. E., Krol, M., Lauer, A., Lamarque, J. F., Liu, X., Montanaro, V., Myhre, G., Penner, J. E., Pitari, G., Reddy, M. S., Seland, Ø., Stier, P., Takemura, T., and Tie, X.: The effect of harmonized emissions on aerosol properties in global models an AeroCom experiment, Atmos. Chem. Phys., 7, 4489-4501, doi:10.5194/acp-7-4489-2007, 2007.

Toon, O. B., McKay, C. P., Ackerman, T. P., and Santhanam, K.: Rapid Calculation of Radiative Heating Rates and Photodissociation Rates in Inhomogeneous Multiple Scattering Atmospheres, J. Geophys. Res., 94, 16287-16301, doi:10.1029/JD094iD13p16287, 1989.

van de Hulst, H. C.: Multiple Light Scattering: Tables, Formulas, and Applications, vol. 1, Academic Press, San Diego, CA, USA, 436 pp., 1980.

Vardavas, I. M. and Taylor, F. W.: Radiation and Climate: Atmospheric energy budget from satellite remote sensing, Int. Ser. Monogr. Phys., 138, Oxford University Press, Oxford, UK, 512 pp., 2011.

Vigroux, E.: Contribution à l'étude experimentale de l'absorption de l'ozone, Ann. Phys., 8, 709-762, 1953.

Walters, D. N., Best, M. J., Bushell, A. C., Copsey, D., Edwards, J. M., Falloon, P. D., Harris, C. M., Lock, A. P., Manners, J. C., Morcrette, C. J., Roberts, M. J., Stratton, R. A., Webster, S., Wilkinson, J. M., Willett, M. R., Boutle, I. A., Earnshaw, P. D., Hill, P. G., MacLachlan, C., Martin, G. M., Moufouma-Okia, W., Palmer, M. D., Petch, J. C., Rooney, G. G., Scaife, A. A., and Williams, K. D.: The Met Office Unified Model Global Atmosphere 3.0/3.1 and JULES Global Land 3.0/3.1 configurations, Geosci. Model Dev., 4, 919-941, doi:10.5194/gmd-4-919-2011, 2011.
Wang, H. and R. T. Pinker: Shortwave radiative fluxes from MODIS: Model development and implementation, J. Geophys. Res., 114, D20201, doi:10.1029/2008JD010442, 2009.

Wei Xiaodong and Zhang Hua: Analysis of optical properties of nonspherical dust aerosols, Acta Opt. Sin., 31, 0501002-1, 2011.

Wiscombe, W. J. and Evans, J. W.: Exponential-sum fitting of radiative transmission functions, J. Comput. Phys., 24, 416-444, 1977.

WMO: Global ozone research and monitoring project. Report 16, Atmospheric Ozone. WMO, Geneva, Switzerland, 1985.

Zdunkowski, W. G., Welch, R. M., and Korb, G.: An investigation of the structure of typical two-stream methods for the calculation of solar fluxes and heating rates in clouds, Beiträge Phys. Atmosph., 53, 147-166, 1980.

Zhang, H., Nakajima, T., Shi G. Y., Suzuki, T., and Imasu, R.: An optimal approach to overlapping bands with correlated-k distribution method and its application to radiative transfer calculations. J. Geophys. Res., 108, 4641, doi:10.1029/2002JD003358, 2003.

Zhang, F., Zeng, Q. C., Gu, Y., and Liou, K. N.: Parameterization of the absorption of the $\mathrm{H}_{2} \mathrm{O}$ continuum, $\mathrm{CO}_{2}, \mathrm{O}_{2}$, and other trace gases in the Fu-Liou radiation program, Adv. Atmos. Sci., 22, 545-558, 2005.

Zhang, H., Shi, G. Y., Nakajima., T., and Suzuki., T.: The effects of the choice of the k-interval number on radiative calculations, J. Quant. Spectrosc. Radiat. Transfer, 98, 31-43, 2006 .

Zhang, H., Suzuki, T., Nakajima, T., Shi, G. Y., Zhang, X. Y. and Liu, Y.: The effects of band division on radiative calculations. Opt. Eng., 45, 016002, doi:10.1117/1.2160521, 2006b.

Zhang, H., Shen, Z., Wei, X., Zhang, M., and Li, Z.: Comparison of optical properties of nitrate and sulfate aerosol and the direct radiative forcing due to nitrate in China, Atmos. Res., 113, 113125, 2012.

Zhang, F., Liang, X.-Z., Zeng, Q. C., Gu, Y., and Su, S. J.: CloudAerosol-Radiation (CAR) Ensemble Modeling System: Overall accuracy and efficiency. Adv. Atmos. Sci., doi:10.1007/s00376012-2171-z, 2013. 